\title{
IntechOpen
}

\section{Consumer Behavior and Marketing}

\author{
Edited by Matthew Reyes
}





\section{Consumer Behavior and Marketing}

Edited by Matthew Reyes 

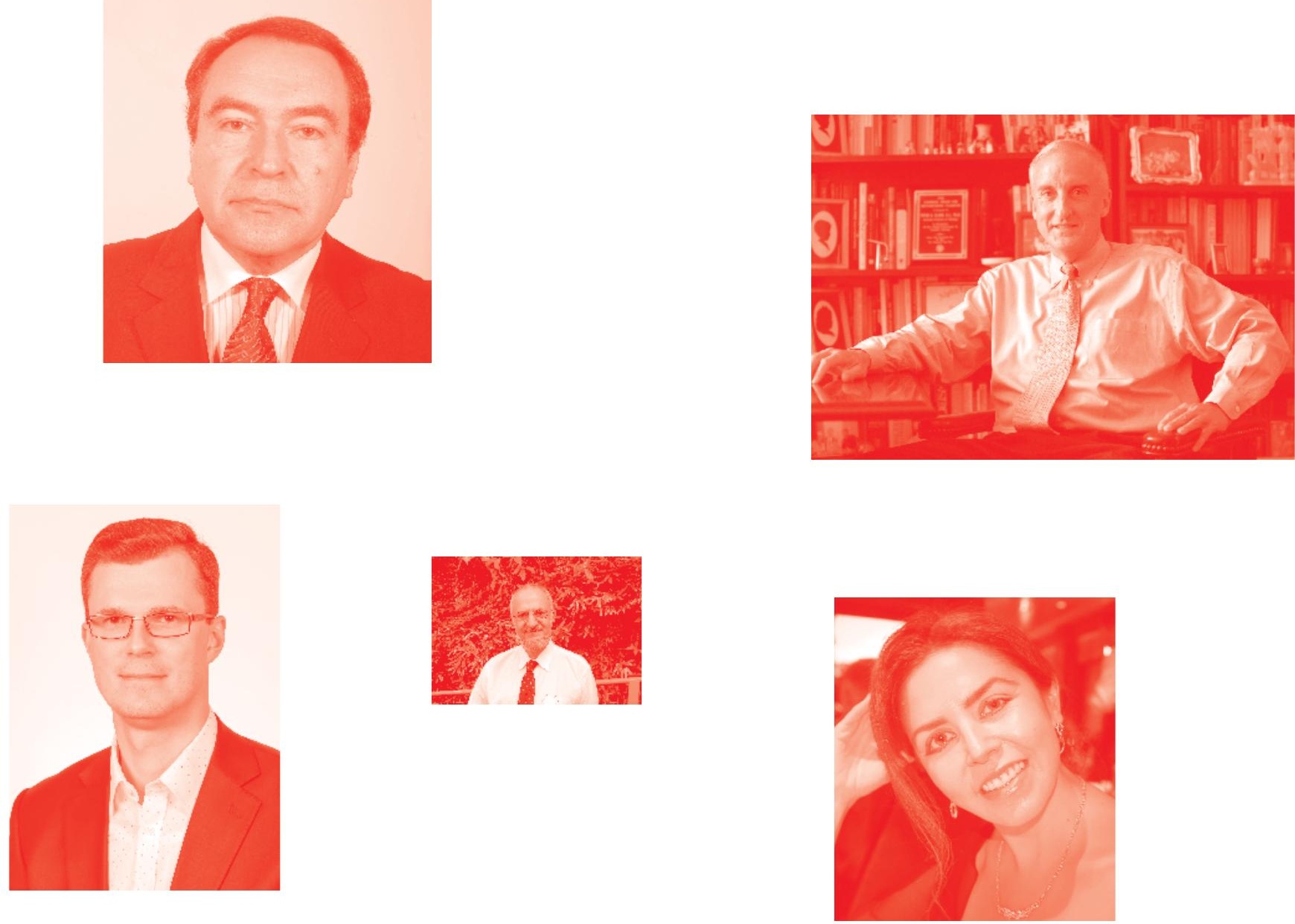

Supporting open minds since 2005
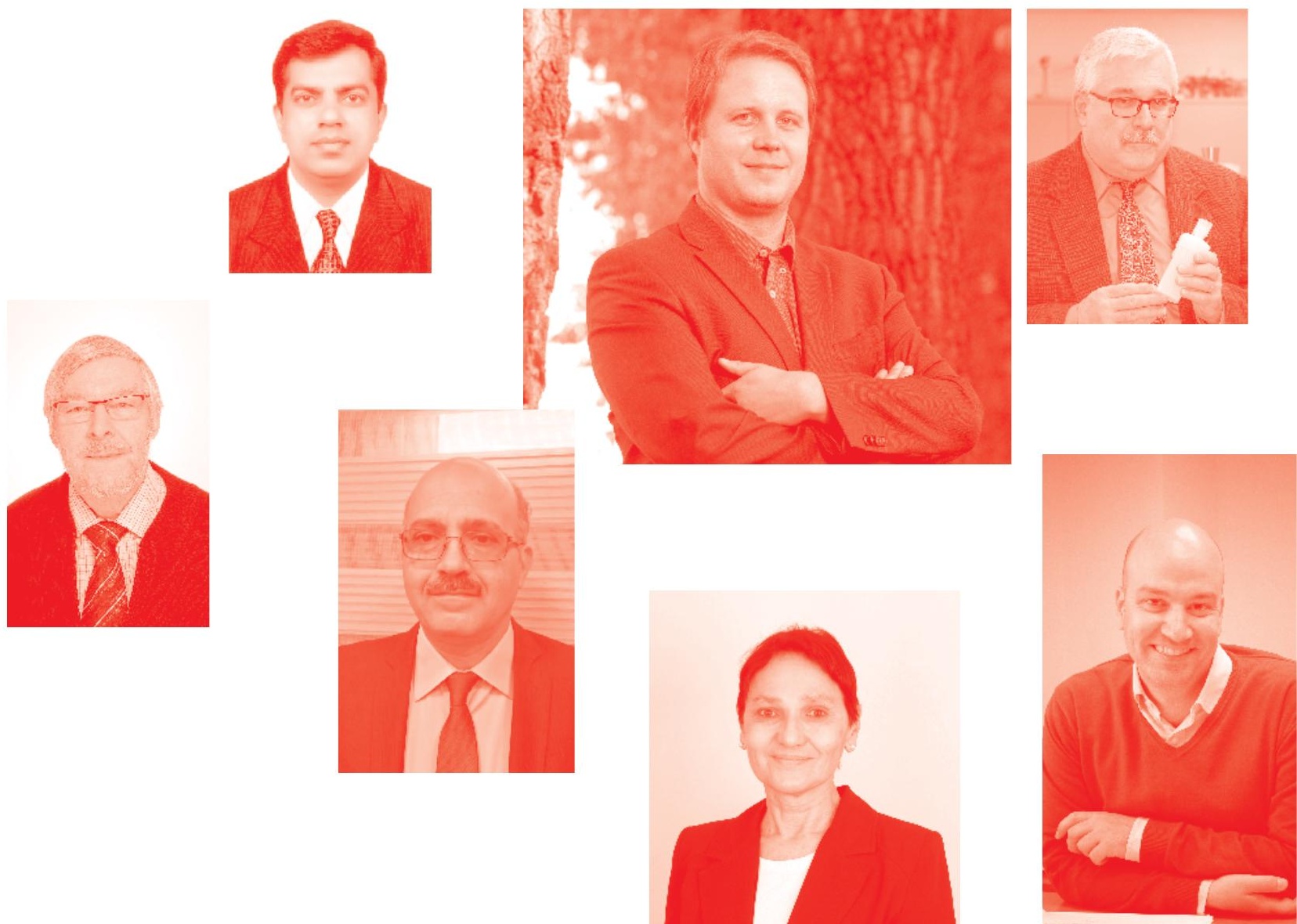
Consumer Behavior and Marketing

http: //dx. doi. org/10.5772/intechopen. 77647

Edited by Matthew Reyes

\section{Contributors}

Abigail Chivandi, Mammo Muchie, Michael Olorunjuwon Samuel, Farruh Kushnazarov, Urška Starc Peceny, Simon Mokorel, Vesna Kuralt, Jurij Urbančič, Tomi Ilijas, Alireza Ziaei-Bideh, Mahsa NamakshenasJahromi, Umut Ayman, Anıl Kemal Kaya, İpek Halim, Zul Ariff Abdul Latiff, Marlene Amorim, Mario Rodrigues, Nazri Nordin, Mohamed Azmi Ahmad Hassali, Matthew Dingee

(๑) The Editor(s) and the Author(s) 2020

The rights of the editor(s) and the author(s) have been asserted in accordance with the Copyright, Designs and Patents Act 1988. All rights to the book as a whole are reserved by INTECHOPEN LIMITED. The book as a whole (compilation) cannot be reproduced, distributed or used for commercial or non-commercial purposes without INTECHOPEN LIMITED's written permission. Enquiries concerning the use of the book should be directed to INTECHOPEN LIMITED rights and permissions department (permissions@intechopen.com).

Violations are liable to prosecution under the governing Copyright Law .

\section{(cc) BY}

Individual chapters of this publication are distributed under the terms of the Creative Commons Attribution 3.๑ Unported License which permits commercial use, distribution and reproduction of the individual chapters, provided the original author(s) and source publication are appropriately acknowledged. If so indicated, certain images may not be included under the Creative Commons license. In such cases users will need to obtain permission from the license holder to reproduce the material. More details and guidelines concerning content reuse and adaptation can be found at http : //www . intechopen . com/copyright-policy . html .

\section{Notice}

Statements and opinions expressed in the chapters are these of the individual contributors and not necessarily those of the editors or publisher. No responsibility is accepted for the accuracy of information contained in the published chapters. The publisher assumes no responsibility for any damage or injury to persons or property arising out of the use of any materials, instructions, methods or ideas contained in the book.

First published in London, United Kingdom, 2020 by IntechOpen IntechOpen is the global imprint of INTECHOPEN LIMITED, registered in England and Wales, registration number: 11086078 , 7th floor, 10 Lower Thames Street, London,

EC3R 6AF, United Kingdom

Printed in Croatia

British Library Cataloguing-in-Publication Data

A catalogue record for this book is available from the British Library

Additional hard and PDF copies can be obtained from orders@intechopen.com

Consumer Behavior and Marketing

Edited by Matthew Reyes

p. $\mathrm{cm}$.

Print ISBN 978-1-78923-855-6

Online ISBN 978-1-78923-856-3

eBook (PDF) ISBN 978-1-78985-468-8 


\section{We are IntechOpen, \\ the world's leading publisher of Open Access books}

\section{Built by scientists, for scientists}

\section{$4,600+$}

Open access books available

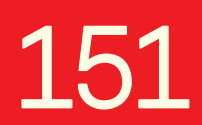

Countries delivered to

\section{$120,000+$}

International authors and editors

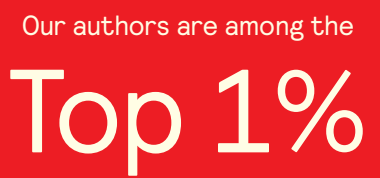

most cited scientists

Contributors from top 500 universities
$135 \mathrm{M}+$

Downloads
$12.2 \%$

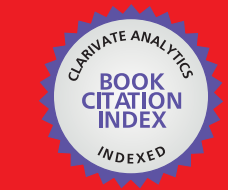

WEB OF SCIENCE ${ }^{\text {M }}$

Selection of our books indexed in the Book Citation Index in Web of Science ${ }^{\mathrm{TM}}$ Core Collection (BKCI)

\section{Interested in publishing with us? \\ Contact book.department@intechopen.com}

Numbers displayed above are based on latest data collected.

For more information visit www.intechopen.com 



\section{Meet the editor}

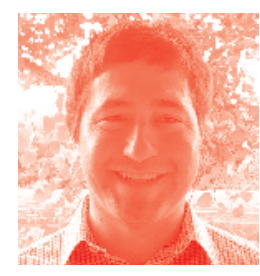

Dr Reyes received his Ph.D. from the University of Michigan in 2011, performing research in data compression and processing of Gibbs fields. From 2010 to 2014, Dr Reyes worked at MIT Lincoln Laboratory on problems ranging from tracking, multi-sensor fusion, simulation, and data analysis. Since 2015, Dr Reyes has worked as an independent researcher and consultant. He is interested in modeling decision-making on social networks and applying his background in data analysis and simulation to marketing analytics. For example, under a random utility logit model of consumer choice, decision-making on a social network can be modeled as Glauber dynamics. Dr Reyes is interested in incorporating more realistic models of consumer choice into models of dynamic decision-making on a social network, and using such dynamic models to mine social media and guide marketing resource allocation. 



\section{Contents}

Preface

Chapter 1

Consumer Life Cycle and Profiling: A Data Mining Perspective

by Kushnazarov Farruh

Chapter 2

Unpacking the Digital Consumer Mindset

by Matthew Dingee

Chapter 3

Social Media, Consumer Behavior, and Service Marketing

by Abigail Chivandi, Michael Olorunjuwon Samuel and Mammo Muchie

Chapter 4

Tourism 4.0: Challenges in Marketing a Paradigm Shift

by Urška Starc Peceny, Jurij Urbančič, Simon Mokorel, Vesna Kuralt and Tomi Ilijaš

Chapter 5

Mobile App Marketing Communication for B2B and B2C: Ingoes as a

Case Study

by Umut Ayman, Anul Kemal Kaya and İpek Halim

Chapter 6

Building on eWOM to Understand Service Quality in Hotel Services by Marlene Amorim and Mário Rodrigues

Chapter 7

Lifestyle Demographic and Food Label Consumption

by Zul Ariff Abdul Latiff

Chapter 8

Profiling Green Consumers with Data Mining

by Alireza Ziaei-Bideh and Mahsa Namakshenas-Jahromi

Chapter 9

STARZ-DRP: Improving Efficiency of Patient Care in Community Pharmacies

by Nazri Nordin and Mohamed Azmi Hassali 



\section{Preface}

This Edited Volume is a collection of reviewed and relevant research chapters, concerning the developments within the 'Consumer Behavior and Marketing' field of study. The book includes scholarly contributions by various authors and edited by a group of experts pertinent to social sciences. Each contribution comes as a separate chapter complete in itself but directly related to the book's topics and objectives.

The book includes chapters dealing with the topics: Analysis Customer Behavior, The Mindset of the Digital Consumer, Social Media Capabilities Towards Consumer Buying/Purchasing Behaviour In Service Marketing, Mobile Apps Marketing Communication for B2B and B2C: Ingoes as a Case Study, Tourism 4.0 - travelling within the digital and physical world, (Using eWOM for customer decison and service value, Lifestyle aspect in consumer behavior of food label consumption, Profiling green consumers with data mining, Consumer behavior of extended pharmacy services in community pharmacy setting: a global approach to improve it.

The target audience comprises scholars and specialists in the field. 



\title{
Consumer Life Cycle and Profiling: A Data Mining Perspective
}

\author{
Kushnazarov Farruh
}

\begin{abstract}
With the development of technology and continuously increasing of the market demand, the concept to produce better merchandises is generated in the companies. Each customer wants an individual approach or exclusive product, which creates the concept: "one customer one product." The implementation of the one-to-one approach in the current days is the main exciting task of companies. Millions of customers lead to millions of exclusive products from the manufactures' views. It is the primary step to study the needs of customers in the market economy. The main task for a company is to know the customer and to provide their desired products and services. In order to get knowledge ahead of the customers' wishes, a system of profiling potential customers is created accordingly. This chapter provides the review of the customer lifetime from the reach customer (claim future customer's attention) to the loyalty customer (turn a customer into a company advocate). During the discussion about the customer lifetime, readers will get acquainted with such technologies as funnel analysis, data management platform, customer profiling, customer behavior analysis, and others. The listed technologies in a complex will be created as the one-to-one product or service with a high Return on Investment (ROI).
\end{abstract}

Keywords: customer lifecycle, funnel analysis, data management platform, customer profiling, data mining, machine learning

\section{Introduction}

Net profits are the most natural and most intuitive metric to determine a Return on Investment (ROI). However, income alone does not make great customers nor do they offer insight into maximizing customer lifetime value. The following discussion in this chapter focus on modeling prediction systems which are oriented from learning the customers' need, by analyzing geographic, demographic, firmographic, behavioral, psychographic, and other types of data. These kinds of analysis include both side (the customer and the company) benefits. The reader will learn types of data which are available to collect during the customer lifecycle and the concept of customer analytics.

Forecasting customer needs and supporting him at each stage of a customer's life cycle entails a significant increase in ROI. We will discuss in the Customer Lifecycle section what is it and what it includes from company view and connects with Customer Relationship Management (CRM). Customer lifecycle with CRM can manage a company with customers. CRM cannot adequately manage customers without data analysis of integration and automation sales, marketing or services without the help of CRM to grow ROI. 
In an age of data, everyday users produce a big amount of data, and Data Management Platform (DMP) helps to manage all of the data related to customer lifecycle, which will be discussed in the related section. The base of DMP is called as a DataBase (DB) system, and we will discuss it on the section Design of DB-from company's IT view, it is DB system. DB oriented structured and unstructured data can be observed in the section of Design of $D B$. Nowadays, the most exited data type is the unstructured data, and this area is not thoroughly researched nor are all of the benefits found.

It is discussed in the section Customer Analytics the analytic model of the classified customer to find a similar customer to offer that what customer need. This section brings a vital moment when data are changed to information and information is transferred to knowledge. The petabytes of data related to the user without transformation are useless.

\section{Customer lifecycle}

The customer lifecycle describes the points in the continuum where [1] explains (Figure 1):

1. Reach—claim future customer's attention;

2. Acquisition—bring them into a sphere of influence;

3. Conversion-turn them into a registered instead paying customer;

4. Retention-keep them as a customer

5. Loyalty/advocacy—turn them into a company advocate.

A customer's life cycle includes a comprehensive study of the customer's path, from the first contact to customer CRM, targeting a specific campaign, channel, or indicator. Instead of focusing on individual indicators, it is necessary to use the "always on" method to view the entire customer path on all possible physical devices and communication channels, as well as optimize message exchange to coordinate with different points of contact in this path. Since the customer's life cycle works on different platforms, it is essential that different teams work with different aspects and exchange information instantly, and all teams go in the same direction when applying the customer's life cycle strategy [2].

CRM is a tool to manage a company's cooperation with the current and the potential customers. The business relationships with customers can be improved by using data analysis with customers' data and focusing on the customer retention and the growth of the sales can also be reached ultimately [3]. The goal of CRM systems is to integrate and automate the sales, marketing, and customer support in the whole lifecycle stages. In the most cases, the CRM system has a dashboard, giving an overview of the functions listed in one customer view, on an individual page for each customer of the company. The dashboard provides information such as the sales history, marketing companies relating to this customer. Moreover, it summarizes the whole relationships between the customer and the company. The operating CRM includes three main functions: sales automation, marketing automation, and service automation.

Salesforce automation requires CPM at all stages, from the reach or first contact with a customer to the conversion into a loyalty customer [4]. It implements 


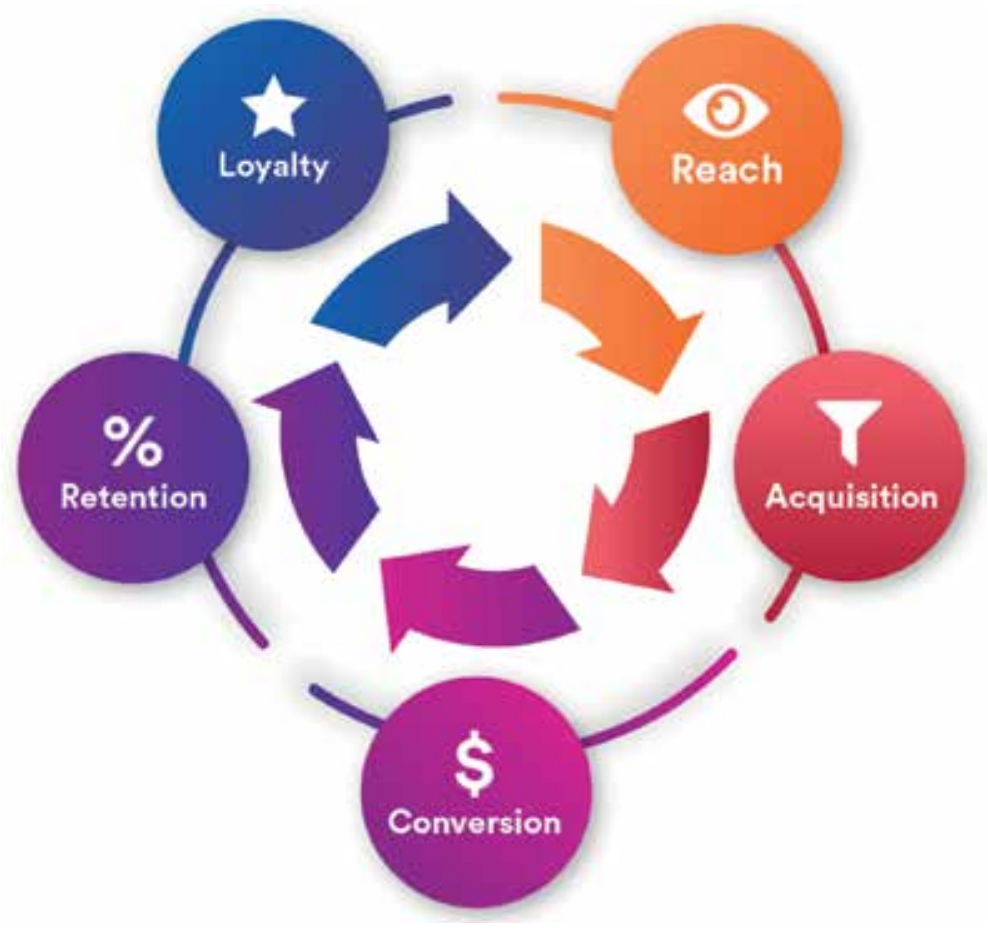

Figure 1.

Customer life cycle.

sales promotion analysis, automates the tracking of the customer history (not only purchases but also actions) to motivate new purchases, and coordinates sales, marketing, call centers, and shops (online and offline). This function prevents the duplication of actions between sales teams and clients. Besides, all communication channels between both parties are automatically monitored and are automatically selected as the most convenient communication channel to the customer.

Marketing automation focuses on improving the entire marketing process, with the goal of increasing efficiency and making it interactive at the same time. This function reaches automate repetitive and routine tasks, such as sending marketing letters to customers at a specific time or posting marketing information on the social networks. The goal of marketing automation is to turn a potential customer into a retention (full-fledged) customer. CRM systems today are also used to attract customers through social networks and other nontraditional communication channels.

Service automation focuses on automating customer clearing and implements the following services: customer support services on the multichannel (telephone, email, social networks, and chat rooms of the knowledge base, ticket sales portals, frequently asked questions, chatbots ${ }^{1}$, and much more).

The CRM system collects data from all possible communication channels, such as the company's website, telephone, e-mail, various messengers, ${ }^{2}$ campaign marketing materials, social networks [5], and others. The CRM system is used to facilitate the work of the enterprise, while the enterprise recognizes their clients from all sides and creates their target audiences. After defined target audience with the help of CPM, it

\footnotetext{
${ }^{1}$ Chat bot (also known as smart bots, chatbot, bot, chat chat, interactive agent, conversation interface (The artificial spoken object) (this is a computer program or an artificial intelligence using hearing or text methods.

2 Messengers-app for messages and voice calls, documents, and user location.
} 
needs to learn how to meet the needs of a specific audience in the best way. A specific audience can be interpreted as a group of people with the same behaviors and needs to be created by machine learning algorithms.

Traffic analysis [6] is the process of intercepting and examining data in order to deduce information from patterns in a customer profile [7]. In general, the higher the number of traffic units observed and stored, the more information can be obtained from the detailed customer's profile and habits. Traffic analysis can be performed in the context of artificial intelligence, counter-intelligence, or patternof-life analysis.

CRM systems contain:

- DMP technology with the purpose to aggregate all information related to customers and to merge the information about products. These data will be the key performance indicators. Hence it is recommended to use NoSQL DB (4.1).

- Opportunity management helps the enterprise to manage unpredictable growth and demand, using a forecasting model with sales history data to predict sales [8].

- System for tracking and measuring marketing campaigns over multiple channels and networks and collect customer clicks and sales for further customer analysis.

- To reach mobility of CRM using SaaS (Software as a Service). This means data and the functionality of CRM will be available through Internet and can be accessed by any devices (including the embedded devices). CRM as SaaS is much convenient to be used instead of using CRM on one local network or the local computer. SaaS cannot be purchased but it is available by typically paying a recurring subscription fee to the software vendor, and by using CRM, there is no need for any big investment at the beginning.

- A basic CRM system includes a contact management system that integrates emails, messengers, documents, jobs, faxes, and scheduling for individual accounts. CRM system is available for all types of markets (finance, accounting, legal, IT, and others).

- E-commerce takes the full advantage of the CRM system, by focusing on automation marketing, sales force, and service process. Like cart rescue, re-engage users throw communication channels (email, social media, messengers, and others), rationalization, or special offers.

- Customer-centric relationship management is a new sub-discipline focusing on the customer preferences instead of the customer leverage, and the main goal is to add values by engaging customers in the individual ways and in the interactive relationships ways [9].

- Membership-based system (based on the nonprofit organizations) aims to collect membership levels, volunteering, and communication with individuals, sponsors' demographics, constituents, fundraising, and membership directories.

\subsection{Compare CRM platforms}

The observation of CRM by customer experience continues to be at the top of the executive agenda by the different institutions. The Gartner's CEO, CIO, CMO, and 
other executive surveys are of one popular observation of CRM. The majority of participants use the external service providers to help them with their initiative, program or project. Gartner [10] identifies the market for CRM and Customer eXperience $(\mathrm{CX})$ implementation services as the project services to support enterprises to create a CX strategy and to design, build, integrate, and deploy process and technology changes that improve the interaction between enterprises and their customers.

CRM and CX projects are aimed at achieving goals through sales, marketing, customer service, local service, digital commerce leaders, and digital company executives. These goals may include increasing the customer satisfaction, attracting new customers, retaining the existing customers, creating a unified customer view, cross-selling customers, increasing the frequency of campaign responses, increasing the use of digital channels, increasing customer protection or recommendations, and price increasing account [10].

Gartner assesses suppliers on two criteria: the completeness of vision [11] and the ability to perform. Using a methodology that Gartner does not disclose, these component estimates lead to the seller's position in one of the four quadrants (Figure 2):

- Leaders-CRM suppliers in the leaders quadrant have total high points for their versatility, vision completeness, and ability to perform the assigned tasks. These suppliers have the greatest prestige, and marketing and sales capabilities necessary for adopting new technologies, while they demonstrate a clear understanding of the market needs, are innovators and ideological leaders. Also, there are formulated plans which can be used by the customers and potential customers while developing infrastructure and strategies. Another criterion of leaders is to have representatives in all continents of the world. Last but not least, suppliers should have the stable financial performance and the broad platform support.

- Challengers - a vendors in the Challenger quadrant is involved in the market and works well enough to pose a serious threat to sellers in the leadership quadrant. They have strong products, as well as a fairly reliable market position and resources to maintain the steady growth. They are financially secure, but not sufficiently developed and expanded as the vendors in the quadrant of leaders.

- Visionaries-vendors are innovators; the products are presented to them on a large scale. It is important for the end user relative to exploitation or finance and not yet demonstrated the ability to capture market share or sustainable profitability. Visionary vendors are private companies, and in most cases, big enterprises want to buy them. When a vendor visionaries are bought by enterprises, the risks associated with installing their systems will decrease accordingly.

- Niche players-vendors in the niche player sector are often narrowly specialized for a specific market or vertical segments. This sector may also include suppliers who are adapting their existing products to enter the market in question or larger suppliers who have difficulty in developing and implementing their vision.

\subsection{DMP}

DMP is used to collect and manage companies and customer data. Digital marketing is the main purpose of using DMP [12]. Because of the massive amount of data the analytical tasks like segmentation, prediction and creating customer profile impossible to reachable without DMP all levels of the customer lifecycle. 


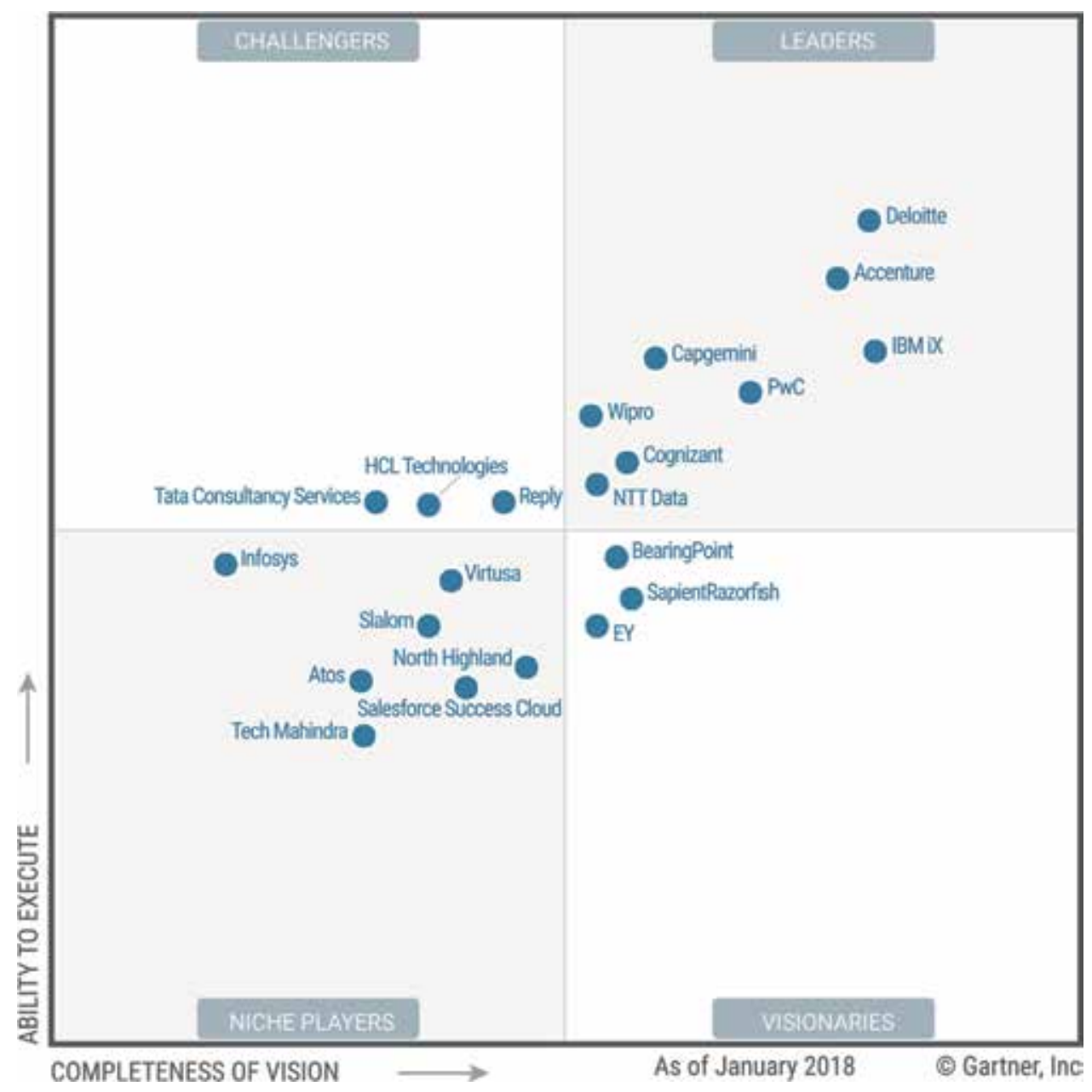

Figure 2.

Magic quadrant for CRM and Customer Experience Implementation Services, Worldwide (2018).

For example, DMP's customer segment targets on the online advertising campaigns. DMP uses big data and artificial intelligence algorithms to process large sets of user data from the various sources.

DMPs are used in the following tasks:

1. Data collection - collects data from the multisources. Data sources from the different parts, usually it is called as the first-, second-, and third-party data.

The first-party data are the data which are generated inside the company data, the second-party data are generated by partnership agreements with other companies or together with partner companies, and the third-party data are the part of data which are bought from data markets customer and product-related data gathering:

- Offline sources (e.g., CRM systems and surveys);

- Online sources-mobile and desktop devices (e.g., the mobile applications, online campaigns, the landing pages, websites, social networks, and instant messengers).

2. Integration-it needs to integrate all data collected from the multisources to create a customer profile. This process is called as "Integration." With machine 
learning algorithms, integration leads to a decent result. During integration, DMP creator should be careful on the points such as the data security, the data quality, and the data trustability.

3. Data management - the collected and integrated data should be transferred to a readable and understandable view or transform to the mode of "information." The machine learning and deep learning algorithms are the mostly used tools to [6] create the individual customer segments and customer profiles.

4. Activation - the managed data will be used by a different team in an enterprise to implement it on the market. With the help of using NoSQL D, it does not spend more than a half an hour time to finish steps from data collection to activation. The data stored and organized on the DMP platforms are used to target the selected audience groups by all possible channels.

\subsection{Design of $\mathrm{DB}$}

The data related to a customer should be saved in somewhere, and that place is called as the DB system. So a DB is a core of custom profile and CRM systems. The structure of the DB will be saved for the whole time during the company existence. The structure of the DB should be taken into account the future development and enlargement of the company for at least 10-20 years. For example, if a company plans to open the future branch office in other places, this condition should be taken into account when creates a DB. Otherwise, it will bring huge money losses for the company in the future, especially when DB with a different structure while transferring data from one DB to another DB.

A DB should include the perspective of:

- Business intelligence: includes strategies, technologies, and information systems aiming to improve decision-making based on the past performance using reporting, OLAP, dashboards, balanced scorecard, scoreboards, data visualization, data storytelling, and others.

- Data analytics: includes strategies, technologies, and information systems aiming to identify patterns and predict trends and behaviors with the help of data mining, text mining, machine learning, deep learning, cognitive systems, and others.

- Big data includes strategies, technologies, and information systems aiming to capture, process, store, analyze, and visualize complex data sets using batch processing, streaming processing, NoSQL, HPC, MPP, In-Memory, and others.

- Data management: includes strategies, technologies, and information systems aiming to provide information management capabilities with the methods of data governance, data quality, master data management, and others.

- Data brokerage: includes strategies, technologies, and information systems aiming to create data marketplaces for raw data or insights.

In twenty-first century, most company's challenge is to decide to choose Structured Query Language (SQL)- or Not Only SQL (NoSQL)-oriented DB. SQL is a structured DB, and functions like the yellow pages in which the company name, 
address, phone, and short information about it are stored. NoSQL DB includes the structured data; it can be document-oriented or distributed, for example, it works as the file folders that hold everything related to a customer such as the personal information in a text format, the picture of the customer, the transactions of a customer, the social network (Facebook and Instagram) accounts ID, and the shopping preferences.

The core of SQL DB is developed by IBM in 1970, whose DB consists of several tables with columns and rows. Records were written in a column by the schema of rows, and types of data (name, phone number, age, and others) show the relationship between the tables and field types. In a SQL DB, the important part during the construction period is that the schema must be clearly defined and get into account all future updates and upgrades data [13].

An effective way for SQL DB is to store data in an organized database. The welldesigned schema helps to omit or minimizes data redundancy and prevents tables from asynchrony, as a critical feature for business. Just imagine what will happen if the record financial transactions do not synchronize. For example, a customer bought a product using credit card, but in credit card app, this transaction is not shown. Nonwell-designed DB schema can cause many headaches due to its rigidity. For example, the customer address is not included in the fields, but probably the company will have customers from different countries. Unfortunately, customers could not enter address information. Hence to solve this issue, we need to recreate the table.

$\mathrm{SQL}$ is a programming language used for $\mathrm{DB}$, but nowadays kinds of literature get used to calling the DB that using SQL as the SQL DB or the type of DB which can be called as the relational DB; the architecture of DB is designed as the relational DB. Examples of SQL DB are MySQL, Sybase, Oracle, or IBM DM2, which executes queries, retrieves data, and edits data by updating, deleting, or creating new records. SQL is a lightweight declarative language that does the much heavy lifting for the relational DB, acting like a DB's version of a server-side script. One particular advantage of SQL is its simple-yet-powerful JOIN clause that gives the opportunity developers to retrieve the related data to store across the multiple tables with a single command.

The reason of popularity SQL DB is that it can fit naturally into many old software stacks. This DB is well understood and widely supported.

Popular SQL DB and RDBMS's

- MySQL_open-source DB, one of the favorite DB for CMS sites and blogs.

- Oracle RDBMS—an object-relational DB Management System (DBMS), mostly used for running online transaction processing, data warehousing. Oracle RDBMS can implement on a private and public cloud environment. The good part of Oracle is that it has SQL and NoSQL DB.

- IBM DB2-IBM product is built based on the SQL DB but which handle advanced "big data" analytics. IBM DB2 is a family of DB server products.

- MS SQL Server-developed by Microsoft. The primary query language used is Transact-SQL. Used to work with DB ranging in size from personal to large enterprise-wide DB; competes with other DBMS in this market segment Microsoft-developed RDBMS for enterprise-level DB that supports both SQL and NoSQL architectures.

- PostgreSQL_object-relational and open-source DBMS, an enterprise-level, can use SQL and procedural languages (Perl, Python). 
If data requirements are not clear from the outset, or if a company is dealing with vast amounts of the unstructured data, the likely company cannot afford to develop a relational DB with a well-defined schema. In such cases, it has an excellent way to solve the problem, that is, to implement NoSQL DB, which is more flexible than SQL DB. The unstructured data can be the data from the Internet, sensor data, social networks data, personal settings, audio data, photos, location information, video data, online activity, utilization rates, etc. Those unstructured data can be stored in one document that can be easily modified, found, but without categorization as the SQL DB does.

Another essential advantage of NoSQL is the ease of access. SQL DB is closely related to applications written programming languages, but NoSQL DB can often solve this problem by using APIs that allow the developers to execute queries without having to learn SQL or understand the underlying architecture of their DB system.

Type of NoSQL DB:

- The key-value model is the least complicated NoSQL option where data are stored without a schema or consisting of the indexed keys and values. Examples: Cassandra, Azure, LevelDB, and Riak.

- Column storage-or storage with full columns that stores data tables in the form of columns, not rows. This is more than just an inverted table-column partitioning provides the excellent scalability and high performance. Examples: HBase, BigTable, and HyperTable.

- Document DB-similar as a key value and complicating the process, each data in each document in the type of DB have a unique key that is used to be obtained. A database of documents is an excellent option for storing, retrieving and managing document-oriented data. Document-oriented DB store and works with unstructured data, but still, data may somewhat structured. Examples: MongoDB and CouchDB.

- DB graphs - some data are interrelated and are the best represented as a graph. This method can be very complicated-examples: Polyglot and Neo4J.

Popular NoSQL DB:

- MongoDB - about the popular NoSQL system, is mostly used by startups. Document-oriented DB with JSON-like documents is used in a dynamic diagram instead of relational tables that are used on server sites, such as Craigslist, eBay, and Foursquare. It is open source, with the customer service.

- Apache CouchDB is a real DB for the Internet, it uses the JSON data exchange format to store its documents; JavaScript for indexing, merging, and converting documents; and HTTP for its API.

- HBase is an open source DB, an Apache project, and is developed as part of Hadoop, column repository, written in Java and provides the features similar to the BigTable.

- Oracle NoSQL_Oracle's entry into the NoSQL category.

- Apache Cassandra DB-Cassandra is a distributed DB created by Facebook, who does an excellent job in handling vast amounts of the structured and the 
unstructured data. Cassandra is well able to be built up. Examples of platforms that implemented Cassandra are: Instagram, Comcast, Apple, and Spotify.

- Riak is an open source key-value DB. It has fault-tolerant replication and automatic data distribution, which provides the satisfied performance in most cases.

NoSQL DB gains its popularity for its speed and scalability; there are still situations where a highly structured SQL DB may be preferable. Therefore, big data are the real NoSQL motivator here, doing things that traditional relational DB cannot. It is driving the popularity of NoSQL DB.

Storage of large amounts of data, that unstructured data, required no restrictions on the types of data that should be stored together and are allowed to add various new types of possibilities reached by NoSQL DB, especially with the document-based DB, and store data in one place, without having to pre-determine what "types" of data they are.

Scaling NoSQL DB requires data to be easily distributed across the multiple servers. Using standardized (affordable and small) equipment in the place or the cloud eliminates the need for additional software, and NoSQL DB, such as Cassandra, is designed to scale across multiple data centers without further problems. Hence, cloud storage will be a great way to save money and time.

Rapid development, a development like Agile sprints, launching fast iterations, or the need for frequent updates of the data structure without much downtime between versions- the SQL DB will slow down the company's work while NoSQL data should not be prepared in advance.

\section{Customer analytics}

Customer analysis is the process where the customer behavior data are used to make critical business decisions through the market segmentation and the predictive analytics. Companies use this information for marketing, site selection, product upgrade, and customer relationship management. Marketing provides services to reach the satisfaction of a customer. Customer analysis uses data starting from the production or the service until the end of the cycle at the consumer, during that period, all possible technologies are used to include as more as possible data related to the customer and product or the service to reach the accurate prediction [6].

The worth situation is when the company or retailers have the limited visibility to their customers [14], to omit this need to implement analytics related to a customer, customer tracking and market research solutions with investmentcustomer analytics used in resolutions ranging from the product promotion, dynamic pricing of products, and distribution management. The primary users of customer analytics are retailers, by developing personalized communications and offer to customers, as well as various marketing programs for the segments [14]. Other benefits from customer analytics are: customizing prices with a special discount, prioritizing product development efforts, and developing a distribution strategy. Collecting and including data like behavior, loyalty, and demographic, lifestyle, preferences value, and predictive behavior data are a crucial point to bring benefits to both sides (customer and company), that is, increasing the accuracy of customer analytics.

Usually, in companies, it happens that customer data are not accurate or with mistakes, and it also happens because of a wrong structure DB or DB logic not following business logic. One of the errors of the DB structure is creating different customer ID for each customer lifecycle level; this will bring massive time-wasting 
during customer analytics. DB for customer analytics should be simple and with zero delays to grab the data from a DB.

\subsection{Predicting the customer behavior}

Predicting the customer preferences and shopping habits is a process of collecting and analyzing data. This information consists of many aspects, such as demographic data, behavior data, location information, purchase goods, payment methods, subscriptions, the loyalty of the customer, surveys results, etc. With consumer, the most profitable customer's segment can be found in profiles. When a group of particular customer segment is increasing sharply, this indicates changes in business orientation and plan for next period buying or producing products. We need to get into account that data related to different activities and travelers will bring significant weight for prediction how much a customer will purchase during traveling or prepare for the event without the customer analysis it is impossible to plan and make decisions for further developing and the acquiring plan.

\subsection{Knowledge discovery in DB (KDD)}

KDD is the method of identifying models in big data sets involving methods at the crossing of machine learning, deep learning, statistics, and DB systems. KDD is an interdisciplinary subfield of computer science and statistics with an overall purpose to extract information with inventive methods from a data set and transform the information into an understandable structure for further use. KDD is used for predictive models using the similar customer interactions to predict future events, and segmentation methods are used to place customers with the similar behavior and attributes in separate groups. This group and prediction help marketers to optimize their campaign management, targeting processes, and predict the quantity of product.

Analyzing customer's data is the primary role in a CRM system after the information is collected from the multiple sources. In most cases, analytics after the created model or some correlation could not show the result in a marvel way, due to lucking of presenting results in business. After the displayed result of analytics, managers can make better decisions [6]. Analytical models could be correlation, segmentation, and pattern recognition methods to analyze the data. The analytics results improve services and targets to the related customers and products, identifying problems and weak part of services or products. For example, one online education company found an increasing weekly session on springtime, but after analyzing, it mostly defined student in a school and university take more class to prepare exams on spring. This result could be used to advertising an individual product on spring period and offer courses related to exam and update products.

\subsection{Customer profiling defined}

The definition of customer profiling is "a description or analysis of a typical or ideal customer for one's business" Harper Collins Publishers. Customer profiling is a marketing tool that businesses use to understand their customers and helps to make better business decisions [15]. Profiling results in customer profiles which describe customers based on a set of attributes.

Customer profiling helps to understand customers, highlighting who they are, what they look like, what their interests and wants are, etc. This insight recognizes the customer's characteristics and traits. Having a better understanding of customers helps the company to communicate with the target customers more effectively. 
Analyzing transaction data can identify patterns and trends among customers by segmenting the needs from the profiled customers. As a result, the customer profile is not only based on demographic information but also takes into account the past behavior. Analyzing of a customer profile is by the product type, value, frequency, and patterns of spending. It provides a clear picture of most profitable customers by analyzing the different patterns of behavior or spending by customers. Next step after understanding the customers' type is to develop a strategy allocating the resource for each segment group and optimizing marketing budget and improving return on investment.

\subsection{Customer profiling models}

Profiling is typically reached by funnel groups and leak out customers according to similar features, providing a segment of customers. Collecting demographic, social, and behavioral data make it possible to classify and measure customer or potential customers according to the different social categories, habits, incomes, living standards, preference, age, wealth, and location. These features can be used in the segmentation and drain customers.

Behavioral classifications give the best result in the segmentation of customers because it is based on the customer's general behavior, likes, and interests. Behavioral classification provides a more in-depth and more reliable look at the customer base and what drives them and motivates them when making purchasing decisions. MOSAIC, ACORN, and Personicx are all well-known examples of the classifications of profiling behavior and hobbies, as well as demographic and social variables.

\subsection{Customer segmentation}

If customer segmentation powerful tool is used in all customer lifecycle, at least double increase in the sales can be reached. The advantage of customer segmentation is that they can be targeted at each customer segment using an individual approach, rather than one size suitable for all technologies, focusing on a specific segment facilitates communication with customers using a message related to them, and providing a more personalized approach with appropriate marketing communications.

The most common forms of customer segmentation are:

- Geographic segmentation: considered as the first step to the international marketing, followed by the demographic and psychographic segmentation.

- Demographic segmentation: based on variables such as age, sex, generation, religion, and occupation and education level.

- Firmographic: based on the features such as the company size (either regarding revenue or number of employees), industry sector or location (country and region).

- Behavioral segmentation: based on the knowledge of, attitude toward, usage rate, response, loyalty status, and readiness stage to a product.

- Psychographic segmentation: based on the study of activities, interests, and opinions (AIOs) of customers.

- Occasional segmentation: based on the analysis of occasions (such as being thirsty). 
- Segmentation by benefits: based on RFM, CLV, and others.

- Cultural segmentation: based on the cultural origin.

- Multi-variable segmentation: based on the combination of several techniques.

Customer segmentation techniques are:

- Single discrete variable (CLV, RFM, and CHURN)

- Clustering: K-means, hierarchical

- Latent class analysis (LCA)

- Finite mixture modeling (e.g., Gaussian mixture modeling)

- Self-organizing maps

- Topological data analysis

- PCA

- Spectral embedding

- Locally-linear embedding (LLE)

- Hessian LLE

- Local tangent space alignment (LTSA)

- Random forests, decision trees

- Deep learning

The customer profiling enterprises can increase ROI rapidly and most effectively. Customer profile will help to find potential customers and effectively target customers. These prospects should have a higher propensity to accept the offer and, therefore, provide more cost-effective means of targeting new customers.

\section{Conclusion}

In conclusion, customer profiling and segmentation provide the tools to fully understand the customer base and increase customer engagement and potential target customers.

\section{Acknowledgements}

The authors would like to express their gratitude to the scientific consultant Professor V. V. Yakovlev for his endless and professional guidance. It is also impossible to achieve and do implement of these results without the support of the 
university “St. Petersburg State University of Railways of Emperor Alexander I." The author especially wants to express his gratitude to his family members and all of the people who helped him to reach these results.

\section{Author details}

Kushnazarov Farruh

Department "Information and Computing Systems", "St. Petersburg State University of Railways of Emperor Alexander I" Saint-Petersburg, Russia

*Address all correspondence to: k.farruh@bk.ru

\section{IntechOpen}

(C) 2019 The Author(s). Licensee IntechOpen. This chapter is distributed under the terms of the Creative Commons Attribution License (http://creativecommons.org/licenses/ by/3.0), which permits unrestricted use, distribution, and reproduction in any medium, provided the original work is properly cited. (cc) BY 


\section{References}

[1] Cutler M, Sterne J. E-metrics business metrics for the new economy. Technical report, NetGenesis 2000. http://www.netgen.com/emetrics [Access date: July 22, 2001]

[2] Customer Relationship Management Smart Insights. Smart Insights. 2018. Retrieved from: https://www.smartinsights.com/ customer-relationship-management

[3] Customer Relationship Management. Bain. 2018. Retrieved from: https:// www.bain.com/insights/managementtools-customer-relationshipmanagement

[4] David J. Reibstein, Neil T. Bendle, Paul W. Farris, Phillip E. Pfeifer Marketing Metrics: The Manager's Guide to Measuring Marketing Performance. 3nd ed.ISBN-13 9780134085968. Pearson Education (US, NJ); 2015

[5] Shaw R. Computer-Aided Marketing and Selling: Information Asset Management (The Marketing Series). Butterworth-Heinemann (UK, Oxford); 1991. ISBN-13: 978-0750600705

[6] Kushnazarov Farruh I. Analysis of performance of algorithms for scoring system in organization of customer profiles. In: IEEE 2nd International Conference on Big Data Analysis (ICBDA); March 2017. pp. 281-285. DOI: 10.1109/ICBDA.2017.8078824

[7] Soltani R, Goeckel D, Towsley D, Houmansadr A. Towards provably invisible network flow fingerprints. In: 2017 51st Asilomar Conference on Signals, Systems, and Computers; October 2017. DOI: 10.1109/ acssc. 2017.8335179

[8] Zeng YE, Joseph Wen H, Yen DC. Customer relationship management (CRM) in business-to-business (B2B) e-commerce. Information Management
\& Computer Security. 2003;11(1):39-44. DOI: $10.1108 / 09685220310463722$

[9] Reinartz W, Krafft M, Hoyer WD. The customer relationship management process: Its measurement and impact on performance. Journal of Marketing Research. 2004, 2004;41(3):293-305. DOI: 10.1509/ jmkr.41.3.293.35991

[10] Gartner Reprint. 2018.

Retrieved from: https://www. gartner.com/doc/reprints?id=14OO2YJ4\&ct $=180111 \& \mathrm{st}=\mathrm{sb}$

[11] Magic Quadrants Research Methodologies. 2018. Retrieved from: https://www.gartner.com/en/research/ magic-quadrant

[12] How Does a Data Management Platform Work? 2018. Retrieved from: https://www.gartner.com/ smarterwithgartner/how-does-a-datamanagement-platform-work

[13] Codd EF. A relational model of data for large shared data banks. Communications of the ACM. 1970;13(6):377-387. DOI: $10.1145 / 362384.362685$

[14] Winston WL. Marketing Analytics: Data-Driven Techniques with Microsoft Excel. Wiley. 2014. Retrieved from https://www.amazon. com/Marketing-Analytics-DataDriven-Techniques-Microsoft/ dp/111837343X

[15] Customer Profile Definition and Meaning Collins English Dictionary. 2018. Retrieved from: https://www. collinsdictionary.com/dictionary/ english/customer-profile 



\title{
Chapter 2
}

\section{Unpacking the Digital Consumer Mindset}

\author{
Matthew Dingee
}

\begin{abstract}
The digital economy is recasting global commerce. The digital drive is often attributed to millennial and Gen $\mathrm{Z}$ technology adoption, purchase power, and societal habits (urbanization and discretionary income). For e-commerce, when defined as the sale of physical product(s) mediated by a digital platform, the pivot point is the consumer mindset. The consumer mindset is the root cause of purchase intent. That collective demand spurs all levels of sellers (firm) to behavioral strategies aimed to complete the commerce circuit; a good or service is sought and sold. During the reign of retail, advances in consumer research and neuromarketing led to a deeper competence (never complete) of the consumer in the retail context, which led to successful strategies of the firm. The consumer mindset in the digital economy can prove vexing for the firm that cannot identify the new cognitive schemas that define the digital path to purchase. This chapter presents no original research but synthesizes the research, existing subject matter expert insight and direct industry experience to give vision to the emerging mindset of the digital consumer, the social context of e-commerce, and the imperative behavioral strategies of the firm in the digital economy.
\end{abstract}

Keywords: digital platform, digital economy, social context, individual decision-making, behavioral strategy of the firm, cognitive schemas, social proof, unboxing, e-commerce

\section{Introduction}

If the consumer mindset instigates purchase intent, then it is the social context that integrates intent into action and delivers the transaction in time and space. Beginning with the psychological underpinnings of the consumer mindset, then the social context is applied and understood in its symbiotic substance with the consumer's mindset. Then the subsequent behavioral strategies of the firm emerge and complete the picture of the commerce. By seeing retail commerce and e-commerce side by side, the transformation becomes clear and actionable.

\section{The age of retail}

The recent period of commerce was an age of retail, defined as transactions within a bricks-and-mortar store. At the height of retail, store counts expounded, and same-store sales increased year over year. The retailer and brand implemented the four Ps with excellence; price, product, promotion, and place. Now blogs 
proclaim - the retail apocalypse is upon us—bricks and mortar are dying, or becoming a showroom for the online shopper. Retail forecast aside, there is no doubt the digital economy is in a rapid ascension; however, in understanding the opportunities and mindsets of each, brands and retailers can leverage the digital economy for growth and manage the evolution of retail.

\subsection{The retail consumer mindset}

In Piaget's framework for childhood development, he describes the progression of childhood development in a spectrum from sensorimotor, whereby children handle and touch to begin to learn, to concrete and operational phases, whereby children recognize sight symbols and recall concepts not tangibly present [1]. This framework can be similarly applied in tracing the consumer mindset in retailwhere consumers operate within the senses to make purchases. The retail consumer consciously draws upon the senses to discover new and appealing products and packaging $[2,3]$. The shopping experience consists of a series of individual decisions made by touching, seeing, tasting (think Costco), listening, and smelling. The consumer mind keeps shortcuts, called somatic markers [3], which link past life experiences with the senses and aid in selection process of new products. Even the in-store bakery is a strategic somatic smell, persuading the subconscious to purchase upon the universal positive association of fresh baked bread $[2,3]$. Additionally, more pre-loaded somatic markers, brand colors and logos, often connect with childhood and first experiences and become a way to speed up individual decision-making [3]. The retail store has a stickiness to the senses that connects the consumer mindset in retail inseparably with the senses-even a conscious consumer with a shopping list must remain a disciplined passerby to reach the milk in the back corner (intentional of course) [2]. Perhaps the most sensual purchase awaits the consumers as they checkout, where candy and confections tug upon the inner impulses [2]. The retail consumer relies upon their senses to make purchases in the retail context. The consumer mindset is operating within the sensorimotor stage 1 [1] of Piaget's framework, a purchase path of the senses. The consumer even operates in the preoperational stage 2 [1] whereby the consumer experiences a sense that recalls a memory or experience that is intuitively applied (subconscious) to the purchase decision-making. So the consumer mindset in retail is anchored to stages 1 and 2 of the Piaget development hierarchy. The consumer mindset now enters a retail social context of competition.

\subsection{The retail social context}

For the consumer, the retail environment is a competitive social context. The consumer enters retail with purchase intent and ready to fight for the best solution according to a vast and diverse set of individual cognitive schema and decisionmaking. The buyer navigates a tactile and physical landscape, expending energy to evaluate a multitude of products and battling to make a series of individual decisions to purchase.

In retail, the brands compete in order to emerge with dominant market share and be crowned as a category captain. For the retailer, the competitive arena, they aimed to offer the best cadre of competitors to give the consumer the power of choice. But, as retail matured, retailers had saturated store count and captured new foot traffic [2]. This intensified competition in store by turning the attention to spending more by measuring year-over-year same-store sales. Growth came from the upsell and more purchase from the same buyers, which intensified the competitive strategies further. 


\subsubsection{Retail strategy: in-store merchandising}

The strategic imperative of in-store merchandising is often a combination of retailer and brand creating in-store point-of-purchase (POP) displays, both elaborate and unexpected, to capture the senses and intrude the attention of shoppers. This strategy initially took a secondary position until brands and retailers realized that an array of seasonal displays, high-impact display graphics, strategic floor placements, and active floor talkers could capture the upsell to the tune of adding $60 \%$ purchase beyond the "list" [2]. This highly effective strategy quickly became a go-to tactical playbook that matured into a lucrative niche industry of its own [2]. This strategy is a collaboration between marketing and sales specialists with targeted retailer intelligence to act upon in execution.

\subsubsection{Retail strategy: product and package differentiation}

Product differentiation and shelf presence became a trusted strategy for brands as they sought novel and new ways for product, packaging, and price strategies to stand out and get selected from shelf across retail channels like club, grocery, and convenience stores. Often new and differentiated packaging utility (like microwave soup vs. a can) would be implemented to stand out and create new consumer utility. Yet other times the best price and best quality caught the consumers' cart. The differentiation strategy involves a mix of risk, reward, and developed points of difference to outmaneuver the rest. With $90 \%$ of new products failing [2], this strategy is a relied-upon behavioral strategy of the firm. In most firms this is where research and development leads the way through the coveted catchall, innovation.

\subsubsection{Retail strategy: consumer insights}

One of the most discussed and contemplated strategies of the retail firm is "market research" or "consumer insights." This consumer-centric strategy aims to understand the consumer mindset and build or fine-tune a product and package to match. This is the heart of focus groups, insight panels, surveys, and the like. The brands segment like-minded or connected demographics and maximize marketing efforts to give the market a reason to believe in the product offering. A consumer insight strategy mines buying patterns of these groups and translates them into sales growth. Brands delve deeper into the consumer's life, with ethnography studies that follow and observe consumers in home or in life. Moreover, brands are gaining new intelligence with neuromarketing and eye tracking and tools to identify the subconscious buying habits are cognitive puzzles of insights. The consumer mind is a complex exploration, and brands have learned that buying. In fact the focus groups often show that action and words do not line up [2-4]. The consumer may say one thing in group while buying another in the moment. The pursuit of deeper consumer insights and cognitive drivers uncovers new opportunities in retail.

\subsection{The digital consumer mindset}

In Piaget's framework of childhood development, stage 3, concrete operational stage, is where symbols are manipulated and take on less egocentric focus, and stage 4 , formal operational stage, is where symbols and relationships can be conceptualized readily [1]. These latter stages of the development are what anchor the digital consumer mindset. The consumer now starts the decision-making without product or package in hand, instead searching and scrolling through symbols, numbers, and images that represent the product. Although the full sensorial experience is restrained 
at this point, this creates opportunity for the consumer to engage and find product attributes, company backstory, and the mission for common good. Perhaps this is where millennial and Gen $\mathrm{Z}$ naturally align with this mindset, as they relish researching a firm(s) bigger purpose and mission prior to the purchase decision. This exemplifies the shifting mindset of the digital economy where cognitive concepts (i.e., mission, story, purpose, product, and social proof) formalize on the front end of the decision to purchase. It also blocks less personal recollection to a tangible product and ascribes value to public good and brand purpose at the onset. In the digital economy, the consumer mindset is distinctly more concrete and abstract in approach [1].

\subsection{Social context of digital economy}

The digital economy has shifted the social context of commerce to connection. As consumers are connected through social media, their leads to products show them what and who to buy and come not from a retailer but from their social network. The trusted advisor role has shifted from what is on shelf to what has been shared [4]. A consumer places trust in what has been shared but then begins a period of researching five-star ratings, blogs, website, and testimonials. In the new digital economy, a consumer no longer has to enter a brick-and-mortar store in buy mode and pick the best available but rather can be ever-present in a buy mode browsing and researching-in no hurry to commit_-gaining whatever is necessary to commit. This process is before any product is physically in a consumer's hands, which is contrary to sensual experience of retail. This contrarian social context in part explains how new brands find success in the digital economy, while big-scale brands find difficulty in shifting strategies for the new context [5].

\subsubsection{Digital strategy: selling small and scaling socially}

In the digital economy, direct to consumer sales is a foundational element of new commerce. The digital platform offers brands a chance to shape and sell their story and product directly to consumers, instead of retailers (as most big brands are accustomed) [5]. This is how the digital mattress brands broke through, by selling and telling about their mattresses directly to the consumer. Even when an e-retailer, like Amazon-a brand has an opportunity to connect to consumers directly with their story, products, and purpose. Once a social network recommends a product, the consumer will begin research and connecting to the brand. This leads to a new behavioral strategy of the firm; sell small and let social scale. The digital economy imperative is to sell small, as if to solve something for a single consumer-by designing an exceptional solution - for a given situation and letting social scale it. If brands focus on superior solution, the consumer will share and scale it socially. This strategic shift is the starting point for winning in the digital economy; the brand must woo the consumer with an exceptional product and offer.

\subsubsection{Digital strategy: caring commerce}

In the digital economy, the brand must show what it cares about, beyond the transaction: a worthy cause, a story of how it started, or a dedication to the craft and quality. As the consumer spends more time researching and browsing before they buy, they set out to discover what the brand cares about and factors into the individual decision-making process. A well-told story and purpose will not only influence the purchase but demonstrate how it aligns with a consumer's life and values. In Martin Lindstrom's bestseller Buyology, he researched three brand sponsors of American Idol and found that only two of the three remained and stuck in 
consumers' mind [3]. The common bond for the two that stuck was they had integrated into every facet of the show: chair shaped, color scheme, functional placement on set, and lending itself an aid to be something bigger [3]. The two brands went beyond the standard advertising spots and into the subconscious appeal that this brand belonged in their own pursuit of making dreams come true. In the digital economy and e-commerce, this is what commerce that cares can do for a brand; it shows creatively what it stands for and that a purchase is investing in something bigger.

\subsubsection{Digital strategy: strategic supply chain}

In the digital economy, supply chain management must become a strategic supply chain. Supply chain was an engine of optimization for the firm in retail: orchestrating just in time trucks and maximized truckload efficiencies across customers and distribution. But now the optimization imperative shifts from cost cutting to consumer demand [6]. Supply chain is no longer just an in-house activity but a consumer facing part of the offer-and it is manifested in no bigger way than free shipping.

Free shipping is the portal to supply chain strategy in the digital economy. Free shipping starts within the cognitive mindset of a digital consumer as they realize the fact that they are buying something that is not physically in front of them-so without the senses, they count the costs of shipping. They often find themselves in an online checkout, ready to buy, when it happens-they drag their mouse to the upper right corner and clicked the X. Why? It is because they did not realize it would be about 10 dollars of shipping on 30 dollars of goods. This is one of the main drivers in online shopping cart abandonment, dissatisfaction with shipping costs [7]. The firm must create a strategic advantage through free shipping. Perhaps it means communicating a clear average order value (AOV) on the website in order to get free shipping. For other brands, it might require product and package innovation, like the digital mattress brands, to capture free shipping.

\subsubsection{Digital strategy: unboxing a new ritual}

The digital economy creates sensual surprise and new ritual of strategic advantage for the brand. The digital economy transaction being highly cognitive on the front end now delivers the products in tangible and sensual experience on the back end. Since the consumer made the purchase, anticipation of arrival is built, until products arrive in a shipping container and are presented inside (with possible other layers of protection). This is a new strategic moment for brands to think about. In retail, these components were disposed of and never seen, touched, or opened by consumers. In e-commerce, unboxing has become a new ritual. The neuroscience of unboxing taps into the brain's dopamine to amp up anticipation [3] and excites in ways that feed social sharing and imitation to unbox with mirror neurons [3]. Rituals are known to drive brand usage and loyalty, like corona with lime, cookies, etc. [3]. In the digital economy, unboxing is a ritual that each brand can customize for a startling new connection to the digital consumer.

\subsection{The digital mattress flip}

The mattress industry exemplifies the emergence of the digital economy and how it disrupted a category and transformed it to the digital consumer. Mattresses are big ticket purchases, made infrequently, and abound with personal preferences. Retailers display showrooms of mattresses from many brands and furnish the sensual discovery process (customers could see, try, and touch) before committing to such a large purchase. This is classic retail strategy in action. But then new 
challenger brands leveraged the digital platform to build a better mattress experience. First, the mattress brands went direct to the customer (DTC) using online storefront(s) to tell their story and show the science of crafting mattresses that meet or exceed sleeping preferences. The new challenger mattress brands built a connection and trust by showing why their solution alone was worthy to be picked. Where the retailers carried many brands and makes, these challengers leveraged one of the basic strengths of e-commerce, direct access to your consumers. They also used the opportunity to show how they care and donate beds, which connects the purchase to a higher purpose [8]. Next, they offered 100-night no-risk, refundguaranteed trial period, with free shipping and returns [8]. This new risk-free extended trial period freed consumers from bricks-and-mortar mattress shopping and demonstrated brand commitment and a real-life test in consumer's home. This also exposed a glaring weakness in the retail trial process-it was awkward and unrealistic [2]. The consumer found no comfort in the mattress buying experience by laying on a bare mattress in a showroom among strangers and salesmen. The digital economy opened opportunity to meet the new digital consumer mindset.

Mattresses are large and bulky. In retail, delivery is arranged and bulky mattresses are carried to place as a service. Any consumer excitement for the new bed is extinguished when they watch the mattress twist and turn into position. Once again, the digital economy and mattress brands reimagined something new for digital-a mattress in a box and free shipping [8]! The mattress in a box is delivered anytime via small parcel carriers and the consumer's apprehension turned to anticipation-at the mattress unboxing. The carefully bundled mattress opens and forms into a bed-watched with the same wonder as when a child sees a ship raised in a bottle. As the consumer watches the bed unfold through this ritual, the worry has been turned to wonder. In order to make this happen, mattress makers redesigned the mattress materials, innovating a design that used various engineered foams to specific consumer preferences. This new material choice triggered equipment to compress and roll the mattress into a box of anticipation. Mattress brands combined the digital platform and product and package innovation to enter the digital economy.

\section{Conclusions}

The consumer mindset is the prominent starter for purchases across commerce. In retail, a consumer mindset operates within the senses to see, touch, and taste their way into decision-making on a multitude of products. This can be thought of within Piaget's stage 1 (sensorimotor) and stage 2 (preoperational) of purchase mindsets. Accordingly, a social context of competition sets off a cast of competing brands vying for attention and floor space from a consumer fighting to get the best solution to their felt needs (or shopping list). This retail commerce environment experiences wild successes for buyers and sellers alike but began to fall upon hard growth times-then the digital shift began.

The digital consumer mindset operates within a concrete operational (stage 3) and formal operational (stage 4) mindset. This manifests itself with abstract and outside contemplations brought into the decision-making; things like company purpose, product design, and shipping are now found upfront in the pre-purchase. Coupled with a social context free from the tangible product-and you have a new digital path to purchase. This necessitates new behavioral strategies of the firm like learning to sell small and socially, getting strategic with supply chain, demonstrating commerce that cares, and creating new experiences and rituals. Each firm will have to implement these abstract principles into a brand articulated plan to win in the new digital economy. 


\section{Author details}

Matthew Dingee

Onpoint 2020 Consulting, Lansing, Michigan, United States of America

*Address all correspondence to: matt@onpoint2020.com

\section{IntechOpen}

(C) 2019 The Author(s). Licensee IntechOpen. This chapter is distributed under the terms of the Creative Commons Attribution License (http://creativecommons.org/licenses/ by/3.0), which permits unrestricted use, distribution, and reproduction in any medium, provided the original work is properly cited. (cc) BY 


\section{References}

[1] Piaget J, Inhelder B, Weaver H. The Psychology of the Child. New York: Basic Books; 1969

[2] Underhill P. Why We Buy: The Science of Shopping. Updated and Revised. New York: Simon and Schuster; 2009

[3] Lindstrom M. Buyology: Truth and Lies About Why We Buy. First Paperback ed. New York: Crown; 2010

[4] Lewis MR. How Customers Buy: Mapping and Managing The Buying Journey DNA. First ed. New York: Diversion Publishing Corp.; 2018

[5] Business Insider Interview At Davos, P\&G's Marc Pritchard says Consumers expect brands to be a force for good [Internet]. 2019. Available from: https://www.businessinsider. com/pgs-marc-pritchard-talkssustainability-at-the-world-economicforum-at-davos-2019-1 [Accessed 23 January 2019]

[6] Supply Chain Brain [Internet]. 2019. Available from: https://www. supplychainbrain.com/articles/29049qa-whats-driving-supply-chainnetwork-optimization [Accessed: 02 April 2019]

[7] Dotcom Distribution 2018 eCommerce Study PDF [Internet]. 2019. Available from: https://dotcomdist.com/ [Accessed: 19 January 2019]

[8] Leesa Mattress [Internet]. 2019. Available from: https://www.leesa.com/ pages/one-ten [Accessed: 02 April 2019] 


\title{
Social Media, Consumer Behavior, and Service Marketing
}

\author{
Abigail Chivandi, Michael Olorunjuwon Samuel \\ and Mammo Muchie
}

\begin{abstract}
This study examined the impact of social media platforms and brand awareness in relation to the consumer decision-making and buying behavior patterns influenced by social media. It also depicts how companies can effectively make use of social media platforms as marketing strategy tools in business performances. Social media platforms seem to be increasingly and effectively bringing brand awareness and influence consumers' purchase decision-making and later on realize repeat purchases that bring about customer loyalty. Social media also has some influence to both the consumer and the marketers and is becoming the most welcomed online selling point by the millennial. Marketers/producers have noticed the rise in social media consumers; however, most of the business entities have not yet utilized social media to its fullest in their marketing activities and business strategies and performances. The study highlights the benefits of using social media platforms and brand awareness strategies that can be utilized through the online social media systems and gives a contemporary research gap, in how frequent businesses are engaging with social media.
\end{abstract}

Keywords: social media, innovative, Facebook, Twitter, YouTube, Internet, millenniums

\section{Introduction}

Social media marketing is now the modern and innovative way of doing business specifically in service marketing, as marketers as move from one strategy (fan accumulation) to another (6-s video) to another (social-local-mobile/SoLoMo), referring to a progressively versatile driven form of the expansion of neighborhood sections to web crawler results to another (messenger bots), looking for the right innovative strategy to improve their brand health [1]. Social media capabilities are the birth of platforms such as YouTube, Facebook, Twitter, WhatsApp, and Pinterest [2]. This has become the new and attractive way as the world has become a global entity and wide coverage of information disseminations shared through social media. The modern-day consumers especially millennials are increasingly using online tools, for example, blogs, "Facebook," and YouTube to share their opinions about products and services they consume [3]. The rise in Internet accessibility and availability of smartphones has led to the new form of what is known as electronic word of mouth (EWOM) which in this research will be referred to as 
social media. Peters [4] et al. states that "Of the various social media networks, Facebook alone has 750 million users, Twitter has 250 million users, and LinkedIn and Myspace have 115 million and 50 million users respectively." Social media has become the new growth strategy for any company that wishes to realize growth and have a mark in this new and uptight market. The generation of millennial consumers is now the largest consumers of goods, and getting their attention has shifted from the traditional methods of advertising to now the new platform of social media. According to Whitler [5], the challenge is that for past years the marketer has been focused more on "collecting" instead of "connecting." In other words Whitler [5] stated that marketers are focusing on having more fans and forgetting the crucial part which is to connect with the fans and create a loyal customer base of those social media fans one has. The marketer tends to forget that social media can be used as a marketing strategy which has an influence on consumer purchase decisions. In this chapter we review research that has been done related to the role of social media in consumer purchase patterns.

Peters et al. $[4,6]$ eluded to the fact that companies may use social media as a strategy to gain more customers or to chase customers away form a company's offerings, stating that a company is able to make or break its image through the social media that is made available to its consumers. Furthermore Suresh et al. [7] pointed out that social media has led to a rise in the consumption of service marketing due to its coverage and influence on consumers of different age groups and different lifestyles, based on their affordability and their consumer behavioral patterns. "What the hell is internet based life and what job does it play in promoting? It is the most widely recognized inquiry that has been inquired."

Online life speaks to minimal effort instruments that are utilized to consolidate innovation and social collaboration with the utilization of words [6]. These instruments are ordinarily web or versatile based. A small number of firms have incorporated social medial innovation such as Twitter, Facebook, and YouTube. Online life gives advertisers a voice and an approach to speak with companions, clients, and potential customers. It customizes the "brand" and encourages the advertisers to spread your message in a loose and conversational way [6, 7]. The Internet-based life, on the off chance that you could call it, will be that it must be a piece of your regular day-to-day existence to keep the energy and consideration you requirement for it to be fruitful. Online networking is not just for the entrepreneurs that are experimenting with an investigation; however it includes bigger organizations all inclusive. The following are a couple of instances of organizations that have turned out to be associated with web-based social networking:

- Absolut Vodka-Online video on YouTube and utilizing Facebook to house their Top Bartender fan page.

- BMW-They are utilizing Facebook to advance their 1-series road trip, and they have made a Rampenfest page for fans.

- Dunkin Donuts-That is correct; they have discovered an incentive in Internet-based life and have set up a microblogging Twitter account.

- Donald Trump-In precedents, we cannot forget President Trump. He has taken the utilization of Twitter to an unheard of level. He has managed strategy that impacted the share trading system and by and large utilized Twitter as an approach to convey specifically to the general population, circumventing the customary news media. 
In the USA, there is high usage by adult beverage companies, exotic automobile manufacturers, pastry shops, and US President using social media tool; it is not too hard to figure out that there is something to it that is innovative in the marketing discipline.

The section highlighted and availed the importance of social media innovations in relation to consumer behavior and service marketing. A background to the social media network usage is also given. Importantly, the review chapter also highlights how retail companies may use social media as a strategy to gain more customer base. The following subsection gives a discussion on the role and the significance of social media in service marketing and the consumer buying pattern.

\subsection{Role of social media in marketing}

Marketing is viewed as a tool that is used to inform consumers about our products and services, revealing the companies' identity and brands being offered. Social media does that tool [3]. Online life gives a character to our identity, and the items or administrations that we offer make connections utilizing Internet-based life with customers who may not generally think about the organizations' items or benefit or what the organizations speak to; social media makes us "genuine" to shoppers $[1,6,8]$. "On the off chance that you need buyers to tail you, don't simply discuss the most recent item news; however, share your identity with them, and social media can also be used as a platform to peers association that may be serving the same target market and also gives facilitation through communication and interaction that consumers look for." Social media carries with it a lot of value, but how do you do it right?

Marketers cannot just depend on social media but must be integrated with other vehicles of marketing. While social media creates awareness, marketers need to be convinced that in the beginning, it will sell a million dollars' worth of product and services $[1,6,8]$. That is not to say that one day once the players have built up their social media "stardom" that it would not, but it probably would not happen tomorrow. And there are no written "right" or "wrong" rules when it comes to social media; only the marketers can determine what will work for them $[1,6,8]$.

Examples of overcoming adversity are plenteous when it comes to utilizing webbased social networking from talent scouts that secure a position for candidates to new organizations that need to present another item just as officially settled Fortune 500 organizations that need to fortify their image. The job of online life in showcasing is to use it as a specialized device that makes availability to those inspired by item and benefits and realizes mark mindfulness and perceivability to those purchasers that do not know about the advertiser's brands $[1,6,8]$. Web-based life can utilize it as an instrument that makes an identity behind the advertiser's image making connections that generally may never have been picked up. It makes rehash purchasers as well as client reliability $[1,6,8]$. The truth of the matter is online life is diversified to the point that it tends to be utilized in the way that best suits the intrigue and the requirements of the business.

Social media is proving to be an effective tool as a marketing strategy; however, most companies are currently dedicating $11 \%$ of their marketing budget to social media, and $44 \%$ of those company executives were of the opinion that social media has an insignificant impact on the growth of a company and its brand [8,9]. Many researchers have conducted studies: Social Media and Negative Word of Mouth: Strategies for Handling Unexpected Comment [10], a study on Factors Determining Social Media on Cosmetic Product [11]. Examining the Beauty Industry's Use of Social Influencers [12], Young adults and ethical consumption: An exploratory 
study in the cosmetics market $[9,12]$, Global beauty industry trends in the twentyfirst century [12], A study of the impact of social media on consumers [13], Social Media as a Marketing Tool: A Literature Review by [14], and Effectiveness of Advertising on Social Network Sites A Case Study on Facebook [15, 9]. However there has not been much research done on an analysis of the effects of social media on purchasing or consumer buying decision-making.

According to Chivandi et al. and Donovan $[9,16]$, many small business are not actively utilizing social media to reach consumers in which she stated that $47 \%$ of the small business do not actively use social medial and $25 \%$ of the small businesses have no plan to use social media at all.

Despite the fact that buying online is spreading and growing fast in short-term period, some regions and countries have very limited volume of online purchasing transactions, such as the Arab world situation. In the past year, Arab has seem a significant evolution of technology which led to many changes in the norms of doing businesses, practicing governance, and carrying out greater growth. With approximately more than 125 million individuals that are using the Internet, the number of social medial active users is very low and in turn makes most marketers not take up social media as an effective marketing channel [17]. Many businesses have noticed the rise in the use of social media consumers; however, many of the bulk of businesses have not yet taken up social media [18] elucidates that of those businesses that are not yet on social media, a significant number plan on establishing a presence within the next year. The study goes on to highlighting that many businesses sense the risk of being left behind; there is still a gap, though, in how frequently consumers are using and engaging with social media as compared to businesses. The social media platform according to [2] is here to stay and is the revolution that has changed our world and time; Ostrow [2] further alluded to the fact that there is one main social media innovation that in all likelihood will not only endure, but thrive, in the decade ahead. This innovation has embodied most of what we have come to define as social media since 2000, and it is not showing any signs of slowing down, and that innovation is YouTube. Deducing from the aforementioned social media is a necessary tool with some form of influence in the growth of a business's brand cutting across internationally.

This section discussed the social media roles, importance, and its application to consumer buying decision patterns. Section 2 gives a highlight, reviews discussion on the social media platforms, and depicts information on study done by other authors in relation to social media consumption and how innovation aspect has been implemented through the platforms. It also gives a brief discussion on consumer decision-making process in relation to social media platforms.

\section{Social media platform innovation}

The start of the century introduced new technology innovations, and social media platforms, which are but to name a few Twitter, Facebook, YouTube, and Pinterest, provide users with a variety of communication tools at their disposal [19]; social media platforms according to [2] are here to stay and are the revolution that has changed our world and time. Ostrow [2] further alluded to the fact that there is one main social media innovation that in all likelihood will not only endure, but thrive, in the decade ahead. This innovation has embodied most of what we have come to define as social media since 2000, and it is not showing any signs of slowing down, and that innovation is YouTube.

The use of social media platform can be described as the new wave of information and communication technology. Social media innovations are tools that are 
used by the consumers to give out information as well as to receive the information [20]. Manzini [21] stated that "Social innovation is a value-adding outcome that emanates from a variety of ways that involve interactions between people"; deducing from the aforementioned social media innovations is a media platform in which people creatively come together and share information. These innovations has made it possible for companies to be able to have a more intimate relationship with their consumers; there are currently over more than 300 hours of video uploaded on YouTube every hour and over 350 million Facebook loads daily [22]. Through the innovation of social media, many bloggers and vloggers are able to share their brand tips and secrets to their worldwide audiences. Zolkepli and Kamarulzaman [19] alluded to the fact that consumers need to interact on social media so as to gain value, self-discovery, entertainment stratification, and social enhancement and maintain interpersonal connectivity with different people across the world, satisfying the need that is within humans which is a need of interaction. Zolkepli and Kamarulzaman [19] in Chivandi et al. [9] further pointed out that according to former studies, consumers use media to fulfill interpersonal needs, which include the needs derived from offline media gratification, for example, relaxation, surveillance, pastime, and escape, and new online media needs are sociability, popularity, convenience, and companionship.

\subsection{YouTube}

This social platform creates the opportunity for the provider of content to target a niche market which is focused on their similar interest and need. "Since launching in 2005, YouTube has played a central role in democratizing video distribution; to present anyone can have their own YouTube channel and become a worldwide sensation" (fastcompany.com, 2018). Fortunelords [23] alludes to the fact that more people between the ages of 18 and 49 now rarely watch TV and all their information and news are obtained through social media channels especially YouTube, as these social media innovations are now applications on our mobile devices.

\subsection{Facebook}

Czinkota and Ronkainen [24] were of the view that Facebook was the most popular site around 2012 and had nearly one billion members worldwide, followed by LinkedIn, Twitter, Myspace, and YouTube. Czinkota and Ronkainen [24] further pointed out that more firms are adopting Facebook and other social media to conduct their marketing functions.

\subsection{Pinterest}

This social media platform enables users to share ideas and thought through pinning pictures on a board they create in the account. The board will be a collection of their favorite things and other users' comment, like, and re-pin of the pictures or visual images on their own boards [25]. Many users find the boards helpful as they are able to discover new products and different brands from the people they follow on Pinterest.

\subsection{Twitter}

Twitter is an online platform that uses short messages to communicate with other users; the short messages are called tweets. The messages will only be 
available to those who follow you on Twitter [26]. Consumers usually use Twitter to discover interesting people and companies, and they are usually influenced by what those people say.

\subsection{Word of mouth}

Wang and Fesenmaier [27] was of the view that word of mouth is the oldest way to convey information. This method has been used by marketers as a way to advertise their products, in that consumers share communication about a product. Electronic word of mouth has taken over the traditional word of mouth as an informal Internet-based communication where all consumers are exposed to the social media innovations which make it possible. Consumers around the world can now share information regarding a product, and this information is accessible to both active and passive consumers everywhere [27]. The consumers' use of technology can have both positive and negative effects to a company, and if it is bad publicity regarding a certain product or service, it can spread to uncontrollable levels in which a company may not be able to contain [3]. Social media according to Ioanăs and Stoica [28] influences the consumers from purchase decisions to postpurchase decision behavior through posts such as dissatisfaction statement on product reviews.

Table 1 depicts information on study done by Chivandi et al. [9] on social medial platforms using haircare products on millennials in South Africa. The table also gives the highly used social media platform.

Table 1 reveals that most of the people who frequented the social media platforms are between the age ranges of 18 and 25 . This is $93.2 \%$ searching for hair products and has the postgraduate degrees at a \% of 97.6 .

\begin{tabular}{|c|c|c|c|c|c|}
\hline \multicolumn{3}{|c|}{ Gender } & \multicolumn{3}{|c|}{ Age } \\
\hline & Frequency & Percentage & & Frequency & Percentage \\
\hline Female & 247 & 98.8 & $18-25$ & 233 & 93.2 \\
\hline Prefer not say & 3 & 1.2 & $26-35$ & 16 & 6.4 \\
\hline Total & 250 & 100 & $36-45$ & 1 & 0.4 \\
\hline & & & Total & 250 & 100 \\
\hline \multicolumn{3}{|c|}{ Highest education level } & \multicolumn{3}{|c|}{ Use of hair products } \\
\hline $\begin{array}{l}\text { Postgraduate } \\
\text { degree }\end{array}$ & 34 & 13.6 & Yes & 244 & 97.6 \\
\hline Degree & 89 & 35.6 & No & 6 & 2.4 \\
\hline Diploma & 2 & 8 & Total & 250 & 100 \\
\hline Matric & 125 & 50 & & & \\
\hline Total & 250 & 100 & & & \\
\hline \multicolumn{3}{|c|}{ Social media platforms } & \multicolumn{3}{|c|}{ Login frequency } \\
\hline Facebook & 38 & 15.2 & 0 & 27 & 10.8 \\
\hline YouTube & 105 & 42 & $1-3$ & 153 & 61.2 \\
\hline Whats app & 19 & 7.6 & $4-7$ & 34 & 13.6 \\
\hline Pinterest & 27 & 10.8 & $\begin{array}{l}\text { More than } 7 \\
\text { times }\end{array}$ & 36 & 14.4 \\
\hline Twitter & 12 & 4.8 & Total & 250 & 100 \\
\hline Other sites & 49 & 19.6 & & & \\
\hline Total & 250 & 100 & & & \\
\hline
\end{tabular}

Source: Ref. [9]

Table 1.

Login frequency of social media platforms, gender, age, and education level. 


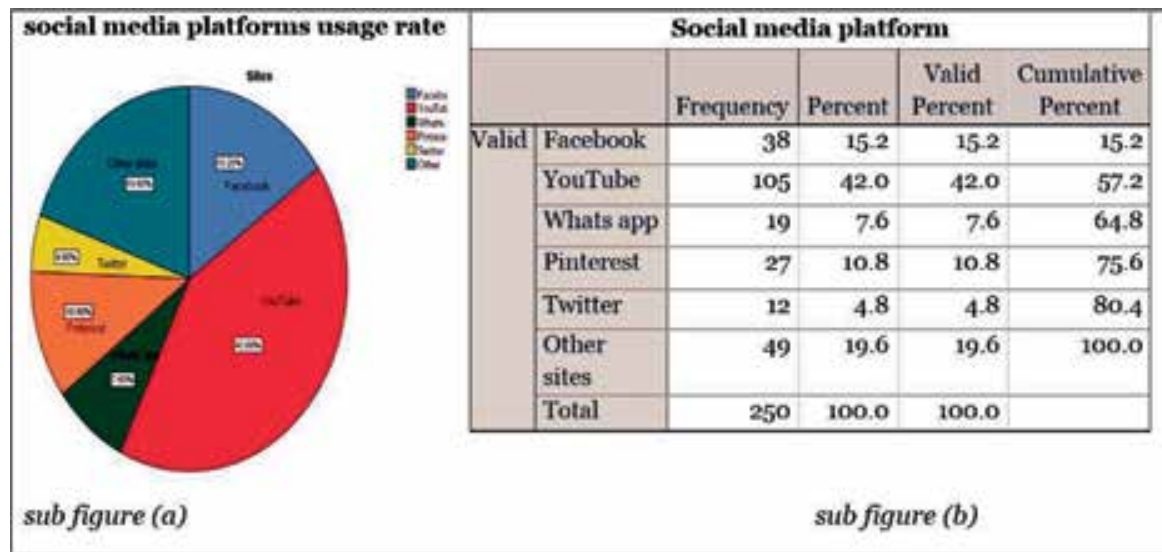

Source: Ref. [9]

Table 2.

Social media platforms and their usage \%.

The pie chart sub figure (a) illustrates the percentage decomposition of usage on different social media platforms, while the sub figure (b) shows that the mostly used social media platform is YouTube (42.0\%) followed by Facebook which is $15.2 \%$ and Pinterest which is $10.8 \%$ (Table 2 ).

\subsection{The consumer decision-making process}

The decision-making process is affected by external environmental factors that affect the process, and these are environmental influence (social class, family, culture, situation, and personal influence); the environment affects the consumer decision-making process as this forms the consumer's personal influence from the early stage of information search as they also serve as a source of information which will affect the overall decision-making process; despite the environment helping the consumer to come to a purchase decision, their individual differences and influences affect the type of choices that they will make in the end, as they will be able to conduct an internal information search in regard to their personal values, knowledge, and motivations which will help the filter from the environmental influences to scale down their purchase choices to a more personal level. Individual differences and influences include knowledge, value consumer resources, motivation, knowledge, personality, and values) [29]. Psychological processes enable the consumer to conduct both information search and an evaluation of alternatives as they engage in information processing which may have an outcome of a purchase decision which leads to a learning stage and determines whether the individual will engage in repurchase as they enter the post-purchase stage. This external factor includes learning, behavior change, attitude, and information processing. Online environmental aspects include website quality, website experience, and website satisfaction; the online environment now has a huge impact on the consumer decisionmaking process as it may trigger the problem recognition stage, through a consumer's online interactions, and affects the whole process up till the post-purchase stage as it provides both information search, evaluation of alternatives, and purchase options. The online environment even provides the consumer with social interactions which may influence a consumer's final purchase decision [29]. This process is illustrated in Figure 1. 
According to McGinn [30], the five-stage decision-making process consumer goes through five stages of decision-making which are problem recognition, information search, evaluation of alternatives, purchase decision, and post-purchase behavior.

\subsection{Problem recognition}

This is the first stage where the need is recognized; the need can be triggered by internal needs or stimuli which may be thirst and hunger or externally triggered through external factors or stimuli like the environment, friends, and family. The magnitude of information search will be reliant on the type of problem solving to be addressed; when the problem related to consumption is new and complex, it will lead to the buyer being involved in in-depth external information search; simpler problems usual depend on simple internal information search.

\subsection{Information search}

The consumer first conducts an internal memory search for information; however, when they fail to get the information they need or do not have enough information internally regarding the problem, they look for information externally. When searching for information about which product to buy, consumers now turn to social media as a reference point on which product best satisfies their needs.

Consumers go through various social media channels to gain information in regard to a particular purchase decision. McGinn [30] stated that social media influencers should be considered by marketers in regard to a company's products as their opinion in regard to a product can influence most consumers' purchase decisions. The brand is the symbol of a company; when a consumer is satisfied with a product, they spread information regarding the brand through word of mouth to other consumers, which will lead to others being interested in the brand and choosing the brand [31].

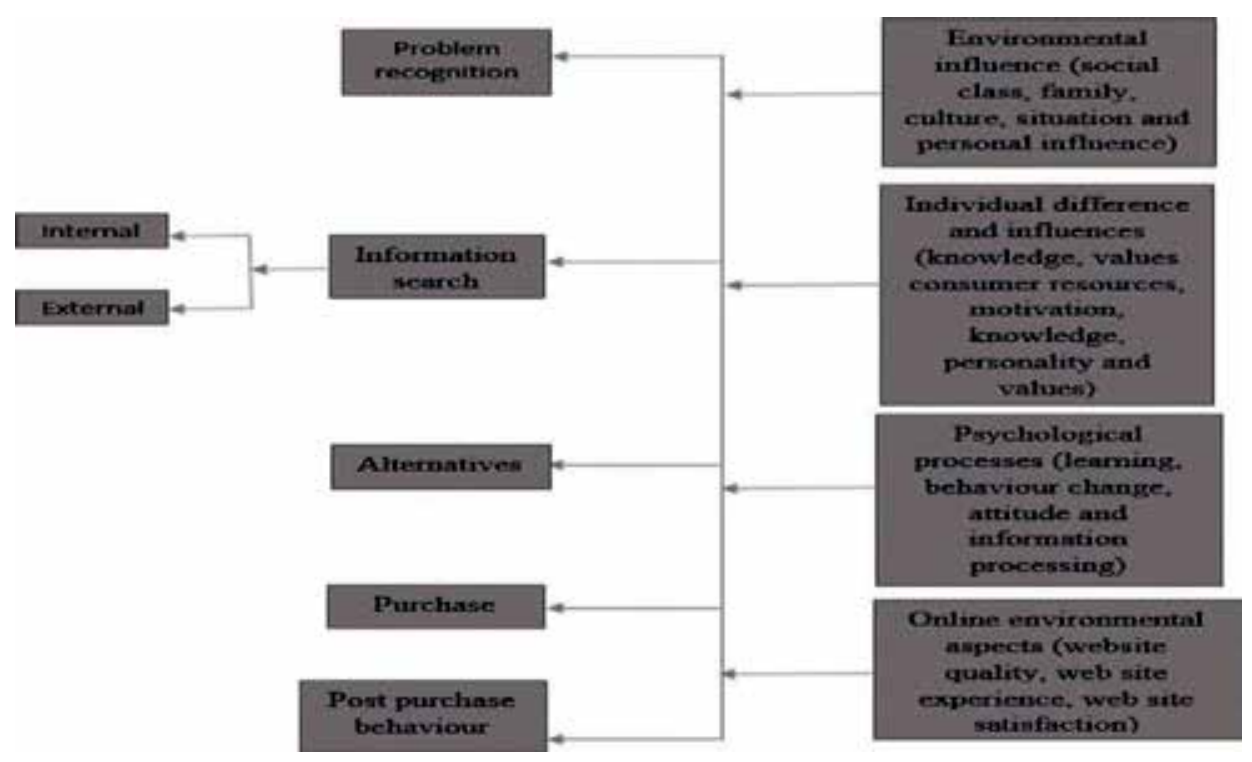

Figure 1.

Consumer decision-making process. The five-stage decision-making process [29]. 


\subsection{Alternatives}

After information gathering the consumer now begins to weigh his or her options in accordance to the information they would have gathered. MacKenzie et al. [32] stated that that "the improvement of criteria part of the model includes a fundamental thought prompting arrangement of an evoked set, and in accordance with this, advancement of the choice criteria that will later be utilized to assess conceivable arrangements offered by the evoked set." This aforementioned then leads to the consumer to be able to evaluate the evoked set in which alternative would best suit them. Consumers use different rules at this stage in choosing the product or service they will take up; some of the choices may be affected by brand preference, product quality, and price.

\subsection{Purchase}

The following stage is purchase decision; the consumer will have made an intention to buy a certain brand; however, their final buying decisions will be affected by other people's attitudes and unforeseen factors that may affect the consumer's decision, postpone, or even lead to the withdrawal of the decision [33].

\subsection{Post-purchase behavior}

The last stage is the satisfaction or dissatisfaction after the purchase decision. This will determine whether the consumer will consider the similar purchase, especially at the stage of need recognition and information search. The consumer will in turn share their experiences on social media as a feedback to peers or the product manufacturer.

The online environment affects the consumer's decision-making process from the need of recognition to the final stage which is the post purchase. Social media is now an effective tool which marketers have to consider when positioning product in the consumers' minds as it now part of the influencers in the decision-making process consumers go through [29]. The theory of the consumer decision-making process is the grounding theory for the social media platform as it relates to consumers and their buying behavior patterns. Deducing from the theory, it is seen that aspects of the environment affect the decision process the consumer goes through; in this case the environment includes social media, and social media influences the decision-making process from problem recognition up to post-purchase decision. Delis [33] pointed out that Greek consumers have adopted social media as a reference point in their decision-making process, and it has influenced their choice of products. However due to the lack of physical contact at times, consumers are not fully confident with the product as compared to one they can touch physically. Bruno et al. [34] was of the view that social media Instagram in particular lead to creation of brand awareness by product users which was authentic and a true reflection of the brand and that users of the social media platform would in turn become loyal to a brand that was being used and spoken about by their peers on social media. Section 3 of the review chapter gives a conclusion based on previous studies and other scholarly contributions on social media innovations.

\section{Conclusions}

From previous studies, according to Alharbie [35], social media innovation led to consumer preference for certain products as consumers have a tendency to learn 
from the influence of other individuals in their social networks which would incline them to prefer a particular brand to another. Bruno et al. [34] also pointed out that peers such as the millennials tend to influence consumption patterns and decisions among each other through social media and therefore cause brand preference and brand love for a particular product. These findings meant that as a company increases, their social media presence in various ways through sites like YouTube and Facebook would in turn have an increase in the level of brand awareness for their products and services as most of the respondents indicated that they discovered new and existing brands through social media [34]. Social media, as a marketing tool, created brand awareness for a company's product as well as got feedback on how companies were able to improve their products from the consumer's perspective [29]. The first point of call is that they are able to make both their new and existing brands made known to more consumers through using marketing strategies which utilize YouTube, Facebook, and other social media sites, as it was seen that these platforms lead to an increase in brand preference and purchase buying behavior patterns [35]. Brand preference was also seen to be derived from users using brands that their social media contacts or influences used; therefore, a company may choose to identify influencers on these social media sites, to use their products and services, that are mentioning the products they are using to their social media followers. Another marketing implication is that, it is derived from the fact that social media was also a useful tool in creating repeat purchase and building relationships and customer loyalty, as the study highlighted that social media platforms had an impact in how consumer perceived a product and it was social media innovation that led to them being influenced to prefer one brand over another. The study also adds to the limited body of literature which surrounds social media and the consumption of product and services through social medial platforms and forms bases for further study in regard to the variables looked at in this particular study. The discussion of the study was also in line with the consumer decision-making model which stated that a person's buying behavior was influenced by their social exposure which is made up of their friends, family, and acquaintances and goes through all the stages [29].

\title{
Author details
}

\author{
Abigail Chivandi $^{1 *}$, Michael Olorunjuwon Samuel ${ }^{1}$ and Mammo Muchie ${ }^{2}$ \\ 1 University of The Witwatersrand, Johannesburg, South Africa \\ 2 Tshwane University of Technology, South Africa \\ *Address all correspondence to: abigail.chivandi@wits.ac.za
}

\section{IntechOpen}

(C) 2019 The Author(s). Licensee IntechOpen. This chapter is distributed under the terms of the Creative Commons Attribution License (http://creativecommons.org/licenses/ by/3.0), which permits unrestricted use, distribution, and reproduction in any medium, provided the original work is properly cited. (c) BY 


\section{References}

[1] Ray A. The best innovation in social media is a return to basics. 2016.

Available from: https://blogs.gartner. com/augie-ray/2016/05/14/thebest-innovation-in-social-media-is-areturn-to-basics/

[2] Ostrow A. Mashable. 2009. Available from: https://mashable.com/2009/12/ 22/youtube-2010/\#SwTTZ7KiraqB

[3] Huete-Alcocer N. A literature review of word of mouth and electronic word of mouth: Implications for consumer behavior. Frontiers in Psychology. 2017;8

[4] Peters C, Thomas J, Robbins K, Emelia H. Social media and negative word of mouth. Atlantic Marketing Journal. 2012;1(2):87

[5] Whitler KA. www.forbes.com. 2014. Available from: https://www.forbes. com/sites/kimberlywhitler/2014/07/ 17/why-word-of-mouth-marketingis-the-most-important-social-media/ \#34c7302254a8

[6] Kietzmann JH, Hermkens K, McCarthy IP, Silvestre BS. Social media? Get serious! Understanding the functional building blocks of social media. Business Horizons. 2011;54(3): 241-251

[7] Suresh V, Chitra, Maran. A study on factors determining social media on cosmetic product. Pharmaceutical Sciences and Research. 2016;8(1):1-5

[8] Moorman C. www.forbes.com. 2017. Available from: https://www.forbes. com/sites/christinemoorman/2017/07/ 26/how-companies-can-capitalize-onsocial-media-investments/\#3361735e7b3c

[9] Chivandi A, Vafana S, Samuel OG, Muchie M. Social media innovation consumption of hair products in South Africa; African female perception manuscript number JJRC2018759
Journal of Retail and Consumer

Services. 2018

[10] Hebl M. Online Statistics Education: An Interactive Multimedia Course of Study. Houston: Developed by Rice University (Lead Developer), University of Houston Clear Lake, and Tufts University; 2017

[11] Forbes K. Examining the beauty industry's use of social influencers. Elon Journal of Undergraduate Research in Communications. 2016;7(2)

[12] Maggioni I, Montagnini F, Sebastian R. Young adults and ethical consumption: An exploratory study in the cosmetics market. In: 12th International Marketing Trends Conference. 2013. p. 23

[13] Hajli MN. A study of the impact of social media on consumers. International Journal of Market Research. 2013;56(3):387-404

[14] Paquette H. Social Media as a Marketing Tool: A Literature. Major Papers by Master of Science Students: University of Rhode Island; 2013

[15] Maurer C. Effectiveness of Advertising on Social Media Network Sites: A Case Study on Facebook. Research Gate; 2011

[16] Donovan L. www.business2 community.com. 2017. Available from: https://www.business2community. com/social-media/many-small-businessesstill-not-using-social-media-01278783

[17] Ismael Al-Mukhaini E, Sara IA-D. The impact of using social media on consumer buying behavior. 2014. Available from: https://www.researchgate. net/profile/Israa_Al-Dhuhli/publication/ 275347329_The_Impact_of_Social_Media_ on_Consumer_Buying_Behaviour/links/ 
5539e3950cf247b858814ad3/TheImpact-of-Social-Media-on-ConsumerBuying-Behaviour.pdf

[18] Sharp BM, Macdonald EK. Brand awareness effects on consumer decision making for a common, repeat purchase product: A replication. Journal of Business Research. 2000;48:5-15

[19] Zolkepli IA, Kamarulzaman Y. Social media adoption: The role of media needs and innovation characteristics. Computers in Human Behavior. 2015; 43:189-209

[20] Mergel I. The social media innovation challenge in the public sector. Researchgate Information Polity. 2012;17:281-292

[21] Manzini ST. Measurement of innovation in South Africa: An analysis of survey metrics and recommendations. South African Journal of Science. 2015;111(11-12)

[22] Kotenko J. Facebook reveals we upload a whopping 350 million photos to the network daily. 2013. Available from: https://www.digitaltrends. com/social-media/according-tofacebook-there-are-350-millionphotos-uploaded-on-the-socialnetwork-daily-and-thats-just-crazy/

[23] fortunelords. youtube-statistics. 2018. Available from: fortunelords.com: https://fortunelords.com/youtubestatistics/

[24] Czinkota MR, Ronkainen IA. International Marketing. Tenth ed. South-Western Cengage Learning; 2012

[25] Moreau E. lifewire.com. 2017. Available from: lifewire.com: https:// www.lifewire.com/how-to-usepinterest-3486578

[26] Gil P. What Is Twitter \& How Does It Work? 2018. Available from lifewire: https://www.lifewire.com/what-exactlyis-twitter-2483331

[27] Wang Y, Fesenmaier D. Towards understanding members' general participation in and active contribution to an online travel community. Tourism Management. 2004;25:709-722. DOI: 10.1016/j.tourman.2003.09.011

[28] Ioanăs E, Stoica I. Social media and its impact on consumers behavior. International Journal of Economic Practices and Theories. 2014;4(2)

[29] Darley WK, Blankson C, Luethge DJ. Toward an integrated framework for online consumer behavior and decision making process: A review. Psychology \& Marketing. 2010;27(2):94-116

[30] McGinn JF. The Analysis of Consumers' Affective Responses to Brand Presentation, Awareness, and Loyalty: A Contemporary Development in Selecting Media Channels. Rochester Institute of Technology; 2016

[31] Azad N, Safaei M. The impact of brand value on brand selection: Case study of mobile phone selection. Management Science Letters. 2012;2(1): 1233-1238

[32] MacKenzie SB, Podsakoff PM, Podsakoff NP. Construct measurement and validation procedures in MIS and behavioral research: Integrating new and existing techniques. MIS Quarterly: Management Information Systems. 2011;35(2):293-334

[33] Delis S-N. The Role Of Internet In The Consumer Decision Making Process And The Experiential Dimension Of Consumer Behaviour With Reference To The Purchase Of Music: An Examination Of Greek Culture. England: The University of Leicester; 2009

[34] Bruno G, Aikaterini M, Daniele P, Joonas R, Gaetano A, Raffaele D, et al. 
Social Media, Consumer Behavior, and Service Marketing

DOI: http://dx.doi.org/10.5772/intechopen.85406

Social media marketing efforts of luxury brands: Influence on brand equity and consumer behavior. Journal of Business Research. 2016;69(12):5833-5841

[35] Alharbie A. Business Growth thru Social Media Marketing. International Journal of Innovation and Applied Studies. 2015;13(4):873-880. ISSN 2028-9324 



\title{
Chapter 4
}

\section{Tourism 4.0: Challenges in Marketing a Paradigm Shift}

\author{
Urška Starc Peceny, Jurij Urbančič, Simon Mokorel, \\ Vesna Kuralt and Tomi Ilijaš
}

\begin{abstract}
Since the early beginnings people have been traveling and tourism industry has been always adapting to the social and technological development. In the era of digitalization, it needs to adapt again. Around 1.3 billion persons are traveling yearly around the world. Thus, a small change in this sector has a huge impact on the whole society. We propose a new paradigm, Tourism 4.0, appearing with the quest to unlock the innovation potential in the whole tourism sector. This will be done with the help of key enabling technologies from the Industry 4.0, such as Internet of Things, Big Data, Blockchain, Artificial Intelligence, Virtual Reality and Augmented Reality. By establishing a collaborative ecosystem involving local inhabitants, local authority, tourists, service providers and government, we can co-create an enriched tourism experience in both the physical and the digital world. With this, we can shift from tourist-centered focus to a tourism-centered focus around the local community. Who is the consumer in this new paradigm of tourism and what is the role of marketing in a paradigm shift? The chapter will analyze the current development and present the main shifts due to it.
\end{abstract}

Keywords: Tourism 4.0, Industry 4.0, collaboration models, new technologies, smart tourism, sustainability, economic impact, human-centered technology

\section{Introduction}

Although tourism is generally understood as people traveling for pleasure, it is nevertheless a complex activity that involves a number of issues that intersect over several branches in the economic and social sectors [1]. Defined by the World Tourism Organization (UNWTO) [2] as "a social, cultural and economic phenomenon which entails the movement of people to countries or places outside their usual environment for personal or business/professional purposes", tourism today is recognized as one of the world's largest economic sector, supporting more than 313 million jobs in 2017 and generating $10.4 \%$ of global GDP [3]. Considering the predictions of increased global growth and the unique connectedness of tourism sector, it is clear why UNWTO has recognized tourism as one of the drivers for realization of the sustainable development goals [4] and even dedicated a separate website to the promotion of the idea and mission [5]. It has long been established that short-term market success might in fact lead to the deterioration of the destinations and therefore natural environment. Sustained market competitiveness requires a balance of growth orientation and environmental commitment at an acceptable rate of return to all industry partners involved in the marketing of a destination [6]. 
For this reason, it is critical for future of the tourism development to adapt marketing in tourism to preserve both natural and cultural heritage. In achieving this, the appropriate use of the key enabling technologies plays the crucial role.

In this book chapter we introduce the largest government-sponsored research project in Slovenian tourism called Tourism 4.0, together with the main marketing challenges of the project itself and solutions developed in it. Slovenia is a small country located in the south of Central Europe with a long history of tourism. For instance, records of people traveling to the spas of Rogaška Slatina go back to the middle of the seventeenth century [7], while modern cave tourism in Postojna began in 1818 [8]. Hence, it is not surprising that the Tourism 4.0 partnership has been established here. Its ambition is to create a testbed in order to transform the tourism industry into an innovation-driven economy by enriching tourism experiences with the use of technology and data. The term originates from the modern paradigm in industry, known as Industry 4.0 [9] and aims to improve the added value to tourism through innovation, knowledge, technology and creativity. This is planned to affect every field around it by creating an ecosystem, in which physical and digital space, infrastructure, personnel and technology behind it merge into one seamless experience of many personalized outputs. The knowledge, expectations and experiences of tourists, defined as Tourist 4.0 in the project frame, will be utilized to build the new services and products to rise up the satisfaction with the experiences of all stakeholders in the tourism ecosystem.

By uniting managers of physical spaces in the ecosystem (towns, municipalities) with leading Slovene research and educational institutions, as well as technology experts and developers, a collaborative ecosystem is being created, which treasures the history and knowledge of tourist business and at the same time transfers it into the digital world. The result will be a new format of dynamic collaboration system among all tourism stakeholders sprouting a new generation of tourist applications and services, which are built on real tourist needs and wishes by using the key enabling technologies from Industry 4.0 harmonized with the Tourism 4.0 principles.

Subsequent to this introductory section, the following chapter is organized as follows: Section 2 provides the description of the future tourism we want to create with Tourism 4.0, in Section 3 the implementation and ambition of the project is shared, Section 4 discusses the marketing challenges as well as introduces the Twirl marketing model of a paradigm shift and in the last section the chapter is reviewed.

\section{Designing tourism of the future}

Tourism is ought to be an enjoyable experience for visitors, while at the same time providing a substantial source of income for many destinations and even entire countries. Unfortunately, several studies, even dating back to the 1960s $[10,11]$ and 1970s [12-14], have indicated the existence of many worrisome consequences of tourism. The areas negatively affected have found out to be $[15,16]$ :

- Environmental-increased consumption of electricity and water, extra waste production, overcrowding, reduction in accessibility, increase in population density, etc.

- Economic - increase in real estate and land price, shift from market prices to higher tourist prices [17], employment fluctuation, economic dependence on a single industry, etc.

- Social—illegal goods and people trafficking, excessive commercialization, loss of cultural identity, etc. 
Since the number of annual international tourists travels has more than doubled in the last 20 years (to over one billion, shown in Figure 1) reaching 1323 million in 2017 [18], it is essential to ensure sustainable growth of tourism in order to avoid the deteriorating effects on both the social and natural habitat.

Many cases of extreme ramifications of tourism can put pressure on resources and the host communities, hence leading to a decline in the quality of living. All of this brought about the issue of overtourism, defined as "the excessive growth of visitors leading to overcrowding in areas where residents suffer the consequences of temporary and seasonal tourism peaks, which have enforced permanent changes to their lifestyles, access to amenities and general well-being" [20].

In 2017, Slovenia recorded more than 4.9 million tourist arrivals and almost 12.6 million overnight stays, which is $13 \%$ more than in 2016 [21]. As shown in the Table 1, the growth is continuous for 4 years already, with this tendency expected in 2018 and also predicted for the near future. By making a total contribution to $11.9 \%$ of GDP in 2017, with a forecast of rise to $14.5 \%$ in 2028 [22], tourism is becoming a more and more important economic activity.

The rapid rising of numbers put Slovenia ahead of new challenges. While each destination has to constantly strive to improve and innovate in order to stay competitive, local communities (not just tourist service providers and the government) must play a key role in the future development of tourism. Another issue in need to be addressed is the fact that there has been a lack of research in Slovenian tourism [23]. Existing studies pointed toward outdated business methods, lack of cooperation between public and private sector tourism managers, a low level of awareness by the government on the importance of responsible tourism practices as a major impediment in improving competitiveness [23, 24]. Fortunately, in the last years this attitude is changing and in 2017, the efforts of Tourism and Hospitality Chamber of Slovenia in the area of sustainable tourism have finally been recognized and included in the development areas of the smart specialization strategy [25]. With this action, the tourism industry has been set up alongside health and medicine, circular economy, factories of the future and others as a prospective field justified for government co-financing on research and development projects. The specific objectives aimed to be achieved are: an increase of energy efficiency in tourist facilities for $20 \%$ by 2021; an increase in the number of the fast-growing companies in tourism from 29 in 2015, to 50 in 2021; a raise in the level of knowledge and quality in Slovenian tourism and a raise in the added value in tourism for $15 \%$.

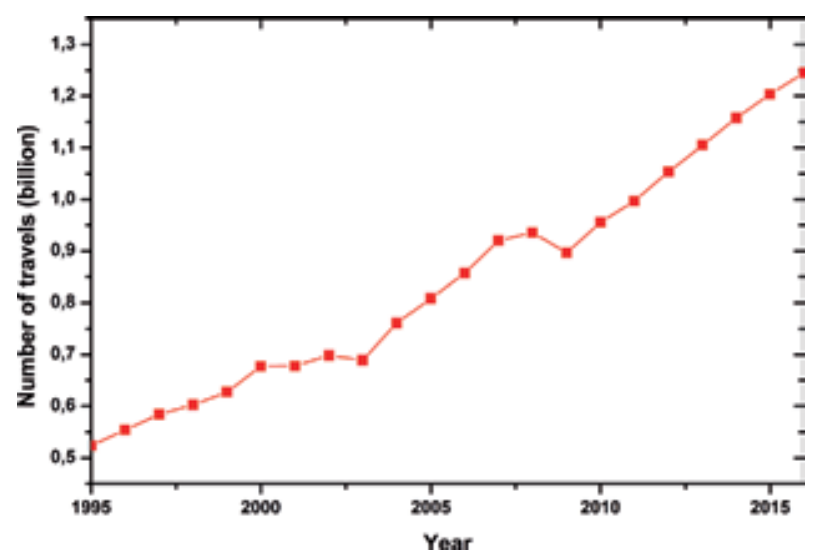

Figure 1.

Number of international tourist travels over the last decade. Source: World Tourism Organization, Yearbook of Tourism Statistics [19]. 


\begin{tabular}{ccccc}
\hline \multirow{2}{*}{ Year } & \multicolumn{2}{c}{ Tourist arrivals } & \multicolumn{2}{c}{ Overnight stays } \\
\cline { 2 - 5 } & Total & Foreign & Total & Foreign \\
\hline 2008 & $3,083,713$ & $1,957,691$ & $9,314,038$ & $5,351,282$ \\
\hline 2009 & $2,984,828$ & $1,823,931$ & $9,013,773$ & $4,936,293$ \\
\hline 2010 & $3,006,272$ & $1,869,106$ & $8,906,399$ & $4,997,031$ \\
\hline 2011 & $3,217,966$ & $2,036,652$ & $9,388,095$ & $5,463,931$ \\
\hline 2012 & $3,297,556$ & $2,155,612$ & $9,510,663$ & $5,777,204$ \\
\hline 2013 & $3,384,491$ & $2,258,570$ & $9,579,033$ & $5,962,251$ \\
\hline 2014 & $3,524,020$ & $2,410,824$ & $9,590,642$ & $6,090,409$ \\
\hline 2015 & $3,927,530$ & $2,706,781$ & $10,341,699$ & $6,614,443$ \\
\hline 2016 & $4,317,504$ & $3,032,256$ & $11,179,879$ & $7,342,118$ \\
\hline 2017 & $4,948,080$ & $3,586,038$ & $12,591,562$ & $8,572,217$ \\
\hline
\end{tabular}

Table 1.

Tourist arrivals and overnight stays in Slovenia from 2008 to 2017. Data taken from the SURS-Statistical Office of the Republic of Slovenia.

Accordingly, the prevailing approach needs to change. Therefore, the aim of Tourism 4.0 is to develop a model of collaboration that minimizes the negative impact of tourism, while at the same time improving the overall experience. This goal will be obtained by using the concepts and tools provided by smart tourism [26-29] — a phenomena describing the convergence of information and communications technology (ICT) with tourism experience, expanding them even further, and integrating them into a platform that will involve all stakeholders active in the tourism sector: the local community, government, tourist service providers and of course tourists-presented in Figure 2.

The main ambition is to build an interactive platform based on the state-of-theart technology infrastructure, guaranteeing the sustainable development of services and products, accessible to everyone at any time. It will facilitate the tourist's integration into the destination, increase the quality of the experience and support individual's interaction to develop tailored products and services. In other words, we want to foster the leap that was enabled by high technologies from Industry 4.0 at products level, by implementing them in tourism services.

For successful implementation of the project goals, the platform will integrate four main pillars or modules, which are at the same time different areas of research for understanding the tourism ecosystem:

- Technology module. With the use of cutting-edge technologies enriched tourist experiences will be delivered. This includes:

1. Internet of things (IoT) for enabling networks of smart device for monitoring and collecting information;

2. High-performance computing systems (HPC) with artificial intelligence (AI) for the purpose of solving most complex challenges involving data;

3. Virtual and augmented reality (VR and AR), which can elevate or enhance the overall experience;

4. Blockchain solutions for a safe and transparent way of delivery. 
- Innovation module. Research and development of practices and methodologies dedicated to the creation and diffusion of innovation in the ecosystem with the aim to raise the level of competences among all stakeholders.

- Ecosystem module. Understanding the tourism ecosystem and all its stakeholders in both the physical and digital world in order to create the space for the new generation of tourism.

- Application module. Enabling systems and applications that improve and enrich the real and digital experiences in tourism with the focus on mobility and services (and processes behind) for persons with the purpose of holidays, leisure or recreation, business, health, education or other.

In the Tourism 4.0 ecosystem the local community is in focus while Tourists 4.0 are very active participants in all processes. They have a direct impact on their own experience and act also as co-creators of the tourist offer. With this in mind, we should not forget that the change is only possible by data sharing of all stakeholders of a given ecosystem, thereby acting as a driver for all of the processes on the platform. Furthermore, the data need to be analyzed, if they should be turned into useful information that can be used for strategic decisions and marketing purposes, such as people flow management.

\subsection{Tourism 4.0 partnership}

After the initiative was launched by the company Arctur, lack of readiness level to embrace the use of the key enabling technologies, especially by small and medium enterprises in the tourist sector, has been identified. As a consequence, the partnership for Tourism 4.0 has been established to enable collaboration of any stakeholder in the world to participate in research or development of tourism of the future. It brings together a consortium of highly relevant industrial organizations, top research organizations in tourism and the leading research organizations in computer and informatics technology.

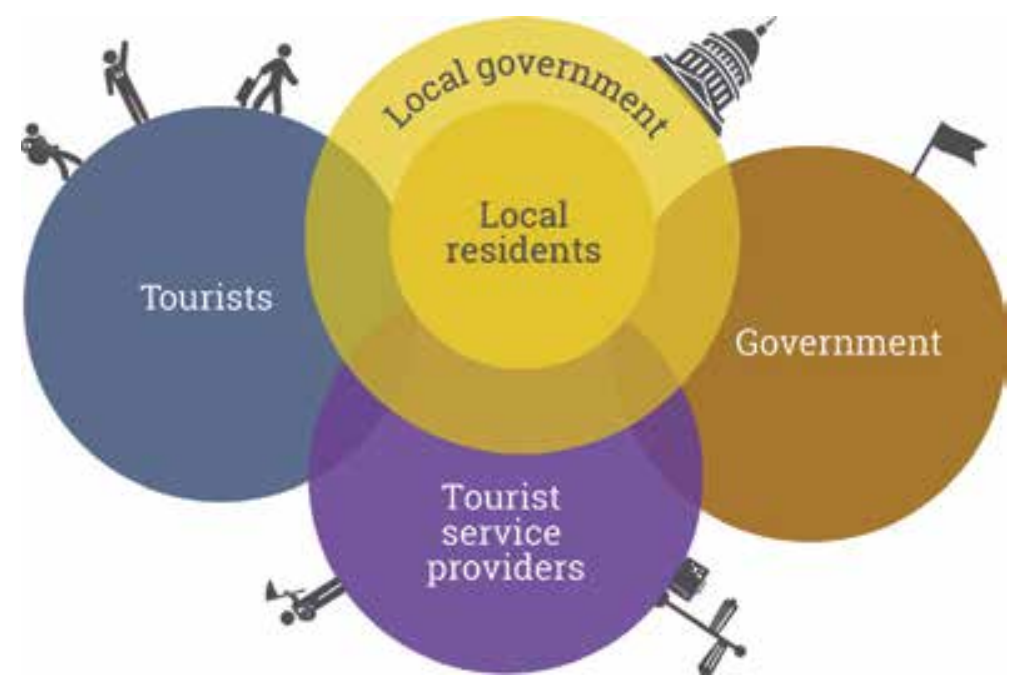

Figure 2.

The core of the Tourism 4.0 concept is to integrate all the stakeholders (local community, tourists, tourist service providers and government) in the sector within a collaborative innovation process centered around the local community. 
The partnership is growing continuously and already boasts with a number of prominent members, such as Slovenian Ministry of Economic Development and Technology as well as Ministry of Public Administration, Tourism and Hospitality Chamber of Slovenia, Association of Towns and Municipalities of Slovenia, University of Ljubljana, University of Maribor, University of Primorska and many partners joining from all over the world. Not only research, also projects focused on validation and deployment of the technologies are planned in order to transform Slovenia into a testbed, Tourism 4.0 Living Lab Slovenia. Further activities in the area of Alps, Danube, Balkans and Mediterranean are set to spread the concepts to an international level.

\subsection{Collaboration impact model}

Sustainable tourism [30-32] is at the core of Tourism 4.0 that is aspiring to using technology to encourage a positive environmental, social and economic impact and collaboration between all stakeholders in the ecosystem. Following the slogan of Slovene tourism: 'Green, active, healthy', new ways of motivating not only individual tourists but all stakeholders will be studied in order to encourage as much of positive contribution as possible for the local environment while traveling and visiting places. This will be achieved by establishing a system of motivation and rewarding for positive behavior i.e. behavior with positive impact on social, environmental and economic elements in a destination-both from tourists and other stakeholders. In this way tourism truly becomes the driver of the sustainable development of the whole society. These are heavily dependent on the quality and intensity of communication, if they are to be reached. For this reason, marketing has a key role in this endeavor since reshaping of the tourism ecosystems with the focus on the local community will not just happen even though this is a crucial step toward the tourism of the future.

The model, that has been so far only theoretically constructed, is named Collaboration impact model (CIM). For its implementation certain tools need to be developed to help with collection, understanding and integration of data. This includes data such as weather prediction, traffic density, number of tourists in a defined area, energy consumption in tourism, etc. In an interactive way, through gamification, we want to reduce the negative and encourage the positive behavior and promote positive attitude to inspire more responsibility among citizens of the globe. The CIM model will use the data of the ecosystem to help tourists with suggestions for tourist activities. When using this model, the tourists will receive real-time information and recommendations based on their own profile, which will help them decide, for example what places to visit or what activities to partake in. Furthermore, users will be able to switch between their own avatars since interest of tourists vary significantly according to their purpose of traveling, which is not limited to for business and pleasure only.

Collaboration impact model is supported by several technological solutions. The most impactful one is the creation of digital tokens, a boosting and rewarding tool of the positive impact accomplished through collaboration within the ecosystem T4.0. In our proposed system, they are named after the model and thus called collaboration impact tokens (CIT). The currency will be needless to say developed on the basis of the blockchain technology. These tokens will be awarded to stakeholders of the tourism ecosystem as incentives for performing certain actions that are beneficial to the local economy and environment. They could help preserve and promote cultural heritage, reduce the consumption of natural resources and support an effective dispersion of tourism. 
Examples of CIT awarding are shown in Figure 3. However, there are many more. With this mechanism, responsible development of ecosystem is enabled by encouraging positive attitudes, using of more ecologically-friendly transportation and stimulating a more favorable allocation of tourists. The latter is a pressing issue as more and more destinations are struggling with negative consequences of overtourism. In the next step, we plan to go further and integrate attitudes that encompass most different aspects of society and include them in the rewarding system. For example, visiting elderly people and spending time with them for few hours or reporting a damaged public trash bin to the municipality could be encouraged by incentives in the form of tokens. We believe that step by step with the technological development as well as by raising awareness through strategic communication rewarding positive impact on wider society will become the norm.

Anyhow, visitor management techniques can also be applied to select or deselect tourists, control their flows and influence their behavior through promotion and education [33]. With the help of internet of things, it is possible to monitor and thus measure many human activities. The most common example in the tourism sector is the water and energy consumption of each accommodation. Many hotels collect such data but they do not use them. In accordance to our collaboration impact model, the tourists, who exhibit ecologically conscious behavior, i.e. consume less than average consume of water and energy of tourists in that specific area, would receive a reward in the form of CITs. The received tokens can be used for purchase of other tourist products or services. In addition to increasing the sustainably driven attitude preserving the environment is this beneficial for the local economy. Another example of desirable

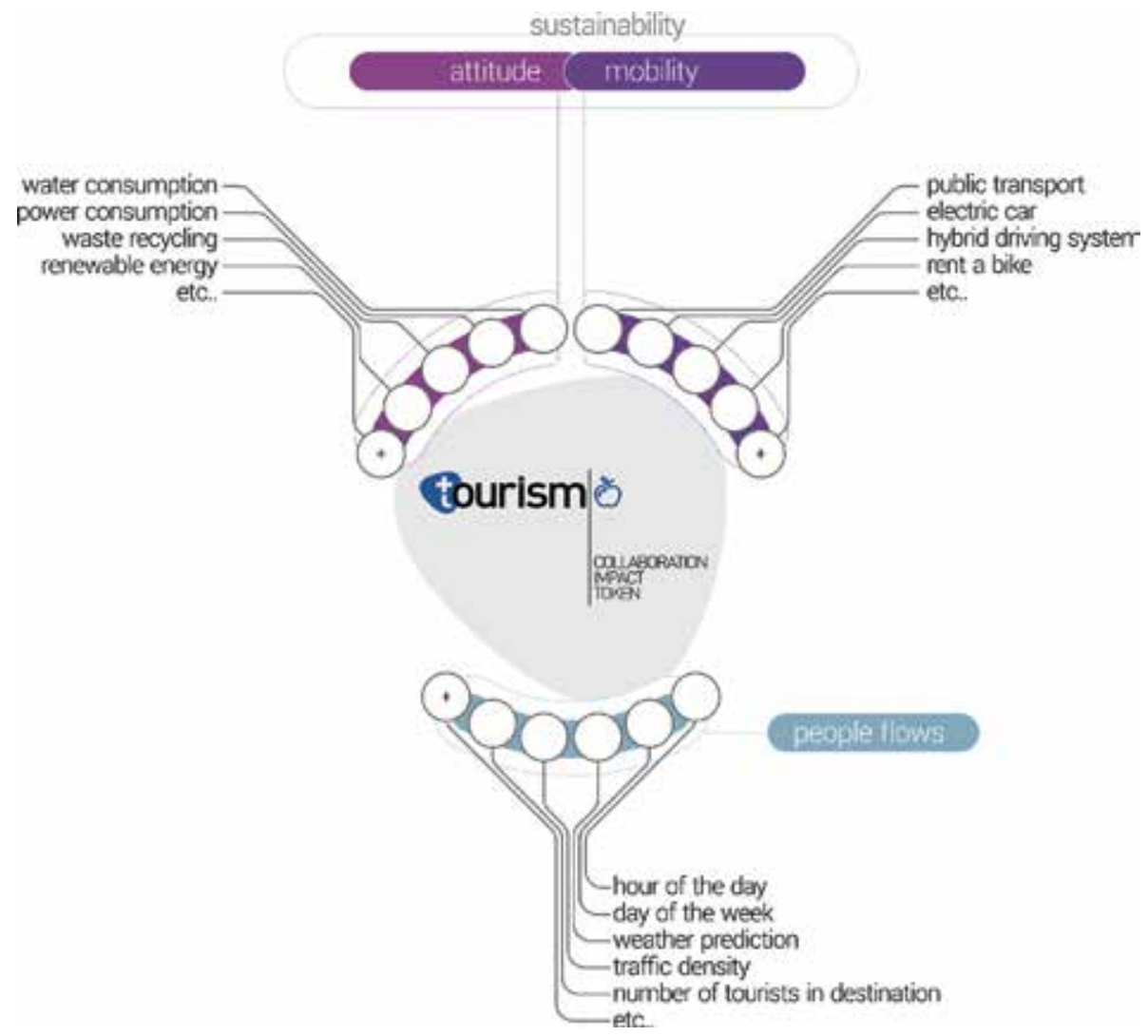

Figure 3.

Examples of methods and actions with which a tourist can earn the collaboration impact token-CIT and the attitudes we want to promote. 
behavior is visit during the low tourist season or places in the touristic periphery. An additional issue of significant importance due to the size of its impact is the mobility. Here good behavior is determined and rewarded by the use of public transport or sharing services besides renting a bike or an electric car. The underlying idea is that tourists are awarded and thus motivated to exhibit behavior with a positive impact more often.

The most important aspect of the collaboration impact token is the assignment of dynamic values according to location and time of its use. For an illustration, we examined the number of tourists' overnight stays for each municipality in Slovenia in 2017 and normalized it to the municipality's population density (residents/ $\mathrm{km}^{2}$ ), as seen in Figure 4. The discrepancy can be noticed immediately. Some areas experience a much higher tourist density than others, with some parts already experiencing overtourism. The value given in the calculation is dependent on:

- visits to the geographic area-lower in the red and higher value in the green areas;

- tourist season-low season means higher value;

- strategic development level of the region —-higher value in less developed regions;

- etc.

As the example of the calculation demonstrates, the use of public data can already enable the first insight into understanding of tourist flows. Building an award-based collaboration ecosystem that helps to manage issues of people flow within a destination, region or even a country is very rational and strategic since it also supports less developed regions in establishing their touristic sites. By implementation of the CIT that provides instant award in discounts, tourism of the beaten path can rise significantly. This does not only reduce the unbearable crowds of tourists in one spot of a destination, but above all immensely improves the tourist experience.

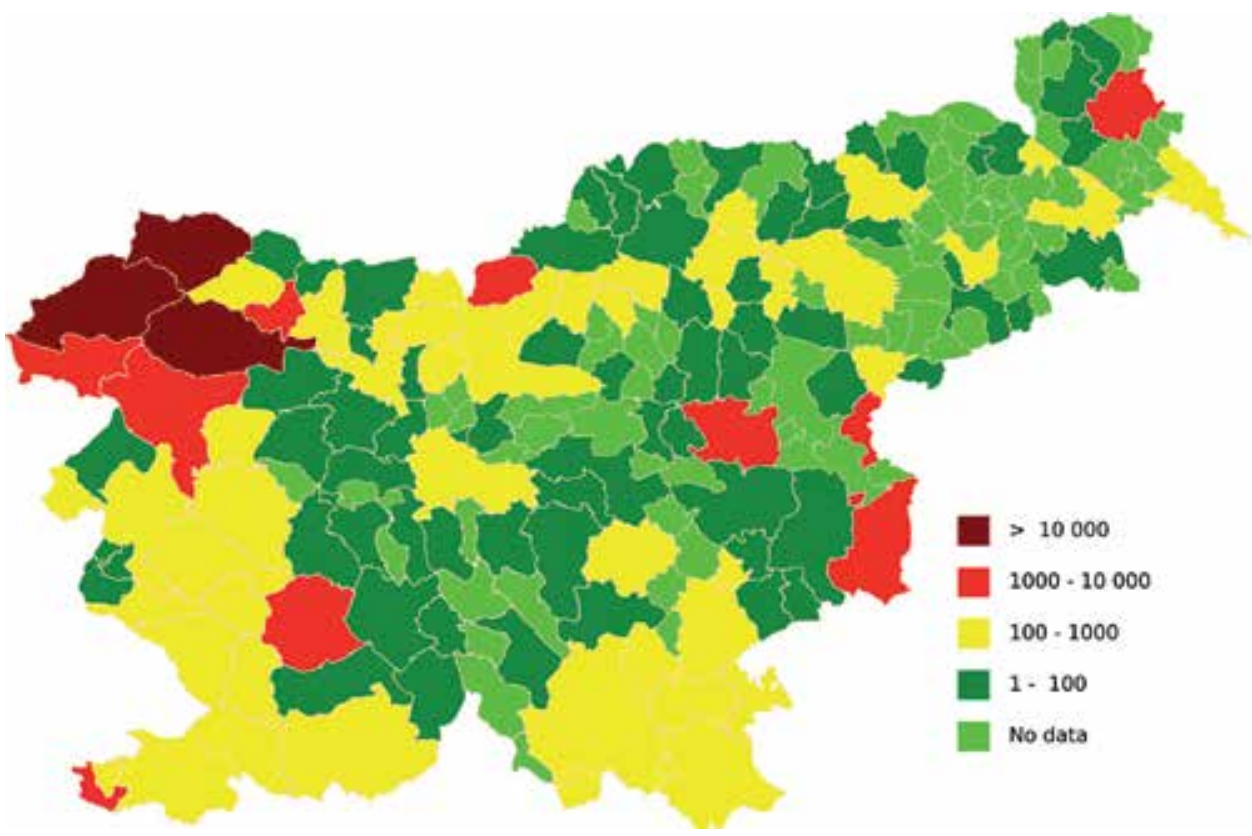

Figure 4.

The number of tourists overnight stays in 2017 for each municipality normalized by its population density (i.e. residents $/ \mathrm{km}^{2}$ ). The data is taken from the SURS-Statistical Office of the Republic of Slovenia. 


\section{Implementation and ambition}

It is the lack of capital, technology and marketing and management expertise that restrains the growth of tourism in many less developed regions in the world [33]. An adoption of societal marketing strategies will thus have to take place, where increased visitations are not the primary concern and visitors are not treated like any other commodity. This will include monitoring of both the tourist and host satisfaction for the purpose of optimizing the of tourism impact on the environment and consequently increasing the benefits for the local community [34, 35]. Since monitoring is dependent on data, access to them is increasingly relevant to the tourism sector as well. It allows for the provision of evidence-based decisions and the development and analysis of future scenarios, which infuse the whole sector with additional efficiency and productivity to face its current challenges. In addition to accessibility, green mobility and connectivity has been identified as a priority area for facilitating the flows of movement, and easing the negative impact of tourism on local environment, along with reducing the effect on climate change.

Moreover, the prevalence of smartphones and mobile devices are swiftly changing the face of technology use for destination marketing as people now have access to the virtual world in palms of their hands [36]. More importantly the new technology enables smaller and peripheral destinations to compete on equal footage with larger and more central ones. The gained competitiveness lies in reduced dependency on intermediaries for the distribution of tourism products. As a consequence, the providers of tourism services are able to improve their negotiation power, which fosters the development of a healthier distribution mix. As aforementioned, this is of even greater importance for remote, peripheral and insular destinations where local principals and authorities have a great dependency on tourism for their income but lack expertise and resources to undertake comprehensive marketing campaigns [31].

Only an advanced ICT infrastructure enables a more dynamic, less rigid, and fast interaction within organizations and between organizations at the tourist destination, which empowers stakeholders through the creation of a technological infrastructure for increased communication and collaboration [34]. Tourist destinations are now, more than ever, building competitive tourist places using state of the art business models. However, without a proper information environment these business models are often subjected to failure. The T4.0 platform facilitates the just-in-time information exchange between various stakeholders from different places or markets using the key enabling technologies available at this time (illustrated in Figure 5). This way, the platform reduces the information and choice overload, which currently presents one of the key barriers in conducting tourism business. What is more, various tourism providers can use the platform to share their services, products or information to users at all levels of the industry (e.g. G2C, B2B, B2C, C2C).

The Tourism 4.0 platform actually enables the communication between stakeholders and collaboration within the ecosystem where users are involved in the development of new tourist products and provide free access to the collected data, thereby encouraging innovation through the use of modern technology. In the implementation of technological solutions of Tourism 4.0, local communities play a vital role, thus we are putting them at the center of the ecosystem of future tourism. As already presented in Figure 2, the Tourism 4.0 platform is envisaged toward four main target audiences:

- The providers of tourism services and packages (e.g. local tourist organizations and tour operators). The interest of this group is in the direct access to their target audiences, which will be enabled through the platform. There is a number of niche web (and mobile) platforms that almost proverbially offer only one solution to the end user (e.g. only hotel reservations, only attraction 
tickets, etc.). Contrarily, the Tourism 4.0 platform will gather together a number of various but complementary proposers of tourist services that will be interested to promote through the platform due to the considerably reduced margin for the referred business.

- The tourist. They will be encouraged to use the platform mainly because of its all-in-one portfolio and also its embedded features. The combination of an all-encompassing offer, accompanied by AI will enable the platform to produce a tailored offer to the user. The AI will have an overview of the interests and preferences of the end-user and the services at offer. By combining the two, the user will get offered first the most interested services for her or him in that moment followed by services listed accordingly to their relevance for the user.

- Local inhabitants. Through the collaborative platform, it will be possible to measure, monitor and manage the impact that tourists have on the local environment. This can be used to control the quality of living of the population and the quality of the tourist experience of the guests. In a second step also measuring of attitudes of local inhabitants are planned to be included in order to incentives all stakeholders to strive for the positive impact.

- Government. Providing a collection and aggregation of data that can help in understanding and development of appropriate policy regulations, which are not only able to react to disruptions but even boost innovations.

In understanding the ecosystem in such way, a question emerges on who is the consumer in this new paradigm of tourism, as every stakeholder is collaborating, profiting and co-creating. These are the challenges that need to be embraced by the marketing specialists in the near future.

Actually, from the technological and business aspect, tourism and e-tourism have always been in the background, in the sense that tourism was predominantly following innovation. In the latest technological wave, many of the most prominent startups and corporations of the new generation are strongly attached to tourism, mainly through sharing economy. Sharing economy is just the beginning of a trend that indicates how the technology allows the sharing of tangible and intangible elements of all kinds of user experiences, in tourism as well. The tendency will continue with the intensive incorporation of all other current trends (AI, VR, AR, IoT, Smart Mobility, Blockchain, etc.). It will not only be about new ways of sharing and building up these elements. For the economic sector, it is important that these elements are appropriately used in new, innovative business models. Therefore, the technological project outcomes will be

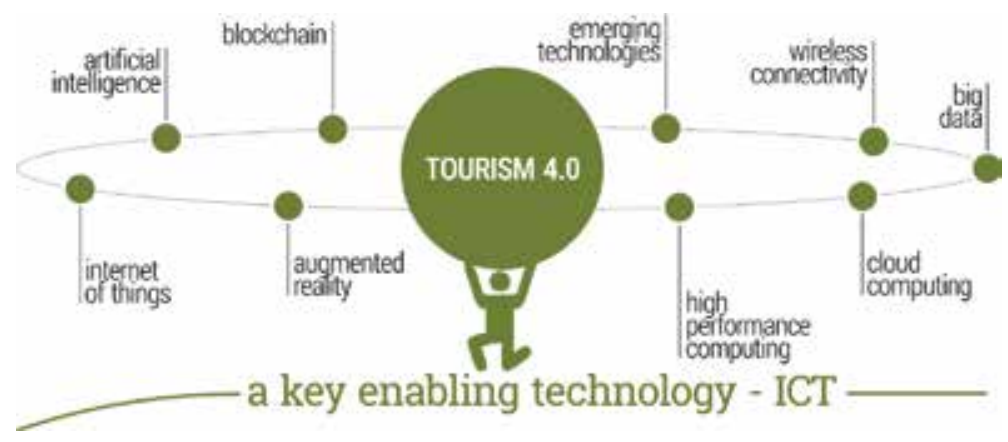

Figure 5 .

The enabling technologies for project Tourism 4.0. 
adopted to the new and innovative business models in tourism in general, as well as in the areas of destination management and event management.

Here are some examples of the use of the key enabling technologies in tourism that will transform the tourism business in near future:

- Virtual reality could help potential visitors to decide which destination they prefer to visit;

- Augmented reality could enable a completely new touristic experience that is either historically informative or adventurous in nature;

- Combination of external data such as weather forecast with travel information would implement an automatic rebooking of a trip in case of a rainy day.

Such and similar future applications could become a new income stream in tourism, especially in relation to natural landmarks since most of them can be experienced for free. We do not promote limited access to nature because access to it should stay free of charge. On the other hand, interactive experience offered via augmented reality app could be payable and the income acquired could be spent on preserving the nature in a given destination. This way we would not rely solely on demand management for sustaining tourism resources with effective marketing, which can channel tourist flow to places that are more impact-resilient, such as urban and seaside built environments rather than to more fragile wilderness areas [33]. With the income from the enriched tourist experience national parks and heritage sites would be able to invest into preservation of natural environment in addition to managing the ever increasing demand.

In fact, the sustainability of local resources is becoming one of the most important elements of the destination image, as a growing section of the market is not prepared to tolerate over-developed tourism destinations and diverts to more environmentally advanced regions. The degree of consumer satisfaction will depend on the assessment of the perceived overall experience of the destination versus anticipated expectations and perceptions [34]. Smart tourism will become the driver of social change due to its high innovation potential and above all impact on economic, cultural and natural environment. As explained, marketing has a crucial role here. Not only in promoting sustainability in tourism but also in marketing in an attractive way of less popular tourist destinations. Inefficient use of many tourist facilities (hotels, for example, often have annual bed occupancy rates of 50-60\% in most countries), indicates that the effective marketing of these tourist resources is of great significance in reducing resource wastage as well [33]. Challenges and opportunities are many, especially because throughout the world tourism services are offered by small and medium tourism enterprises, which tend to be family managed. Hence, the challenge for destination management organizations is to provide leadership in the development of innovative products and create local partnerships for the delivery of seamless experiences [34]. The collaboration impact model can provide that but marketing and communication experts will need to develop new strategies to make better use of the new tools with the purpose of optimizing the positive impact of tourism while increasing the benefits of the local community.

\section{Challenges in marketing Tourism 4.0}

In marketing of new concepts, such as a new paradigm, the first issue everybody is facing is how to build trust and rise interest for complex and new solutions 
since trust and perceived risk are shown to be direct antecedents of intention to transact, suggesting that uncertainty reduction is a key component in consumer acceptance [37]. Hence, it is crucial to be aware of the lack of readiness level of the target groups in terms of lack of skills and lack of processes, in which research and development spirit could fit into strategies and implementation of changes.

To address this, the Twirl marketing model of a paradigm shift, presented in Figure 6, has been developed that shows in which process the appropriate target groups were identified and how the nature of communication has been growing into collaboration. In this process the communication starts with the informative phase addressing a broad public. It is upgraded in the second step with educational dimension that focuses on a smaller target group, which is then in the third step reduced to the key persons of each specific target group. With them conversations take place in order to find the possibilities to embrace the new concepts. This leads to collaboration, with which the amount of people reached via informational, educational and conversational communication raises again. In the best case, such organic growth occurs through community building. This is the reason for establishment of the Tourism 4.0 partnership, which is open to new interested stakeholders. ${ }^{1}$ In addition, an online form is available on the website, where anyone can share their idea or solution in the field of Tourism 4.0 and are later connected to potential partners.

How does the Twirl marketing model of a paradigm shift prove to work in practice? In the informative phase all available tools to spread information are used, such as digital presence (website with news section for updates, social media, newsletter, etc.) and participation or organization of events with good media coverage or specific to the topic performed. This enables the reach of the appropriate target groups. Tourism 4.0 as a new paradigm has been presented both at events organized locally and around the globe, in China and Mexico for example, but always accompanied with good national media coverage. ${ }^{2}$ The goal was to awake interest and give it relevance through international dimension. In the second phase, education in the form of presentations at conferences, forums ${ }^{3}$ and fairs were given in order to provide knowledge of the paradigm shift and its necessity while getting experts and policy makers in the tourism sector acquainted with the Tourism 4.0 objectives. To achieve this, concrete examples of technologies were presented in the form of vivid storytelling. ${ }^{4}$ The play of concepts around marrying tourism with technology has been created to help novices with low to limited knowledge of technology to embrace the new concepts and possibilities they bring.

\footnotetext{
${ }^{1}$ Joining the Tourism 4.0 Partnership is simple via an online form (https://www.tourism4-0.org/en/joinus/) and has no preconditions or restrictions.

${ }^{2}$ For example media coverage on the National RTV (https://4d.rtvslo.si/arhiv/prvi-dnevnik/174547134, https://radioprvi.rtvslo.si/2018/06/turizem-4-0/) and the only daily Slovenian business and financial newspaper (https://izvozniki.finance.si/8933310/Googlu-bi-Arctur-in-slovenske-univerze-odrezalikos-torte-v-korist-slovenskega-turizma?cctest\&cookietime=1525669980). The panel on Tourism 4.0 at the 31st Bled eConference also attracted much attention from the media in Slovenia (https://www. tourism4-0.org/en/news/2018062610122048).

3 Media coverage from European Forum Alpbach (https://svetkapitala.delo.si/aktualno/slovenija-sturizmom-4-0-predstavljena-v-alpbachu-6374) and Strategic Forum Bled (http://www.sloveniatimes. com/technology-will-completely-transform-tourism-panel-hears).

${ }^{4}$ See an example of a keynote speech from 1 minute 15 seconds. Available from: https://www.youtube. com/watch?v=W4BgwFrWV54\&fbclid=IwAR0DWdinudMJeBB3XJpS6m0AVguDOZtaWPK5Mmtq4B5F 7i8sHQ3rtQhhaQo
} 


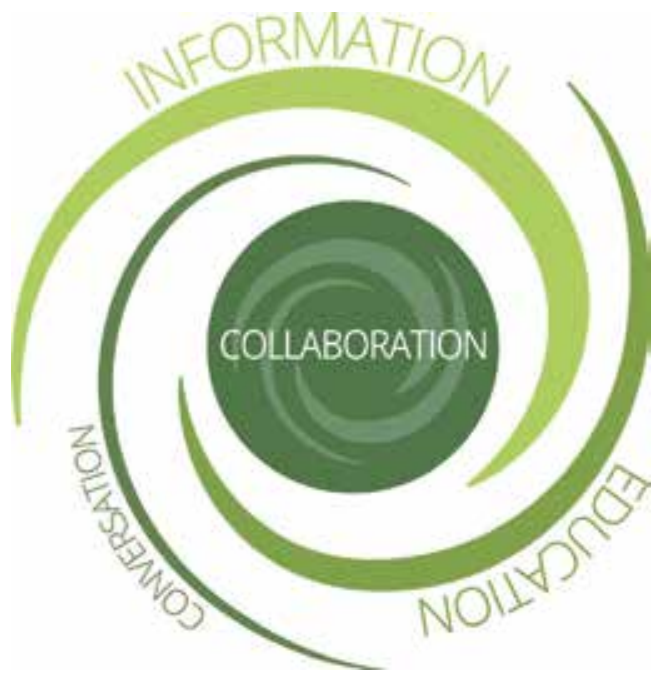

Figure 6.

Twirl marketing model of a paradigm shift.

From persons targeted during the education phase some individuals, small groups and organizations showed interest for a further conversation, which is the activity of the third phase of the Twirl marketing model of a paradigm shift. This phase includes personal conversations with tourist organizations and institutions and service providers. At the same time, deep conversations will take place through an extensive survey conducted as a part of the Tourism 4.0 research project that include local and national authorities, tourist organizations and tourist providers. The goal is to understand the current state and technology readiness level in the tourism ecosystem in Slovenia and to discover its innovation potential to develop the Tourism 4.0 collaborative ecosystem. For this reason, concrete tools such as guidelines for development of Tourism 4.0 ready multimedia contents, portal, archive and reservation system ${ }^{5}$ have been published to help the key persons include the new concepts into their strategies and implementation. The importance of providing relevant information in the future tourism marketing environment is also evident in the literature. In the scientific contribution on Tourism Marketing in an Era of Paradigm Shift the dimension of information knowledge proves to be crucial for the future tourism marketing and is added to the standard time and place dimensions of the old way of thinking because only available information can turn tourists into value co-creators, competitors into potential partners and even marketers to learning facilitators [38].

Only after informing the public, educating specific target groups and conversing with key decision makers an inclusive collaboration at a local or global level is possible. In the marketing model of a paradigm shift after performing the first 'round of process' further marketing strategy builds on an eternal interviewing of all communication methods from the first three phases for multiplication of collaboration. However, the precondition remains the trust of all stakeholders, which is being built by interaction that hopefully grows into collaboration. This interactivity is enabled by the modern tools for tourism marketing and management that can re-engineer the entire process of developing, managing and marketing tourism products and

\footnotetext{
5 The guidelines in Slovene. Available from: https://www.tourism4-0.org/mma/priporocilat4_0_v0_1pdf/ 2018121908553371/?m=1545206133
} 
destinations as well as provide the competitive advantage with the ability to redevelop the tourism product proactively and reactively [39].

Therefore, the next step of the Tourism 4.0 project marketing strategy is testing of above-mentioned solutions with a series of products at TRL 6-8 stage. ${ }^{6}$ The goal is to test the prototypes in operational environment to support commercial activity in ready state in environments called living labs, where future reality and future tourism in it are simulated. Imagine a playground in which technology service providers can test their gadgets with tourists, who want to be part of such a testing experience accepting the violations of their privacy. At the same time, public decision makers can learn from the reality and adapt the legislation accordingly. Students, waiters and all other personnel in contact with tourists get the possibility to train how to deal with crypto tokens while children will be educated about their water consumption and challenges that we as citizens of the world are facing and how to behave to minimize our negative impact. Key to the marketing a paradigm shift is to understand that the marketing process needs to address all stakeholders. To mention the most crucial fact, we are aspiring to facilitate the break down the silos mentality where stakeholders do not wish to share information and provide feedback with one another. Such trials will connect consumers (both local community and tourists) and tourist providers, (local) government as well as high-tech companies in order to unify the dispersed ideas, experiences, knowledge and expertise with the intent of integrating them in a collaborative manner around the Tourism 4.0 platform and later used in real business environment.

\section{Conclusions}

With more than one billion persons traveling yearly around the world, a small change in this sector has a huge impact on the whole society. The new paradigm, Tourism 4.0, build around technologies from Industry 4.0 can path the way of transformation not only in tourism, but also as driver of the UN sustainable development goals. In Slovenia, the biggest research project on tourism in the history of the country called Tourism 4.0, which has already grown into a Tourism 4.0 partnership, gathering academia, business and public partners, is focused on defining the ecosystem, in which these changes could take place. Hence, the main objective is the development of a platform for a new form of active cooperation system among the local community, tourists, tourist service providers and the government.

The system aims to encourage positive behavior among all stakeholders in order to maximize positive impact on the local environment through the collaboration impact model. For its implementation certain tools need to be developed to help with collection, understanding and integration of data. This includes data such as weather prediction, traffic density, number of tourists in a defined area, energy consumption in tourism, etc. In an interactive way, through gamification, encouragement of the positive behavior and promotion of positive attitude to inspire more responsibility among citizens of the globe is foreseen. Digital token, to mention the most impactful one, is a boosting and rewarding tool of the positive impact accomplished through collaboration within the T4.0 ecosystem. The so-called collaboration impact tokens (CIT) is a currency developed on the basis of the blockchain technology. These tokens will be awarded to stakeholders of the tourism ecosystem as incentives for performing certain actions that are beneficial to the local economy and environment. In addition to gamification and incentives, social marketing strategies promoting sustainability and positive impact will be used.

\footnotetext{
${ }^{6}$ Technology Readiness Level. Available from: https://ec.europa.eu/research/participants/data/ref/ h2020/wp/2014_2015/annexes/h2020-wp1415-annex-g-trl_en.pdf
} 
The Tourism 4.0 ecosystem is built around the problems and wishes of local inhabitants and in only in the second step around those of other stakeholders. Hence, we are facing the shift from tourist-centered focus to a tourism-centered focus around the local community. During the development of such an ecosystem a question emerges about who is the consumer in this new paradigm of tourism as every stakeholder is collaborating, profiting and co-creating. As the right answer due to the collaborative nature of the Tourism 4.0 ecosystem is everyone, the Twirl marketing model of a paradigm shift emerged. The model leads to collaboration through the process of finding the right partners that bring new collaboration and help spreading the messages and ideas of the paradigm shift. This occurs by first addressing the broader public, educating the appropriate target groups via innovative marketing tools and event presentations at various conferences, forums and fairs, where interested individuals and organizations are found. This leads to personal conversations with them aimed at finding common goals and their implementation into strategies and actions plans. In this way an environment in which collaboration can emerge and grow is created. And this is the beginning of the story of a new paradigm shift which might have or not, depending a lot on communication and marketing experts, a huge impact on our future.

To conclude, such an ecosystem does not only provide immense opportunities for technological innovation and new business models but also represents an extremely rich environment for identifying and studying new interaction paradigms and forms of value (co-)creation. The stakeholders interact with information and with technologies in new ways that have yet to be identified and understood, the challenges that need to be embraced by the communication and marketing specialists in the near future.

\section{Acknowledgements}

This work is carried out within the framework of the research project Tourism 4.0-enriched tourist experience (OP20.03536), co-funded by the Slovenian Ministry of Education, Science and Sport and the European Regional Development Fund. The consortium is led by Arctur company and includes top experts from three Slovenian universities: the Faculty of Tourism Studies-Turistica (University of Primorska), the Faculty of Tourism (University of Maribor) and the Faculty of Computer and Information Science (University of Ljubljana). We would also like to acknowledge the ongoing support from the Association of Municipalities and Towns of Slovenia (Skupnost občin Slovenije-SOS).

\section{Conflict of interest}

The authors do not declare any conflict of interest.

\section{Thanks}

The authors of this chapter would like to thank Dejan Šuc for providing the graphic designs. 


\section{Author details}

Urška Starc Peceny ${ }^{1,2,3 *}$, Jurij Urbančič ${ }^{1}$, Simon Mokorel $^{1}$, Vesna Kuralt ${ }^{1}$ and Tomi Ilijaš ${ }^{1}$

1 Arctur d.o.o., Nova Gorica, Slovenia

2 DOBA Business School, Maribor, Slovenia

3 NASA Space Apps, Vienna, Austria

*Address all correspondence to: urska@arctur.si

\section{IntechOpen}

(C) 2019 The Author(s). Licensee IntechOpen. This chapter is distributed under the terms of the Creative Commons Attribution License (http://creativecommons.org/licenses/ by/3.0), which permits unrestricted use, distribution, and reproduction in any medium, provided the original work is properly cited. (cc) BY 


\section{References}

[1] Bădiță A. Approaches to the analysis and evaluation of urban tourism system within urban destinations. Revista de Turism-Studii si Cercetari in Turism. 2013;16:58-66

[2] UNWTO. Available from: https:// statistics.unwto.org/sites/all/files/ docpdf/glossaryterms.pdf [Accessed: November 28, 2018]

[3] World Travel \& Tourism Council. Available from: https://www.wttc.org/-/ media/files/reports/economic-impactresearch/regions-2018/world2018.pdf [Accessed: November 28, 2018]

[4] The Sustainable Development Goal. Available from: https://www.un.org/ sustainabledevelopment/sustainabledevelopment-goals/ [Accessed:

November 28, 2018]

[5] UNWTO. Available from: http:// tourism4sdgs.org/ [Accessed: November 28, 2018]

[6] Hassan SS. Determinants of market competitiveness in an environmentally sustainable tourism industry. Journal of Travel Research. 2000;38(3):239-245

[7] Horvat U. Razvoj in učinki turizma v Rogaški Slatini. (Vol. 4). 2000.

Ljubljana, Slovenia: Založba ZRC

[8] Gunn J. Encyclopedia of Caves and Karst Science. New York, USA: Taylor \& Francis. 2004

[9] Lasi $\mathrm{H}$ et al. Industry 4.0. Business \& Information Systems Engineering. 2014;6:4, 239-242

[10] Forster J. The sociological consequences of tourism. International Journal of Comparative Sociology. 1964;5:217

[11] Wagar JA. The carrying capacity of wild lands for recreation. Forest Science. 1964;10(suppl_2):a0001-a0024
[12] Jafari J. Role of tourism on socioeconomic transformation of developing countries [Diss.]. Graduate School Cornell University; 1973

[13] Young SG. Tourism: Blessing or Blight. London, UK: Penguin Books. 1973

[14] Butler RW. Tourism as an agent of social change. In: Proceedings of the International Geographical Union's Working Group on the Geography of Tourism and Recreation. 1975

[15] Pizam A. Tourism's impacts: The social costs to the destination community as perceived by its residents. Journal of Travel Research. 1978;16(4):8-12

[16] Sunlu U. Environmental impacts of tourism. In: Conference on the Relationships between Global Trades and Local Resources in the Mediterranean Region. 2003

[17] Martín M, José JGM, Salinas

Fernández J. An analysis of the factors behind the citizen's attitude of rejection towards tourism in a context of overtourism and economic dependence on this activity. Sustainability. 2018;10(8):2851

[18] World Tourism Organization. UNWTO Tourism Highlights: 2018 Edition. 2018

[19] World Tourism Organization. Yearbook of Tourism Statistics, Compendium of Tourism Statistics and Data Files. Available from: https://data.worldbank.org/indicator/ ST.INT.ARVL [Accessed: November 28, 2018]

[20] Milano C, Cheer JM, Novelli M. Overtourism a Growing Global Problem. 2018. Available from: https://www.researchgate.net/ publication/326573468_Overtourism_a_ 
growing_global_problem [Accessed: December 2, 2018]

[21] Statistical Office of the Republic of Slovenia. Available from: https://www. stat.si/StatWeb/en/News/Index/7411 [Accessed: November 28, 2018]

[22] Travel \& Tourism Economic Impact. 2018. Slovenia: World Travel \& Tourism Council. Available from: https://www. slovenia.info/uploads/dokumenti/ raziskave/slovenia2018.pdf [Accessed: November 28, 2018]

[23] Dwyer L et al. Fashioning a destination tourism future: The case of Slovenia. Tourism Management. 2012;33(2):305-316

[24] Omerzel Gomezelj D, Mihalic T. Destination competitiveness e applying different models, the case of Slovenia. Tourism Management. 2008;29(2):294e307

[25] Government Office for Development and European Cohesion Policy. Slovenian Smart Specialisation Strategy-S4. Available from: http:// www.svrk.gov.si/en/areas_of_work/ slovenian_smart_specialisation_ strategy_s4/ [Accessed: November 28, 2018]

[26] Buhalis D, Amaranggana A. Smart tourism destinations. In: Information and Communication Technologies in Tourism, 2014. Cham: Springer; 2013. pp. 553-564

[27] Gretzel U, Sigala M, Xiang Z, Koo C. Smart tourism: Foundations and developments. Electronic Markets. 2015;25:179-188. DOI: $10.1007 /$ s12525-015-0196-8

[28] Hunter WC et al. Constructivist research in smart tourism. Asia Pacific Journal of Information Systems. 2015;25(1):105-120
[29] Gretzel U et al. Conceptual foundations for understanding smart tourism ecosystems. Computers in Human Behavior. 2015;50:558-563

[30] Bramwell B, Lane B. Sustainable tourism: An evolving global approach. Journal of Sustainable Tourism.

1993;1(1):1-5

[31] Waligo VM, Clarke J, Hawkins

R. Implementing sustainable tourism: A multi-stakeholder involvement management framework. Tourism Management. 2013;36:342-353

[32] Hunter C. Sustainable tourism as an adaptive paradigm. Annals of Tourism Research. 1997;24(4):850-867

[33] Liu Z. Sustainable tourism development: A critique. Journal of Sustainable Tourism. 2003;11(6):459-475

[34] Buhalis D. Marketing the competitive destination of the future. Tourism Management. 2000;21(1):97-116

[35] Ryan C. Tourism and marketing-A symbiotic relationship? Tourism Management. 1991;12(2):101-111

[36] Li SCH, Robinson P, Oriade A. Destination marketing: The use of technology since the millennium. Journal of Destination Marketing \& Management. 2017;6(2):95-102

[37] Pavlou PA. Consumer acceptance of electronic commerce: Integrating trust and risk with the technology acceptance model. International Journal of Electronic Commerce. 2003;7(3):101-134

[38] Li X, Petrick JF. Tourism marketing in an era of paradigm shift. Journal of Travel Research. 2008;46(3):235-244 
Tourism 4.o: Challenges in Marketing a Paradigm Shift

DOI: http://dx.doi.org/10.5772/intechopen.84762

[39] Buhalis D, Law R. Progress in

information technology and tourism

management: 20 years on and 10

years after the internet-The state

of eTourism research. Tourism

Management. 2008;29(4):609-623 



\title{
Mobile App Marketing \\ Communication for B2B and \\ B2C: Ingoes as a Case Study
}

\author{
Umut Ayman, Anıl Kemal Kaya and İpek Halim
}

\begin{abstract}
In today's marketing world, there are highly competitive business environments in every industry. The companies try to survive, and their strategical conceptual thinking and entrepreneurship levels help them to be unique in their industry. The innovative ideas and alterations on consumer behavior create success stories in the future survival of the companies. Ingoes is a real estate platform that brings real estate buyers and sellers together and must be research case since it is the first mobile application for property market in Northern Cyprus. Thus, this chapter is helpful as a literature source for mobile application sector usage of marketing communication strategies when they are newly entering in their markets. Diffusion of innovation theory is considered while analyzing Ingoes brand. The aim of this study is to focus on the diffusion of innovation for mobile application marketing perspectives. This chapter covers both quantitative and qualitative research method content analyses by focusing on Ingoes new media usage while they are reaching their current and potential consumers.
\end{abstract}

Keywords: mobile application, marketing communication, property market, Ingoes, Northern Cyprus

\section{Introduction}

The companies provide similar goods and services in their market, and their strategic plan makes their differentiation as a business in the market. Thus, the companies have to create a unique selling proposition and experimental marketing which lets the consumers to have chances for identifying the new experiences and its value to receive a benefit from them. Technological advances have a great power on the market. It is not only on changing the business models of companies but also changes tactics which companies use for their marketing communication strategies because of changing consumer behaviors. As mobile applications make consumer life easier by saving their time and energy, day-by-day popularity of mobile applications increases no matter which sector business they are in; they try to serve their customer with this new technology. As real estate is a growing sector in Cyprus, Ingoes is the first mobile application in North Cyprus market that serves both for businesses and consumers. "Marketing communication practitioners impose some ideas which are designed for the goods and services and they try to normalize their messages, slogans, packages or designs etc. through integration of 
those into daily lives of the consumers" [2]. This research is going to be a good source for literature both for academic fields and business markets because this case study exemplifies the principle of diffusion of innovation theory as articulated by Everett Rogers. Research has three sections. Section 1 is the introduction part. Section 2 has four main parts. In the first and second parts of Section 2, there is a theoretical framework of this research, in the third part is the research methodology, and in the fourth, Ingoes mobile application is discussed. Section 3 is about conclusion of this research.

\section{The growth of marketing in the new media era}

Inevitable growth of new media within technological advances and enormous consumers' Internet use cause changes on the companies' marketing communication strategies to have competitive advantage within the marketplace. Therefore, new media is considered as a global marketplace that covers the use of marketing communication tools in a technological facet. The new media campaigns give an opportunity for the companies to analyze the campaign's success easily by checking the pre-/post-launches of their marketing communication campaigns by using the number of interactions, accessions, views, previews, engagement rates, and electronic word-of-mouth communication (eWOM) responses. One of the traditional ways of face-to-face communication known as word-of-mouth (WOM) communication transforms into eWOM after the use of new media platforms.

Integration of new media usage and marketing communication leads to new kinds of marketing as mobile marketing. Hence mobile marketing comes to a space that the companies use applications to create another platform for their customers, clients, and prospects that can be moved from new media and Internet-based activities to application platform. Thus, the companies need to design their strategic mobile marketing planning to achieve competitive advantage especially in the service industry to create superior value to their consumers. As the service industry is not like the production sector that the consumers cannot use their adoption of five senses before they decide whether it's a right choice or not, it is full of intangible values that are generated by the companies and then delivered to clients and consumers. Therefore, the perceived value and the brand image are a basic asset for the companies in such cases.

\subsection{Mobile marketing}

As nothing is stable, consumer expectations and their behaviors are not stable as well. No matter which generation the consumer belongs to, they try to adopt these changes in their lives through passing different processes that vary from consumer to consumer, but surely, they adopt these changes in their life cycle period.

"Mobile marketing is the use of the mobile medium as a communication and entertainment channel between a brand and an end-user. This is the only personal channel enabling spontaneous, direct, interactive and/or targeted communications, any time, any place" [1]. Since mobile marketing is a new trend for business to reach their consumer efficiently and effectively, Michael and Salter pointed out that the advantages of mobile marketing advantages as a concept of response that recall rates as being cheapest communication model and attempting minimum act to use a pilot with advantageous commission margins (p. 25).

As Rowles [8] pointed out, marketing and mobile marketing activities are attached to each other and have a power to affect mutually marketing channels as online and offline [7]. The inevitable role of mobile marketing has a huge impact on 
the use of mobile medium as a communication route in the context of integrating marketing within mobile commerce, e-commerce, and the Internet, both offline and online. Michael and Salter mentioned that, especially, mobile marketing has a role to have extremely personalized, instant impression with interactivity [1]. Therefore, it becomes popular in different markets where companies reserve some amount of money for their companies' mobile application as an investment.

\subsection{Diffusion of innovation theory}

Especially, technological improvements and its diffusion and adoption are one of the major essentials in the marketing field. Rogers developed diffusion of innovation theory with "knowledge, persuasion, decision, implementation, and confirmation" steps [6].

Rogers' model dealt with consumers who experience all steps as in a process [3]. In Ingoes case, "knowledge" stage is the consumers' first exposure to the information about Ingoes real estate platform. Ingoes use both traditional media and new media to create awareness for consumers and businesses. Second step "persuasion" is to create positive perceptions for B2B and B2C. "Decision" comes as the third step in which they adopt or reject the Ingoes application. Then, "implementation" covers a trial period which the consumers and businesses experience in a time circumstance. The final step is "confirmation" in which Ingoes application is being adopted by $\mathrm{B} 2 \mathrm{~B}$ and $\mathrm{B} 2 \mathrm{C}[6]$.

Some authors declared the prominence of adoption process [3, 4].

With the roots of Rogers' model, Etzel et al. explain the adoption process within different category names [4].

From a marketing perspective, awareness stage is the initial communication way with the B2B and B2C. Specially, awareness plays a vital role for new introductions of the companies, and the companies heavily use marketing communication tools to create awareness and interest. Also, with the rapid changes in technology market, mobile marketing is a new way to reach different segments in b2b and b2c. Ingoes uses free mobile application which affects the trial and evaluation stages of them. Marketing communication tools and experiences of B2B and B2C segments cause confirmation of the adoption of the application.

Rogers [6] pointed out that there are five adopters' categories according to consumers' rate of adoption process as innovators who firstly adopt new products/ services during the introduction stage and are about $2.5 \%$ of the market. The second one is early adopters who are followers of innovators and adopt the products during the growth stage and about $13.5 \%$ of the market [6]. The third category is the early majority, which rely on marketing communication tools, and they can adopt the products at the beginning of maturity stage and are about $34 \%$ of the market. Fourth stage is late majority, which cover $34 \%$ of the market and prefer to adopt products in late maturity stage of the product life cycle. Last one is laggards, which are $16 \%$ of the market, and they refuse to use products or lately adopt them during the decline stage of cycle [6]. Marketing scholars prefer to use Rogers' adoption categorization in their studies $[3,4,5]$.

When we look at Ingoes example, Ingoes is at the introduction stage of its life cycle. Also, it is at the awareness stage of its adoption process.

\subsection{Research methodology}

This is a research paper to focus on the use of mobile marketing in property market. As mentioned earlier Ingoes is the first property market application for Northern Cyprus, and it is selected as a case study in this chapter. The methodology 
covers both quantitative and qualitative research methods as content analysis to discover Ingoes media usage while they are trying to reach their clients and consumers to influence their perception and behavior especially on social media and application manner. This chapter covers both quantitative and qualitative research method content analyses by focusing on Ingoes new media usage while they are reaching their current and potential consumers. In quantitative part Ingoes mobile application media usage frequency was analyzed, and in the qualitative part of this research, the content of each campaign for every media usage was analyzed to understand the level of diffusion of Ingoes mobile application in North Cyprus as a developing county. Data about the development process and campaigns were collected from social network sites, and content of the messages were analyzed to understand the purpose or the aim of the campaigns while reaching their consumer's. Hence, the aim of this study is to focus on the diffusion of innovation for mobile application marketing perspectives.

\subsection{Analysis}

\subsubsection{About the market}

Recently, consumers prefer to compare the products and services through the Internet or social network sites, and as a new trend, the high use of mobile phones creates another platform and marketplace for clients and consumers to reach information. Real estate market is considered as a highly competitive business around the world, and the Internet and new technology bring new products and services to reach the consumers.

As being in real estate industry, Alibaba is the biggest marketplace, and Rialto and Zillow are the most popular property marketplaces in the world. In Northern Cyprus, Ingoes application platform has a competitive advantage as being a unique real estate application in mobile marketing industry. Ingoes has been developed for local market for B2B activities. Ingoes uses word-of-mouth communication for faceto-face launching of events with the real estate agency clients; and, it focuses on local prospects in property market with the use of mobile marketing strategies and tactics through the use of social network sites such as Facebook, Instagram, Twitter, SMS message, and application-oriented notifications as B2C. Also, foreign prospects have a chance to browse Ingoes application; however, real estate agencies play a vital role as a means of sales force actions for that group because the use of marketing tools are in Turkish language.

In Northern Cyprus, 101 evler and Hurriyet Emlak are preferred and used by real estate agencies to reach buyers. Emlak, Zingat, or Emlak jet are either both dedicated for this specific market or they are only web based.

\subsubsection{About the product}

Ingoes brand name comes from Turkish Cypriot local street dialect that means hitting the target or Gotcha. While selecting the application name, a representative from Perceptio company, Public Modus as Communication Consultant, and the financial supporter for the application made a list of names and conducted a focus group and asked their opinions and preferences. Finally, Ingoes was selected as a name for the mobile application.

The ownership of Ingoes application belongs to Cyprus Consulting Company. Ingoes has business partnership with Limonist, Perceptio, and Public Modus. 
Ingoes' slogan is Cebindeki Emlak Uygulaması (property in your pocket or property application in your pocket). Slogan was written by Communication Consultant Public Modus.

Ingoes was launched in June 2018. It is an application for mobile phones.

With the use of Ingoes, property developers or real estate offices can upload their products where they can associate with location and many other information and criteria, enabling determination of price intervals, selection of number of rooms, age of the building, number of bathrooms, balcony, colons, swimming pool, etc. with many photographs of the product as being a flat, bungalow, villa, etc.

Furthermore, potential customer can reach directly to the real estate agency or the property developer either by calling or text messages or by emailing from his/ her mobile phones. Also, potential buyers can create a profile to get news about the properties or the market trends with notifications. Ingoes is free of charge application for the potential customers who are interested in real estates. Moreover, Ingoes' clients are the property developers as well as the real estate agencies. Also, Ingoes has two full-time employees and three part-timers. Since June, it has been upgraded two times. Ingoes sends notifications to its users every Thursday.

The idea was discovered and created during the browses and searches of similar applications which are developed and used in Europe and America.

The Ingoes application provides a business platform to real estate agencies in which they can market and sell their apartments, villas, shops, or lands to customers through Ingoes application platform as a B2B service. Plus this application also frames it's one way selling with business to consumer transaction B2C as business is real estates and try to reach renter/buyer as consumer side. Since real estate agencies professionally update their products and have credibility and apply realistic activities to survive into market.

Ingoes has two full-time employees and three part-timers. There is one general manager coming from the banking industry (Selcen Erguven). Second full-time employee is responsible for real estate agency visits and communication and office writings. Part-time employees are from Perceptio company who are editing, entering, and updating data for application (Figure 1).

As seen above visuals the first visual is the visual of their web page that gives information why consumers need to download that application. While giving information about that mobile application, they use some signs to persuade people more both visually and verbally. Such as; easy to use support with the symbol of shining hand that represent "yes, I did it", quick search represent analog clock, using mobile phone represent that its an mobile application so the people can download it and they use a tree and use special tong that uses Cypriots mostly use to
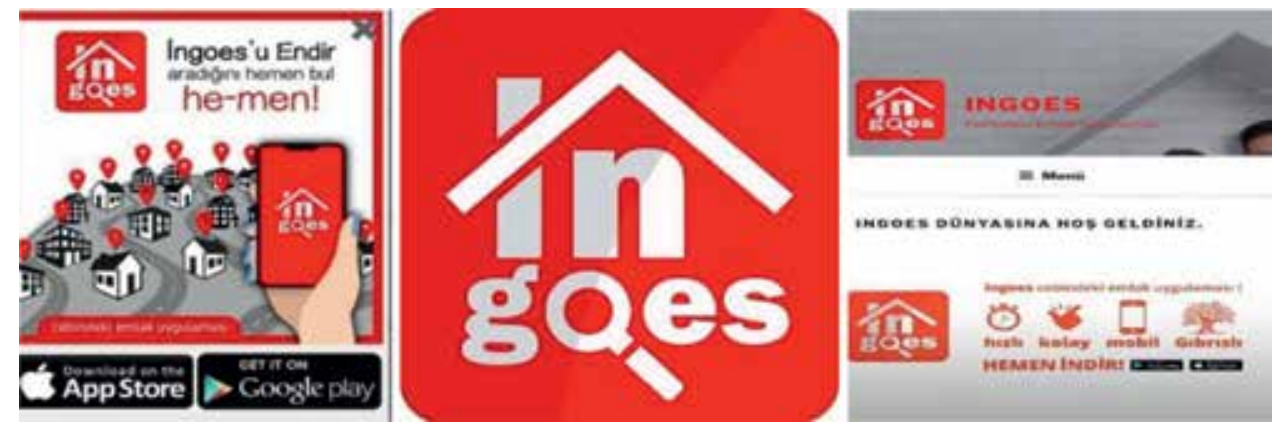

Figure 1.

Ingoes visuals. 


\begin{tabular}{lcc}
\hline Ingoes mobile users & Number of people & Number of people \\
\hline Retrieved date & $20 / 10 / 2018$ & $21 / 11 / 2018$ \\
\hline Registered users & 879 & 1050 \\
\hline Android users & 467 & 462 \\
\hline IOS users & 412 & 485 \\
\hline
\end{tabular}

Analysis results were based on October 20, 2018 and November 21, 2018.

Number of people who clicked for Ingoes from Facebook: 953.

Number of people who clicked on Ingoes from Instagram: 135.

Number of inputs: 2429.

Table 1.

Reflections of Ingoes on new media.

get the attention of Cypriot people. They use red color in their logo to get more attention both businesses' and consumers' attention. When analyzed deeper, the roof used in logo represents property. Capital "I" represents the house chimney, and there is magnifier used that represents go and search, in other words the search button, which is used instead of letter "O." The third visual is the pop-up ads that they use. In that visual it is seen that they play with some words, and instead of using the words in how it's written, they use words as how Cypriots talk to get more attention such as ENDİR instead if INDIR and use red balloons above the houses to represent the different locations. At the bottom of the visual, they use Apple Store and Google Play Store icons signifying both Android and IOS platforms can download the application as 467 Android user and 412 IOS user download that mobile application in 20/10/2018 and 462 Android user and 485 IOS user download it in 21/11/2018/ within one-month period that application find out 171 different new users from both platforms (Table 1).

According to the text messages, it is assumed that one property has been sold via Ingoes and one flat has been rented via Ingoes till November 2018.

Around 135 real estate agencies were accepted and uploaded their products, and total registered users are 1400 till the end of December 2018.

\subsubsection{Communication and media planning of Ingoes}

Ingoes communication process was divided into two stages. One of them focused on end users, and the other one directed to real estate offices.

\subsubsection{Stage start-up (launch) (focused on end users, B2C)}

Facebook, Web TV broadcast, and banners: On June 2018, Ingoes had ad banners on Sami Özuslu Sabah Kahvesi Program (Kanal Sim, 2-hour program, and every 20 minutes banners appear on program) and Hüseyin Ekmekçi News Program (Haber Kibris 45 minute program, and every 20 minutes banners appear on program) for a 1-month period.

Aim: These programs were selected for banner because these two morning news programs have many followers. Traditionally, news programmers have live connection, and the audiences can expose and write comments immediately, and the programmer can read the comments and answers the questions of followers.

Communication Consultant Public Modus created and designed the process, and Cherry Red Ad Agency produced the ad banners.

The majority of information diffusion for creating awareness was done through Facebook. Monthly 400-450 TL sponsored advertisements and news were diffused 
on Facebook. Ingoes appeared three times on the news on local digital media as Haber Kibris, Vayguzzum, and Kibris Postasi. Also, Ingoes had only a one-time campaign based on Facebook. The reward was a dinner for three couples in Ambiance restaurant.

Radio advertisements: Ingoes has radio advertisements on Dance Fm-Enerji Fm in which its jingle and radio ad appear five times in the morning broadcast and five times in the noon broadcast.

Aim: To inform and create awareness of Ingoes on the way to work and home. Radio ad process was done by Communication Consultant Public Modus, and the jingle was created by musician Çağıl İşgüzar.

Facebook and Instagram: Facebook and Instagram appearances started up in April 2018, and initially the teaser took place to catch attention. They used two visuals such as in first visual asking "What is Ingoes?" and in the second one "Be Curious, be soon". The idea of teaser and post creation was done by a communication consultant, and Cherry Red Ad Agency produced the output (Figure 2).

On May 2018, they started to introduce Ingoes to the new media. On June, they started to share the visuals as sponsored through Facebook and Instagram.

On May 23, they asked the meaning of Ingoes through Redrofon street interviews.
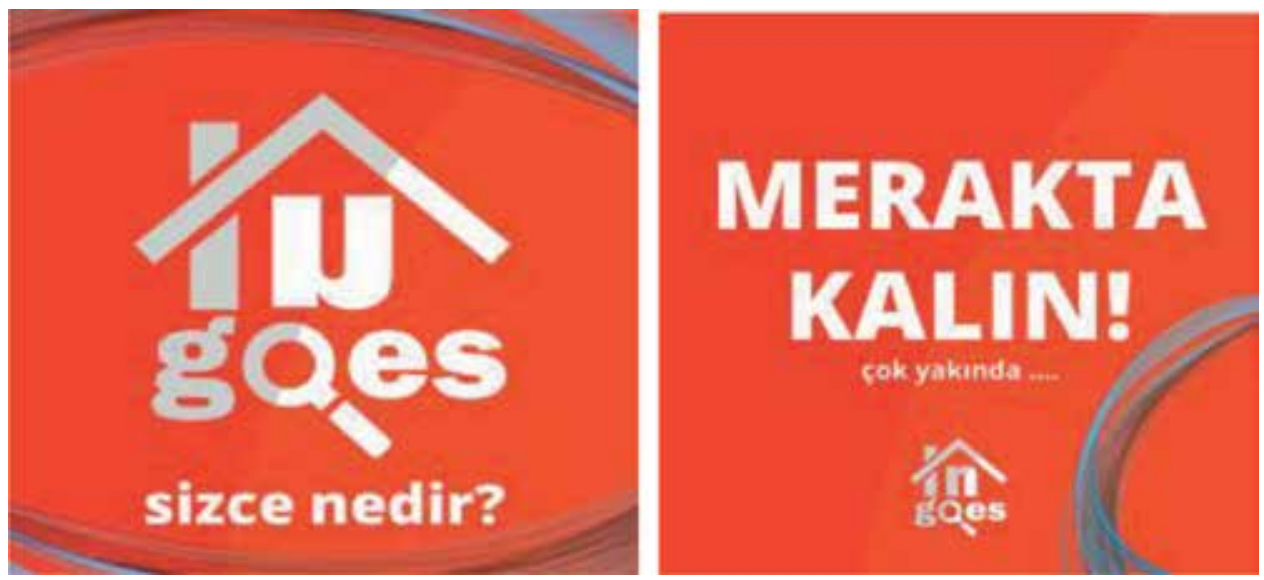

Figure 2.

What is Ingoes?

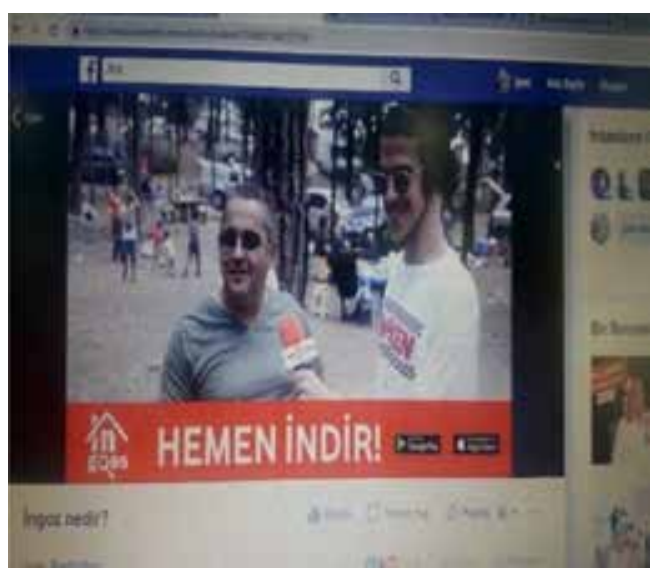

Figure 3.

Redrofon. 
This program took place on Facebook. Ingoes banner was passed and displayed on the video, and there was an Ingoes ad video at the end of the program with the program link given below (Figure 3).

Video 1 as shown in Appendix [9].

Aim: Increasing awareness and reaching younger generation

Google Ads: As a part of its introduction tactic, Ingoes has started to use Google Ads on October 2018. The trial use of Google was only 11/2 month. They stopped to use in January 2019.

\subsubsection{Stage (focused on end users, B2C)}

Radio advertisements: Ingoes was explained in Sabahların Efendisi radio program, and its jingle was played as a theme in the morning 7 am-8 am on October and November 2018.

Aim: To inform and create awareness of Ingoes for radio audiences

Radio ad process was done by General Manager Selcen Erguven, and content information was created by Communication Consultant Public Modus.

Digital and new media: Ingoes was displayed as news four times in Haber Kibris and Vayguzzum sites. Also, those news were shared on new media as well as shown in Appendix (Figure 4).

Facebook sharings: Continuous scheduling technique is being used on Facebook for animation video and visual sharings which are sponsored continuously for 50TL, two times sharing every week occurs, and news and special day celebrations take place.

Aim: creating awareness-focus on advantages and lead to downloading of the application. The information on visuals has "quickly download" information and download link is given. DesignLab Marketing/Advertising Agency is responsible for managing of Ingoes Facebook. Content, sponsored sharings, and time duration are determined by Public Modus, DesignLab Marketing/Advertising Agency, and General Manager Selcen Erguven.

Videos: Three videos with real actors were taken. First presents Ingoes, second one signifies the advantages of easy search by filters, and the third states the advantage of location presences in searches.

These videos were shared on Facebook and Instagram as shown in Appendix.

Video 2 as 1. Ad [10], Video 3 as 2. Ad [11] and Video 4 as 3. Ad [12]

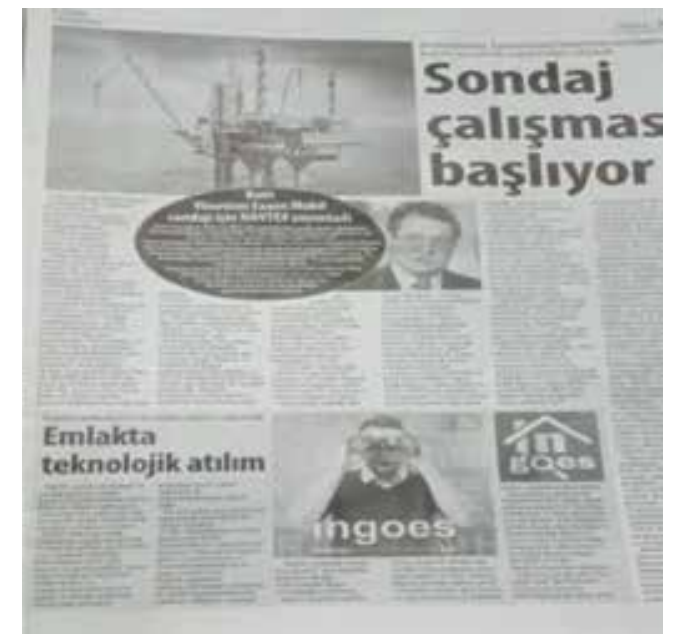


Mobile App Marketing Communication for B2B and B2 C: Ingoes as a Case Study

DOI: http://dx.doi.org/10.5772/intechopen.85008

\begin{tabular}{lccc}
\hline & Video 2 Ad1 & Video 2 Ad 2 & Video 3 Ad 3 \\
\hline Views & 6613 & 14458 & 8377 \\
\hline Click the link & 24 & 22 & 54 \\
\hline Payments for sponsored ads & $50 \mathrm{TL}$ & $50 \mathrm{TL}$ & $50 \mathrm{TL}$ \\
\hline
\end{tabular}

Table 2.

Facebook videos' information.

The video content and flow were determined by Public Modus, and video preparation and broadcast were done by freelance Uygar Erdim. Facebook videos' information are given in Table 2 with views below; click the link and payments for sponsored ads.

SMS: Ingoes sent one-time SMS message to 10, 000 people with a download link on October 22, 2018. The feedback was very low as 60 people downloaded the Ingoes.

Message: "Meet Ingoes that brings a new dimension to the property sector in Northern Cyprus. Click immediately, download, search, find and be happy"

Future planning tactics for end users:

1. Billboards

2. Transit advertising (out-home media)

3. Continuous digital media and newspaper outputs

4. Continuous to Facebook

5. Give ads to present in newspapers and magazines

6. Attending festivals in summer

\subsubsection{Communication process toward real estate agencies (B2B)}

1. Ingoes sent emails to all registered real estate offices. Content was inserted into the mail. General Manager Selcen Erguven sent email to them. There was no reply to these emails.

2. Direct marketing technique was used to inform all real estate offices about Ingoes through telephone calls focusing on all Kyrenia (including Catalköy, Alsancak, and Lapta as well) and Nicosia (including Hamitköy and Gönyeli as well). Also, all construction companies were called by telephone, and they were informed about Ingoes. The visits were done in September and October and completed on time. No photos were taken during these visits.

3. For $\mathrm{B} 2 \mathrm{~B}$, Ingoes prepares a promotion file and advertising specialties as promotions were given to agencies with Ingoes flyers and Ingoes notebook and pencil with message from the general manager. One by one, Ingoes marketing employee visited each agency to create face-to-face communication and create awareness and give information about their application. Also, Ingoes flyer looked like a mobile phone, and visual design is as shown below.

Ingoes was free of charge in first 3 months of its introduction period. After that, the free period was extended to first 4 months. Now, there are different packages 
for registration and membership of Ingoes with cost. Types of memberships are as 3-month, 6-month, and 1-year periods (Figure 5).

Moreover, for 1-year membership, Ingoes provides free advertising space on Haber Kibris and Vayguzzum ad spaces. Also, they give a space on Web TV-Property TV for 1-year membership agencies. First program was broadcasted with representatives initially from Özyalçın Construction Company and the next from Limasol GYO (Property Investment Partnership). Programs were broadcasted on Web TV as Property TV on December 28, 2018, and January 3, 2019, consecutively (Figure 6).

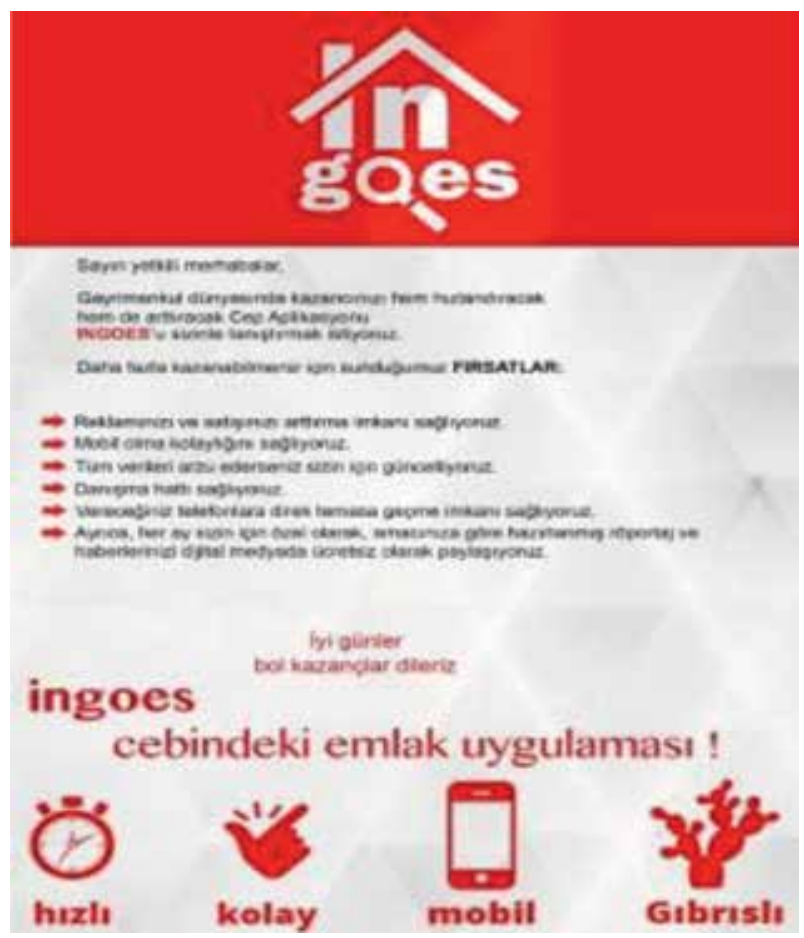

Figure 5 .

E-mail content.
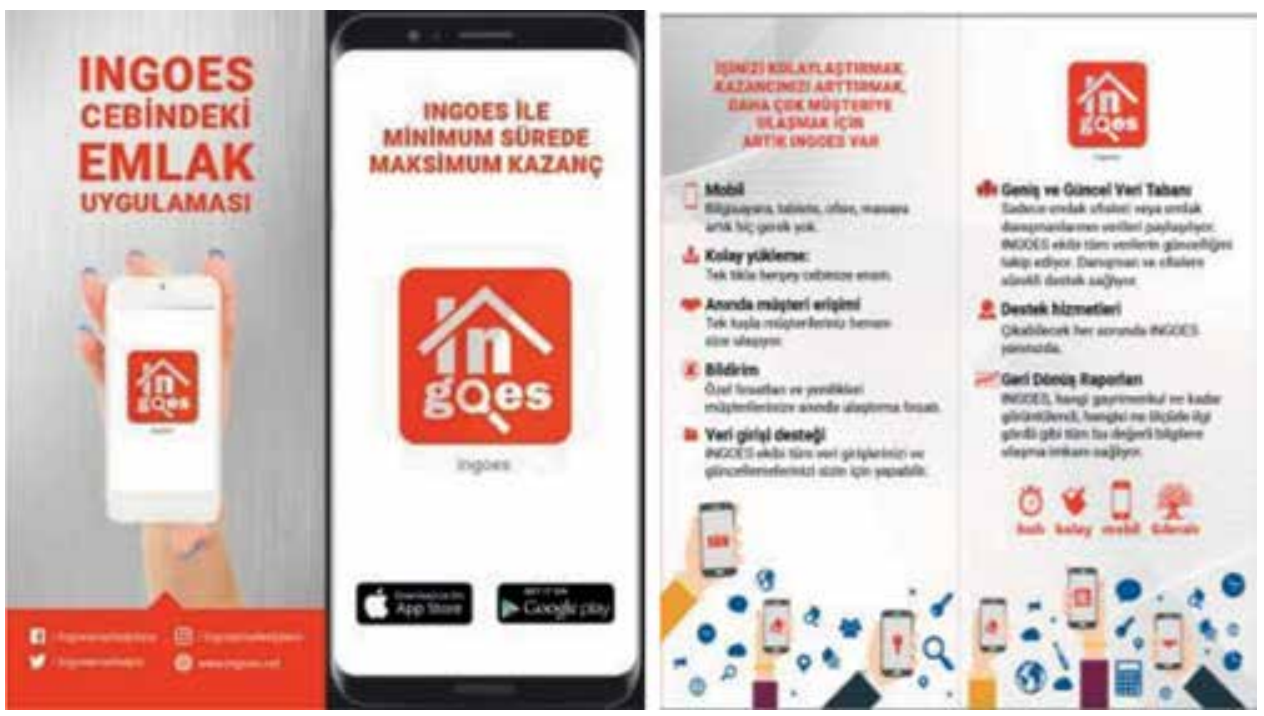

Figure 6.

Ingoes flyer. 

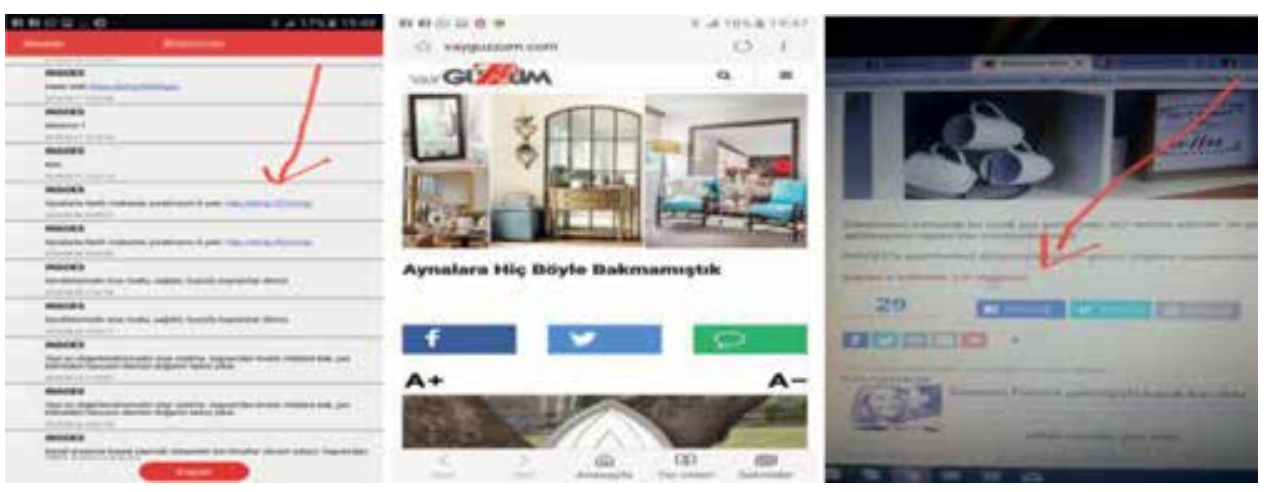

Figure 7.

Vayguzzum content.

All of the visuals and contents can be uploaded by either real estate offices themselves or Ingoes, and the visuals and contents can have a spacing and sharing free of charge. Furthermore, Ingoes is on the way to put quota on the number of sharings which is a topic that Ingoes tries to make a decision.

Public Modus is the communication consultant of Ingoes. Public Modus is responsible from all communication flow and process. Logo idea came from Public Modus and is designed by graphic designer Kenan Erdim. Jingle was prepared by musician Çağıl İşgüzar. Social media management is the responsibility of DesignLab Marketing/Advertising.

Flyers, design of photos on media, and the future billboard designs are the responsibility of Cherry Red Advertising Agency. Video ads' scenario and contents are the responsibility of Public Modus.

Art director freelance Uygar Erdim managed the videos. Theater artist Çağla Topcan had roles in the video. Also, radio advertisements were done By NRG group.

There are continuous meetings with all of the agencies face-to-face once a month. The creative ideas are produced by Public Modus.

Ingoes sends notifications to end users every Thursday. Also, the notifications are created by Public Modus. Sometimes, Ingoes put links to notifications, and they try to inform people about new trends on home and furniture designs. Also, they can put a download link as well (Figure 7).

Content is shown in Appendix [16].

\section{Conclusion}

Ingoes is the first mobile real estate application in Northern Cyprus. It has a local dialectic name with an attempt to focus on local market as well. Its introduction was on June 2018; they try to create a competitive advantage to B2B and B2C with a mobile application in real estate industry. By using word-of-mouth communication for face-to-face and launching of events with the real estate agency clients, they focus on B2B market and using of mobile marketing strategies and tactics through the use of social network sites such as Facebook, Instagram, Twitter, SMS message, and application-oriented notifications; they focused on B2C market. It's a pioneering idea to have a real estate mobile application in Northern Cyprus which is a Mediterranean island country. In the last 7 months after they start up their business, they tried to reach their B2B and B2C market effectively and efficiently by using different mediums by emphasizing special cultural values. According to Everett Rogers' "diffusion of innovation" theory, the analysis shows that Ingoes mobile application is at introductory level of its life cycle as a real estate platform 
that brings real estate consumers and clients of Ingoes together with high-quality service approach. Since the consumers' rate of adoption process as innovators who firstly adopt new services is about $2.5 \%$ of the market, till the end of November 2018, 1050 consumers download that mobile application (462 as Android and 485 as IOS users), and some of them buy an estate or rent a flat during that introduction stage. All their advertising videos are focused on application advantages and information about the service to create some insights to their consumers.

According to reflections and communication processes, its newly introductory stage can be a platform for innovators in Northern Cyprus. New media tactics and traditional media, direct marketing, and sales forces are actively used by Ingoes.

\subsection{Recommendation}

There is no question about demographic structure determination such as age and gender of the registered users. Only the location of registered users was examined, which can only signify 35 out of 40 users were from Kyrenia. The application has to use market segmentation for future business success. Also, Famagusta and Iskele cities are left behind the promotional activities of Ingoes. Famagusta and Iskele, with their seaside locations and affordable prices, are promising places both for client agencies and consumers for near future.

\subsection{Future study}

For next year, a longitudinal study and quantitative research could be conducted by involvement of demographic structure with an aim to focus on the diffusion of innovation through mobile application marketing perspective with the clients' (Ingoes) attitude, perception, and behavior.

\section{A. Appendix}

\section{See Table 3.}

\begin{tabular}{|c|c|c|}
\hline Name & Link & Published date \\
\hline Video 1 & https://www.facebook.com/redrofon/videos/1704993186257539/ & $\begin{array}{l}\text { Published in October } 1 \text {, } \\
2018[13]\end{array}$ \\
\hline New & https://haberkibris.com/-son-teknoloji-gayrimenkul-dunyasi-ve-green-box- & Published in September \\
\hline Media 1 & 2018-10-01.html & $19,2018[15]$ \\
\hline New & https://haberkibris.com/emlak-sektorunde-guven-saglayan-uygulama-ingoes- & Published in November \\
\hline \multirow[t]{2}{*}{ Media 2} & 2018-11-05.html?fbclid=IwAR1XEhrn4Mx6QbPFrMM-T-kgIich & $11,2018[14]$ \\
\hline & MSW9AniOPvPO2a5gh5MbXrJ4Or8MvRg & \\
\hline New & http://vayguzzum.com/gayrimenkul-dunyasina-yerli-doping1909181200.html? & Published in November \\
\hline Media 3 & $\begin{array}{l}\text { fbclid=IwAR1ifCsaiAvmKTyVSRtBB6Skq52uit6jySK8cb0Aq1KE0r4B7KHW_- } \\
\text { N7IKA }\end{array}$ & $4,2018[15]$ \\
\hline Video 2 & https://www.facebook.com/ingoesmarketplace/videos/269089170378525/ & $\begin{array}{l}\text { Published in September } \\
17,2018\end{array}$ \\
\hline Video 3 & https://www.facebook.com/ingoesmarketplace/videos/2168055343414030/ & $\begin{array}{l}\text { Published in October 2, } \\
2018\end{array}$ \\
\hline Video 4 & https://www.facebook.com/ingoesmarketplace/videos/171269203821920/ & $\begin{array}{l}\text { Published in October } \\
31,2018\end{array}$ \\
\hline $\begin{array}{l}\text { New } \\
\text { Media } 4\end{array}$ & $\begin{array}{l}\text { http://vayguzzum.com/masanizla-birlikte-ruhunuzu-da-canlandirin-2507181200. } \\
\text { html }\end{array}$ & $\begin{array}{l}\text { Published in July 25, } \\
2018\end{array}$ \\
\hline
\end{tabular}

Table 3 .

Ingoes communication. 
Mobile App Marketing Communication for B2B and B2C: Ingoes as a Case Study DOI: http://dx.doi.org/10.5772/intechopen.85008

\section{Author details}

Umut Ayman*, Anıl Kemal Kaya and İpek Halim

Eastern Mediterranean University, Famagusta, Northern Cyprus

*Address all correspondence to: umut.ayman@emu.edu.tr

\section{IntechOpen}

(C) 2019 The Author(s). Licensee IntechOpen. This chapter is distributed under the terms of the Creative Commons Attribution License (http://creativecommons.org/licenses/ by/3.0), which permits unrestricted use, distribution, and reproduction in any medium, provided the original work is properly cited. (cc) BY 


\section{References}

[1] Michael A, Salter B. Mobile Marketing: Achieving Competitive Advantage through Wireless Technology. 1st ed. UK: Elsevier, Butterworths Heinemann; 2006

[2] Ayman U. Profiling consumer decision-making styles and consumption among young adult consumers in Northern Cyprus: From marketing communications perspective [PhD thesis]. Northern Cyprus: Eastern Mediterranean University; 2015

[3] Blackwell RD, Miniard P, Engel JF. Consumer Behavior. 9th ed. FL: Harcourt Publishing; 2001

[4] Etzel MJ, Walker BJ, Stanton WJ. Marketing. 14th ed. New York: McGraw-Hill; 2007

[5] Lowrey TM. The use of diffusion theory in marketing: A qualitative approach to innovative consumer behavior. In: Holman RH, Solomon MR, editors. NA-Advances in Consumer Research. Vol. 18. Provo, UT: Association for Consumer Research; 1991. pp. 644-650

[6] Rogers EM. Diffusion of Innovations. 3rd ed. New York: Free Press; 1983

[7] Lamb C, Hair J, McDaniel C. Essentials of Marketing. 2nd ed. USA: South Western Publishing; 2004

[8] Rowles D. Mobile Marketing: How Mobile Technology is Revolutionizing Marketing, Communications and Advertising. 2nd ed. Kogan Page; 2017

[9] Video 1. Available from: https:// www.facebook.com/redrofon/videos/ 1704993186257539/ [Published in 1st of October 2018]

[10] Video 2. Available from: https:// www.facebook.com/ingoesmarketplace/ videos/269089170378525/ (Published in 17 th of September 2018)
[11] Video 3. Available from: https:// www.facebook.com/ingoesmarketplace/ videos/2168055343414030/ (Published in 2nd of October 2018)

[12] Video 4. Available from: https:// www.facebook.com/ingoesmarketplace/ videos/171269203821920/ (Published in 31st of October 2018)

[13] New Media 1. Available from: https://haberkibris.com/-son-teknolojigayrimenkul-dunyasi-ve-green-box2018-10-01.html (Published in 19th of September 2018)

[14] New Media 2. Available from: https://haberkibris.com/emlaksektorunde-guven-saglayan-uygulamaingoes-2018-11-05.html?fbclid= IwAR1XEhrn4Mx6QbPFrMM-T kgIichMSW9AniOPvPO2a5gh5MbXrJ 4Or8MvRg (Published in 11th of November 2018)

[15] New Media 3. Available from: http:// vayguzzum.com/gayrimenkuldunyasina-yerli-doping1909181200.html

[16] New Media 4. Available from: Vayguzzum.com http://vayguzzum. com/masanizla-birlikte-ruhunuzu-dacanlandirin 2507181200.html?fbclid= IwAR3ft0GeiPg0MlAls0-U0TLPtkqbSK QaxKDn4CGdhAjLH46UrxyTO_nkx1c (Published in 25th of July 2018) [Accessed: 2018-12-24] 


\title{
Building on eWOM to Understand Service Quality in Hotel Services
}

\author{
Marlene Amorim and Mário Rodrigues
}

\begin{abstract}
In recent years the volume and the reach of available online content in the form of electronic word-of-mouth (eWOM) has grown at an unprecedented pace. eWOM exerts an important influence for consumption decisions of consumers, and is acknowledged to be more accessible and trustworthy than other commercial information provided by companies by means of advertising and sales. The sophistication and widespread of communication technologies is making the volume of information released online by customers to become overwhelming. For consumers and for business managers alike, making sense of the available information is a challenge that needs to be met urgently in order to keep the pace with the expectations of consumers whom, as engaged providers of feedback require their observations to be taken into account. This advances with a contribution to support the development of methods for the analysis and visualization information from online sources, by adapting an importance-performance analysis for identifying salient quality attributes from eWOM, offering an efficient approach for extracting information and identifying priorities for service improvement.
\end{abstract}

Keywords: eWOM, information extraction, service quality, importance performance analysis, service attributes

\section{Introduction}

Consumers increasingly use online means to share their experiences and perceptions about the quality of services they use. Every day overwhelming volumes of information are produced and published online, and these seem to exert a critical influence on service choices and purchase decisions. This context is very much facilitated by the dissemination of technologies that encourage the production and sharing of user crated content. Likewise, there is a growing familiarity of customers with Internet technologies that is fueling this trend. Service providers, by their turn are keeping the pace by implementing and adhering to online tools that offer efficient ways for users to make their ideas available to vast audiences in a fast manner [1]. The importance of such form of communication, known as electronic word-of-mouth (eWOM) or word-of-mouse, has been extensively acknowledged in the literature, often being referred as a more effective means to influence customers' consumption decisions than other tools, such as personal sales or advertising, because it can be perceived by costumers as a rather reliable source of information. Whereas customer reviews are now a common feature in many company websites, and platforms, research is still necessary to gain knowledge about how to effectively use eWOM data as a valued adding tool to inform customer decision making, as well 
as to guide managerial actions towards service improvement and innovation. This study proposes a contribution in this direction.

The study describes the development of a methodology to support the analysis of eWOM, in order to facilitate the systematic analysis and visualization of insights from online reviews concerning service quality. The proposed methodology is useful to both academics and managers as it proposes a concise display of the data analysis results, allowing for a quick identification and debate about priorities and concerns for quality management, while building on a frame of reference for quality attributes that is derived from service management literature. The study was developed in the particular context of the hotel industry in Portugal, as a representative business sector for the volume and reach of online consumer reviews. The development of the proposed data analysis and display method was built on a selected sample of customer reviews extracted from a prevalent online service for hotel bookings. The hotel industry offers an adequate and rich context for the nature of this study for the fact that the travel and tourism industry is known for being a pioneer for the growing trends of promotion and distribution of services over the Internet [2].

The chapter offers an approach for making sense of customer reviews, by identifying relevant service quality dimensions embedded in the voices of hotel customers, while offering a concise tool for the visualization of the results. To this end, the study employed the principles of importance-performance analysis (IPA), a marketing research technique acknowledged for offering a concise graphical representation of results, to develop a framework for identifying salient hotel service attributes from the available and uncategorized information provided by customer reviews. The study offers a timely approach for assisting managers in the task of sense making from growing volumes of user generated information from a key source of information for the identification of priorities for service improvement and innovation.

Following this introduction, this chapter offers in Section 2 an overview of the conceptual background of the study, namely addressing on the topics of service quality and service quality assessment approaches while discussing some of the key challenges in measuring service results. In Section 3 is devoted to describe the application of the importance-performance analysis (IPA) approach to the context of eWOM in hotel services, and to presented and discuss some representative results of the application of this methodology to extract meaning from user generated context. The chapter closes with a presentation of key contributions and conclusions in the last section.

\section{Approaching quality and quality assessment in service settings}

The understanding of service quality and the deployment of robust and replicable methods to conduct its assessment have been in the core of the agendas of service management scholars and practitioners for many years. Despite an early consensus about the relevance of service quality for customer satisfaction, loyalty and company's profitability $[3,4]$, the operationalization of methods and tools to measure service quality and inform managerial practice and consumer decision making has generated extensive debate and challenges. Many of the results of service experiences lack tangibility and for this reason many approaches for service quality assessment rely on information from customers' "perceived" experiences $[5,6]$.

Many of the prevalent approaches to capture consumers quality perceptions build on the development of survey methods for data collection, consisting of multi-item scales. Such multidimensionality is aligned with the conceptualization 
of services as experiences that enact perceptions about multiple attributes and dimensions that affect customer value such as service responsiveness, reliability, and even elements such as the characteristics of the tangible elements such as service facilities, equipment, etc., and the performance and empathy of service professionals. In service experiences customers receive a combination of outcomes including direct process results (e.g., availability of required items in a retail store, on-time arrival to a flight destination in transportation services, etc.) along with other results related to the process experience resulting from customers' contact and involvement in the service process (e.g., store atmosphere in retail services, comfort in a flight, etc.). Service quality is therefore conceptualized as a construct, featuring distinct dimensions that correspond to the diverse benefits that a customer can derive from a service. These dimensions of service quality are present across the prevalent service quality models and mirrored in the generalized generic scales such as SERVQUAL, SERVPERF, along with other sector specific scales where items are adapted to business particularities, such as in retail, health or hospitality and tourism services. Prevalent models account for the recognized dual nature of service quality determinants, i.e. the quality of service outputs as well as the quality of the experience with the delivery processes [4].

Overall service quality models, and the derived methods for its assessment, analysis and interpretation are built on customers' perceptions about the performance of service delivery, rather than on objective assessments of quality items $[7,8]$. Perceived service quality is defined as the customer's evaluation of the overall excellence of a service and has been persistently distinguished from objective quality measurements, which were typically associated to the quality assessment of manufacturing products. The use of perceived service quality models is motivated by the specific nature of service outputs, which involves both tangible and intangible components and, as such, are often hard to assess and can result into very heterogeneous evaluations across customers.

Despite of the popularity of the [quantitative] multi-attribute type of measurement that has prevailed in the service quality domain along the years, several debates have highlighted the limits of such instruments. Among these are the difficulties of interpreting and using the standardized results of multi-attribute measurements. Data collected in this form offers only limited information about the richness, and the details, that contextualize customer perceptions about a service. More importantly, survey data fails from capture information about contradictions in service experiences as the respondents are forced to aggregate their quality experiences into ratings for a limited number of items. Any comprehensive listing of all quality aspects would result into lengthy questionnaires that would exceed customer's willingness to answer and therefore hurt the validity of the information collected. A customer of an accommodation service of asked to evaluate the friendliness contact employees is forced to choose a single point on a scale despite the number of contacts and different staff met whose behavior and friendliness might vary considerably.

Overall the standard attribute-based quality and satisfaction surveys are not perfect when it comes to capturing all relevant managerial information, and for this reason other complementary approaches have been advanced, such as focus groups studies, analysis of critical incidents, among others, in order to capture richer consumer insights. In this context, word-of-mouth, i.e. the expressions about the service experiences as expressed in the words of the consumers have always been acknowledged as an important source of information, and a key determinant for consumer choice. Generally, it is referred to as an informal and personal form of communication [9] that has been acknowledged by its influence for customers 'decisions [10], being source of trusted information [11]. 
In recent years, the advent of electronic-word of-mouth (eWOM) has created a rich field of data for deepening the understating about consumer experiences. Differently from traditional WOM, the its electronic version eWOM offers the advantage of being preserved, and accessible, over time in a written format that can be revisited and analyzed in detail, with distinct lenses.

The volume and reach of eWOM content have expended enormously, and are increasingly calling for the development of methods and tools that can assist consumers and managers to filter and make sense, in a timely manner of such large and rich amount of information. Consumers are expressing their opinions using multiple sources that include blogs, online reviews, and social networking websites, while interacting virtually to share information about their experiences with all sorts of goods, services, and brands [12]. eWOM has been defined as "any positive or negative statement made by potential, actual or former customers about a product or company, that is made available to a multitude of people and institutions via the internet” ([1], p. 39).

The tourism sector is a prominent example of a setting where eWOM has grown in volume and popularity, notably by means of online reviews that are the concrete examples of electronic versions of traditional WOM and result in a volume of comments from travelers about their experiences, the products, and the services they find along their journeys [13]. eWOM is available for other tourist to read and revisit, as well as for service managers to learn about their experiences. In fact many of the tourism service providers actively encourage their consumers to post reviews on their sites, social media platforms and other sources of reference [14]. The growth in eWOM is motivating increased research attention in several fronts, such as the investigation of the impacts of eWOM on sales, on consumer behavior. In tourism industry the results support that eWOM is considered credible [15], reducing consumers resistance to booking [16] and affects the sales of hotel rooms [17] and the motivations to visit some specific destinations [18]. Despite the growing number of studies that cover, the field is still far from being fully covered, and is still very much concentrated in exploring the behavioral implications of eWOM on travelers [19]. In this study we take a different approach aimed at developing approaches to make sense of the rich information contained in the reviews' texts with the purpose of advancing in the creation of tools to support data analysis and visualization that can assist managers and consumers in extracting valuable information from eWOM sources.

Importance-performance analysis is a popular approach for interpreting customer satisfaction and for setting up priorities for upgrading service quality proposed by [20]. IPA builds on customers' assessments concerning the importance and the performance of quality attributes in order to diagnose areas for improvement- typically using data collected by means of questionnaires employing service scales. IPA offers a plot representation for the measurements for importanceperformance, declared by customers, consisting of a four quadrants matrix. The IPA matrix plots these values against two axes: a vertical axis-for the values of performance of service attributes; and an horizontal axis-for the values of attribute importance (see Figure 1).

Such concise display enables the quick visual identification of what elements demand for managerial improvement actions (i.e. attributes ranked in the quadrant for high importance vs. low performance) as well as others where the providers efforts are potentially misplaced (i.e. attributes ranked in the quadrant for low (customer) importance vs. high (provider) performance).

Subsequent studies have proposed modified approaches building on the principles of the IPA framework, extending its scope of application. For example CIPA, that stands for "Competitive Importance Performance Analysis", is focused on the gaps of the performance of a given service company and that of its competitors, 


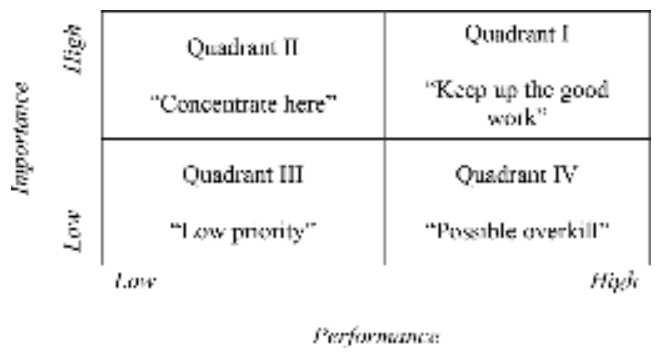

Figure 1.

Quad chart illustrating the breakdown of traditional importance-performance analysis approach. Desirable re-allocation of resources would go from the lower right quadrant to the upper left quadrant. Source: Adapted from Martilla and James [20].

offering a tool to diagnose which competitive attributes demand for improvement. In this adaptation the horizontal axis represents the differences between a company's performance towards the other market players.

Other formulations of IPA aim to address criticisms about its assumptions, namely the independence between the importance and performance measures and the linear relationship between the attributes and the performance. The so-called IPA with the three factor theory employs also a matrix representation for the measurements but takes into account the fact that not all service attributes are equally important for customer satisfaction [21-23]. This approach distinguishes three types of factors: (i) basic factors, i.e. minimum requirements that cause dissatisfaction if not fulfilled while not leading to customer satisfaction if fulfilled; (ii) performance factors, i.e. elements that cause satisfaction or dissatisfaction, depending on their performance level and (iii) excitement factors that can increase customer satisfaction if delivered but do not cause dissatisfaction if not delivered [24]. The modified IPA approach employs this three factor theory [25] and uses estimations of the relative importance of the quality attributes, instead of using customer declared information. The importance-performance lens of analysis therefore offers a versatile methodology for approaching the prioritization of service attributes.

This study builds on prevalent approaches of extending the applications of IPA by developing a modified version of IPA for identifying areas for service improvement building on qualitative data in the context of hotel experiences.

\section{Developing an IPA analysis for eWOM in hotel services}

The main purpose of this work is to develop a flexible and concise methodology to make sense for the ever growing online customer reviews that are available for a wide diversity of service business, in an abundant and unstructured manner. Despite the volume and richness of data available, the ability of both customers and providers to summarize and interpret customer generated content is still very limited and often done ad hoc by managers, therefore hurting its utility and value for customer decision and company improvements. Yet recent research results confirm that such sources of information are increasingly accessed by customers to support purchase decisions [26]. To this end, the study focuses on customer online reviews in the context of the hotel industry for several reasons. Tourism and hospitality services are experiential in nature which makes pre-purchase quality assessments rather difficult, leading customers to search for various clues and information to support their choices. In this context the opinions of other customers assume a critical role. In addition this service industry has a pioneering record in the utilization of online means for customer service interactions (e.g. travel reservations), and for the abundance of eWOM behavior. 


\begin{tabular}{|c|c|c|c|c|c|}
\hline Hotel & $\begin{array}{c}\text { Star } \\
\text { rating }\end{array}$ & Rooms & Location* & Available services & Average price** \\
\hline Moliceiro & 4 & 49 & 0 & 16 & $€ 99$ \\
\hline Aveiro palace & 4 & 49 & 0 & 13 & $€ 62$ \\
\hline Melia Ria & 4 & 128 & $10 \mathrm{~min}$ & 22 & $€ 94$ \\
\hline Américas & 4 & 70 & 5 & 16 & $€ 79$ \\
\hline Imperial & 3 & 107 & 0 & 8 & $€ 63$ \\
\hline Jardim & 3 & 48 & 0 & 11 & $€ 56$ \\
\hline Afonso V & 3 & 78 & 5 & 6 & $€ 49$ \\
\hline Veneza & 3 & 49 & 0 & 7 & $€ 68$ \\
\hline Aveiro center & 2 & 24 & 0 & 8 & $€ 58$ \\
\hline J. Estevão & 2 & 12 & 1 & 6 & $€ 57$ \\
\hline Salinas & 2 & 18 & 0 & 7 & $€ 58$ \\
\hline \multicolumn{6}{|c|}{$\begin{array}{l}\text { Walking time to the city center (minutes). } \\
\text { * Standard double room, average. } \\
\text { The first column contains the hotel name, the second column the official star rating at the time of the study, the third } \\
\text { contains the number of rooms and the fourth the estimated walking time to the city center. The fifth and sixth columns } \\
\text { present the number of services available at the hotel and the average price per night, respectively. }\end{array}$} \\
\hline
\end{tabular}

Table 1.

Characterization of the hotel sample.

The study addresses a sample of customer reviews for a selected number of hotels in a medium sized tourist destination city in Portugal available in the online reservation website Booking.com. The choice of using Booking.com as a source is justified for being the website offering the largest volume of reviews and diversity of customer profiles, and for offering a significant volume of data for all the units in the selected sample of hotels. Data extraction returned a volume of over 5.600 customer reviews, for a set of 11 hotel units (described in Table 1), for a period of 1 year.

The chosen hotel reservation Website exhibits written online customer reviews, organized into groups-positive and negative reviews-as well as a rating obtained from customer scoring. In order to guarantee reliability, i.e. that the reviews resort from individual experiences, the Website only allows for reviews from customer who have effectively made a reservation.

The IPA addresses the data from the sample of extracted customer reviews. The first step in the analysis involves the identification of the most frequent terms and expressions about the hotel experience as stated by customers, for which text mining tools were employed, including a preliminary cleaning of symbols and words with no relevant meaning, and the standardization of terms, whenever synonyms are used to refer to a same hotel service element. The terms and expressions with higher frequency were retained for inclusion in the IPA analysis. A second step involves the identification of dimensions of affinity for the service quality attributes present in customers' statements. This process leads to the identification of three dominant service quality elements, motivating the expression of (positive or negative) customer opinions: room, location and staff. Whereas a more detailed list if attributes can be retained the choice is for the use of a more aggregated level of analysis given the exploratory nature of the study.

The IPA matrix for the 11 hotels is displayed in Figure 2, where the data points for importance-performance for the three salient attributes, room, location and staff are, respectively $\bullet, \boldsymbol{\Delta}$ and ${ }^{*}$. In the traditional IPA the horizontal and vertical axis represent the coordinates for the values of importance, and the performance as perceived by the customers, usually resulting from structured questionnaire 


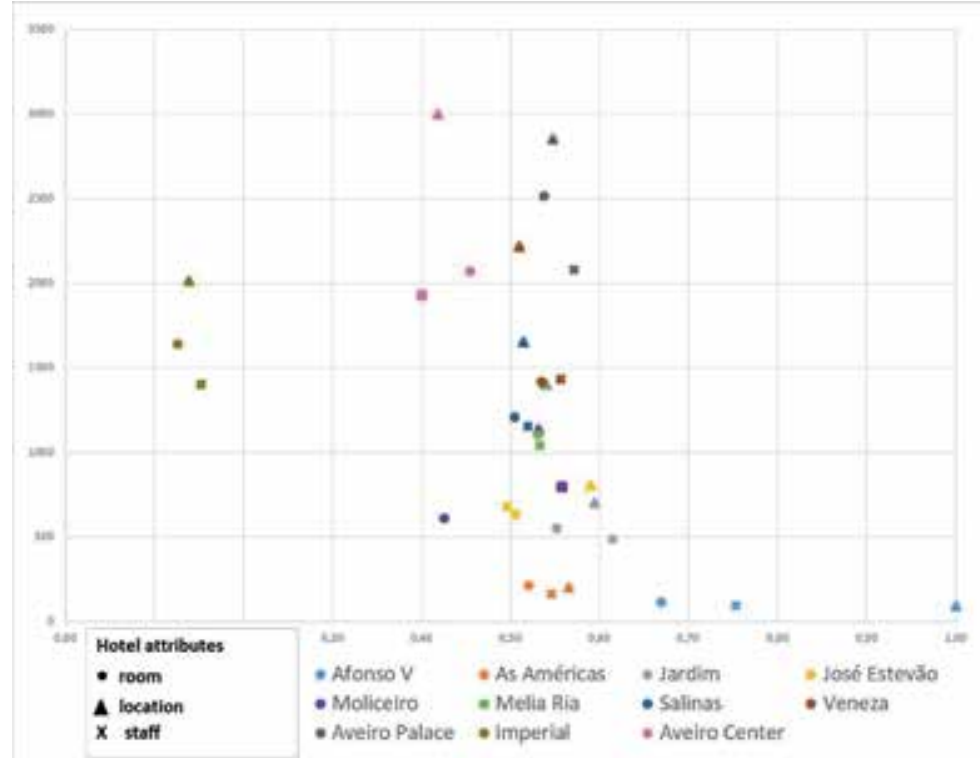

Figure 2.

Modified IPA graph for the hotel sample in the study.

answers, using ordinal scales (e.g. 1-7), where customers sate their expectations (i.e. interpreted as importance) and service perceptions (i.e. experienced performance). In the current study, and given the qualitative nature of the available data-the reviews - the values for the matrix coordinates are obtained as follows.

For each service attribute (room, location and staff) the total frequency (considering all the terms and expressions associated to a given service attribute) is employed as a proxy for the importance of the attribute, therefore assuming, that customers express more opinions for items that are more relevant for their experience. As for performance, the analysis employs the ratio of the number of positive reviews towards the sum of positive and negative comments, for a given service attribute. According to this logic a hotel for which the proportion of positive comments is higher than the negatives corresponds to a positive performance. This proxy measurement for performance therefore varies between 0 (when all comments are negative) and 1 (when all comments are positive). Also, the traditional IPA usually employs a central tendency measure (e.g. mean, median) to split each axis and identify the four quadrants. In the current study the value of the mean is employed to split the plot area.

The interpretation of the IPA graph offers a number of interesting insights. Overall, for each hotel unit, the three service attributes considered in the analysis are closely positioned next to each other. This suggests that when hotel customers are pleased with a hotel, or with the particular performance of one service attribute and they engage in offering positive comments, they tend to be positive about the remaining attributes. Whereas there's some natural dispersion in the points exhibited in Figure 2 most service attributes, for the diverse hotels, is positioned in the quadrants II and IV pointing towards urgent action and resource underutilization, respectively.

Overall the service attributes for the various hotel units are positioned very closely in the IPA map. A look at the positioning of the service attributes (room, location and staff) the one with stronger consistency in customers' opinions is staff, as in $90 \%$ of cases appears as the most important attribute. An opposed pattern is shown for the attribute room, for which customers seem to hold more 


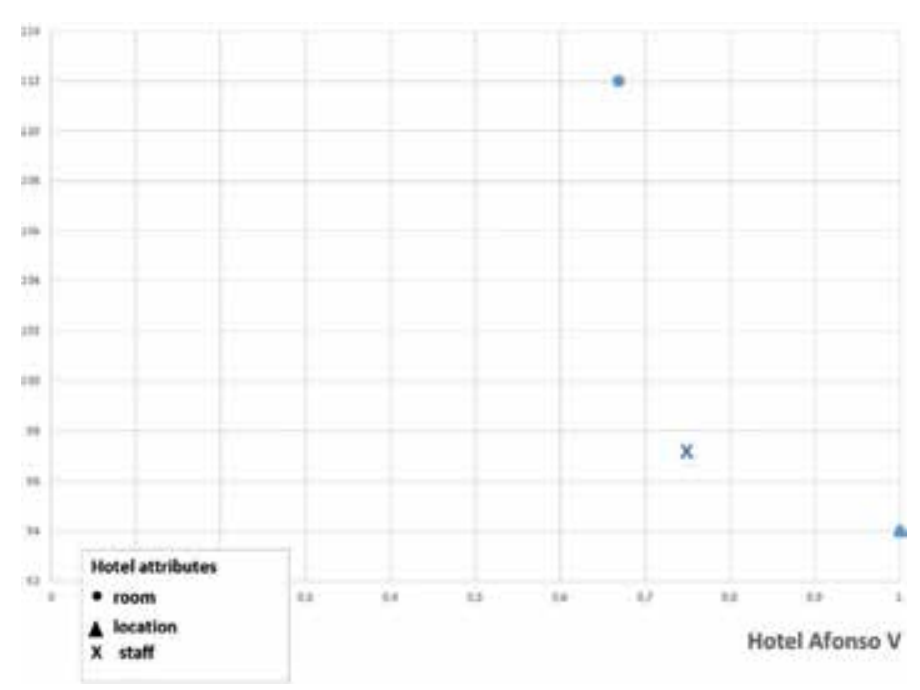

Figure 3.

Modified IPA displaying in detail the positioning of the three salient attributes [room, location and staff] for a single hotel unit (Hotel Afonso V).

heterogeneous opinions about its importance. Overall the data suggests some inconsistency in customers' perceptions about the importance of the service attributes. Of particular interest is the observation that there is a great variability in what regards the number of positive or negative comments. Most of the hotels exhibit a value for the performance measure (i.e. positive comments divided by the sum of positive and negative comments) not very distant from 0.5 , therefore suggesting the existence of some level of service inconsistency across customers, a characteristic that is rather undesirable in service settings. The proposed analysis is susceptible of being conducted at a more fine grained level, i.e. in this case, for each hotel (see for example Figure 3).

\section{Conclusions}

This study, although exploratory and restricted to a small sample of service providers, from a specific service context-hotels_offers an illustrative insight of how existing managerial analytical tools can be adapted to help making sense of large volume of customer generated content. Whereas the study was applied in the context of hotel services, it is clear that the principles of the tool are applicable to any service industry, given that there is some kind of customer content to work with. Customer reviews are proliferating across service websites, platforms and social media contexts, therefore providing an ample and rich field for the development of new approaches to develop knowledge about service quality. The study illustrates that is possible to apply tools to offer a concise and structured view of the content generated by customers in their service reviews, and therefore to extract value from this abundant source of information. The extracted service attributes (room, location and staff) are particular to this study, its context and the limitations of sample selection, not meaning that they are the overall more important in the hotel industry. In order to do so, the study would have to be extended to a wider sample, and account for any conditioning variables (e.g. seasonality, weather, customer experience, etc.). As such this work suggested that there is a vast array of models and tools for assessing service quality that can be called to help make sense of the overwhelming volume of eWOM. 
Building on eWOM to Understand Service Quality in Hotel Services

DOI: http://dx.doi.org/10.5772/intechopen.85403

\section{Author details}

Marlene Amorim ${ }^{1 *}$ and Mário Rodrigues ${ }^{2}$

1 GOVCOPP and DEGEIT, University of Aveiro, Aveiro, Portugal

2 IEETA and ESTGA, University of Aveiro, Aveiro, Portugal

*Address all correspondence to: mamorim@ua.pt

\section{IntechOpen}

(C) 2019 The Author(s). Licensee IntechOpen. This chapter is distributed under the terms of the Creative Commons Attribution License (http://creativecommons.org/licenses/ by/3.0), which permits unrestricted use, distribution, and reproduction in any medium, provided the original work is properly cited. (cc) BY 


\section{References}

[1] Hennig-Thurau T, Gwinner KP, Walsh G, Gremler DD. Electronic word-of-mouth via consumer-opinion platforms: What motivates consumers to articulate themselves on the internet? Journal of Interactive Marketing. 2004;18(1):38-52

[2] Werthner H, Ricci F. E-commerce and tourism. Communications of the ACM. 2004;47(12):101-105

[3] Cronin JJ Jr, Taylor SA. SERVPERF versus SERVQUAL: Reconciling performance-based and perceptionsminus-expectations measurement of service quality. The Journal of Marketing. 1994;58(1):125-131

[4] Seth N, Deshmukh SG, Vrat P. Service quality models: A review. International Journal of Quality and Reliability Management. 2005;22(9):913-949

[5] Parasuraman A, Berry L, Zeithaml VA. Refinement and reassessment of the SERVQUAL scale. Journal of Retailing. 1991;67(4):420-450

[6] Brady MK, Cronin JJ Jr. Some new thoughts on conceptualizing perceived service quality: A hierarchical approach. Journal of Marketing. 2001;65(3):34-49

[7] Grönroos C. The perceived service quality concept-A mistake? Managing Service Quality: An International Journal. 2001;11(3):150-152

[8] Kang GD, James J. Service quality dimensions: An examination of Grönroos's service quality model. Managing Service Quality: An International Journal. 2004;14(4):266-277

[9] Ha Y, Im H. Role of web site design quality in satisfaction and word of mouth generation. Journal of Service Management. 2012;23(1):79-96
[10] Sharma G et al. Communication in virtual world: Second life and business opportunities. Information Systems Frontiers. 2013;15(4):677-694

[11] Allsop DT, Bassett BR, Hoskins JA. Word-of-mouth research: Principles and applications. Journal of Advertising Research. 2007;47(4):398-411

[12] Bronner F, De Hoog R. Vacationers and eWOM: Who posts, and why, where, and what? Journal of Travel Research. 2011;50(1):15-26

[13] Yoo KH, Gretzel U. What motivates consumers to write online travel reviews? Information Technology \& Tourism. 2008;10(4):283-295

[14] Mayzlin D. Promotional chat on the internet. Marketing Science. 2006;25(2):155-164

[15] Dickinger A. The trustworthiness of online channels for experience- and goal-directed search tasks. Journal of Travel Research. 2011;50(4):378-391

[16] Gretzel U, Yoo KH, Purifoy M. Online travel review study: Role and impact of online travel reviews. Austin, TX: Laboratory for Intelligent Systems in Tourism, Texas A\&M University; 2017

[17] Ye Q, Law R, Gu B, Chen W. The influence of user-generated content on traveler behavior: An empirical investigation on the effects of e-Wordof-Mouth to hotel online bookings. Computers in Human Behaviour. 2011;27(2):634-639

[18] Tang LR, Soocheong SJ, Morrison A. Dual route communication of destination website. Tourism Management. 2012;33(3):38-49

[19] Vermeulen IE, Seegers D. Tried and tested: The impact of online hotel reviews on consumer 
consideration. Tourism Management. 2009;30(1):123-127

[20] Martilla JA, James JC. Importanceperformance analysis. The Journal of Marketing. 1977;41(1):77-79

[21] Eskildsen JK, Kristensen K. Enhancing importance-performance analysis. International Journal of Productivity and Performance Management. 2006;55(1):40-60

[22] Bacon DR. A comparison of approaches to importance-performance analysis. International Journal of Market Research. 2003;45(1):55-73

[23] Yavas U, Shemwell DJ. Modified importance-performance analysis: An application to hospitals. International Journal of Health Care Quality Assurance. 2001;14(3):104-110

[24] Matzler K, Bailom F, Hinterhuber HH, Renzl B, Pichler J. The asymmetric relationship between attribute-level performance and overall customer satisfaction: A reconsideration of the importance-Performance analysis. Industrial Marketing Management. 2004;33(4):271-277

[25] Deng WJ, Kuo YF, Chen WC. Revised importance-performance analysis: Three-factor theory and benchmarking. The Service Industries Journal. 2008;28(1):37-51

[26] Ye Q, Law R, Gu B, Chen W. The influence of user-generated content on traveller behavior: An empirical investigation on the effects of e-wordof-mouth to hotel online bookings. Computers in Human Behavior. 2011;27(2):634-639 



\title{
Lifestyle Demographic and Food Label Consumption
}

\author{
Zul Ariff Abdul Latiff
}

\begin{abstract}
The lifestyle aspect can influence people buying intention on food label products and services. This paper is conducted to examine on the lifestyle demographic of consumer that need to be highlighted before consumer come up with the buying decision on food labelling products. Knowing how consumer lifestyle pattern is important in order to gain information on food label products about what they most preferred in purchasing the products or services. Furthermore, this study also helps in fulfilling the national agenda in Malaysia National Agro Food Policies 2011-2020. Hence 200 respondents were given a structured questionnaire to know the lifestyle aspect in consumer behaviour of food label consumption the result of this study shows that attitude and awareness of consumer play a crucial role in deciding the food labelling products that contains nutritious, healthy and most important is halal certificate. The major finding shows there are different awareness and attitude of consumers on food labelling towards buying decision when they are in the different of lifestyle aspect. In addition result also shows that consumers are concern about the quality, safety, and nutritional content of food labelling on food products enable to obtain healthy lifestyles.
\end{abstract}

Keywords: lifestyle, attitude, knowledge and awareness, religious awareness, health consciousness, environmental activist and consumer

\section{Introduction}

The pattern of lifestyle nowadays has reflected on the image of someone or public life. Knowing the personal habits of someone like what individual love or what they do not like will cause someone to have lifestyle based on what they want and need which can give full satisfaction to the users. People currently love own lifestyle to meet the expectation towards products or service rather than copying or followed others lifestyle. This is because individual are already in comfort zone. The consumer behaviour towards food label consumption is one of the lifestyle patterns. Majority of public is concern about food label before deciding to purchase or buy the products and services. Therefore, the lifestyle aspect in consumer behaviour of food label can enhance and influence someone on making buying decision. The awareness and knowledge and attitude might be reflected to the lifestyle aspect. The different lifestyle aspect of consumers means that they are having different awareness and knowledge as well as attitude towards food labelling products. The Food and Drug Administration recognizes the importance of food labelling as a vehicle for dietary messages and, produce guidelines to the users in order to maintain the integrity of the food label. As food labels is one of key element, the upgrading of 
fool labels is compulsory in making them more effective and easier to understand, the Food and Drug Administration considers what information will be most useful for consumers to make right decision. Harold W. Berkman and Christopher Gilson [1] define lifestyle as 'unified' patterns of behaviour that both determine and are determined by consumption. The term 'unified patterns of behaviour' refers to behaviour in its broadest sense.

\section{Literature review}

Lifestyle aspect in consumer behaviour of food label consumption in determining and deciding what should buy or what should not buy is very important part because it can generate level of satisfaction if the consumers know what to buy especially by looking and depending on food label. The Marketing Dictionary of Rona Ostrow and Sweetman R. Smith [2] describes lifestyle as 'a distinctive mode of behaviour centred around activities, interests, opinions, attitudes and demographic characteristics distinguishing one segment of a population from another. Lifestyle marketing is a process of establishing relationships between products offered in the market and targeted lifestyle groups [3]. This shows lifestyle aspect can be highlighted as a vital before come up with the purchasing decision. Modern theory gives the definition of lifestyle as a summary construct defined as patterns in which people live and spend time and money [4]. In order to describe lifestyle, it is important to know the demographics characteristics in the market segment. The demographics characteristics that need to be concerned are gender, age, income and occupation. There are three elements of lifestyle that give impact in considering food label which are health consciousness, environmental activist, and religious awareness.

\subsection{Health consciousness}

People with more available time for grocery shopping have been found to be more likely to be classified as label users. It also appears that consumers who are more concerned about nutrition and health are more likely to use nutritional labels. Consequently, consumers on a special diet, organic buyers, and those aware of the diet-disease relation are more likely to search for on-pack nutrition information than others [5]. The regulatory environment of some countries (e.g. the USA, Australia, etc.) has also recognized the potential of standardized on-pack regarding nutrition information available and has mandated the presence of nutritional labels on all processed food products. This health consciousness will help consumer to choose food that contain nutrition label rather than pick up food or products contain high chemical.

\subsection{Environmental activist}

Consumers are expected to double their spending on 'green' products, reaching $\$ 500$ billion in 2009 [6], and many consumers state that they are willing to pay a price premium for these products [7]. Environment information on food label may represented by a local such as eco-friendly and green food. This environment label also can be recognized by organic ingredients. Consumer who environmental friendly usually intended to purchase products of food that free from preservative ingredients. The quality of environment can be improved when people choose to buy organic food. Environmental information on products can be presented on a continuum that ranges from simple symbols, to colour codes to other labels with basic information and to detailed environmental information about single or multiple product ingredients [8]. 


\subsection{Religious awareness}

The food label that has halal logo plays important role for consumer especially Muslim. This logo helps consumers to buy food or products confidently. According to Burgmann [9], the halal growth status can be linked to religion and beliefs which means it is cleaner, healthier, and tastier. Sumali [10] stated that manufacturers and producers who manage to obtain the halal products certification by Jabatan Kemajuan Islam Malaysia (JAKIM) are providing the consumers assurance the ingredients that has been use in processing, preparation, hygienic, and cleanliness procedures complying with the halal requirement and are consistent with HACCP and other quality assurance standards. The religious awareness gives a great impact to those who put their religion as first priority especially Muslim consumer. For Muslim consumers, confidence in Halal food relates to the ways of production, processing, and handling food along with safety in terms of wholesomeness [11]. In Malaysia's food industry, food status especially involving Halal status is one of the prime area that has potential to leverage this technology. This is simply because the Malaysian Muslim consumers' are very much concern about the authenticity of Halal food products claimed by food producers [12]. This shows that the religious awareness in food label becomes one of the important aspects in creating consumer buying intention.

These three elements can be link and recognized after knowing the consumers awareness and knowledge as well as attitude towards food label. These elements also represent that the consumers have different awareness and knowledge as well as attitude when they are in different lifestyle aspect which are health consciousness, environmental activist and religious awareness. Attitude can be defined as an individual's overall evaluations of the behaviour as positive or negative [13]. While awareness and knowledge is refer to the knowing that something (such as a situation, condition, or problem), exists feeling, experiencing, or noticing something (such as sound, sensation or emotion), knowing and understanding or having knowledge about what is happening in the world or around community.

\section{Methodology}

The research methods used for this thesis are includes survey questionnaire design, the sample and method of data analysis. The sample for this study is random sampling where 200 respondents were given a structured questionnaire to know the lifestyle aspect in consumer behaviour of food label consumption. The questionnaire of this study is more focus on lifestyle aspect in consumer behaviour of consumption on deciding to purchase the food with labelling or not. By using this questionnaire, the study can know the relationship between the lifestyle aspect with the awareness and attitude that can influence buying decision of food with labelling. The different awareness and knowledge and attitude influence the lifestyle aspect by using the questionnaire. The questionnaire was divided into three sections which include socio-demographic characteristics like gender, residential area, age, marital status, education, occupation, religion, income and lifestyle aspect in Section A. Whereas in Section B focus on awareness and knowledge and the third section is Section C focus on attitude. Both of the Sections B and C were intended to measure the relationship between lifestyle aspect which are health consciousness, environmental activist and religious awareness with the awareness and the attitude towards food label before deciding to purchase the products. These sections also allow the study in knowing the different awareness and attitude bring different lifestyle aspect. 


\subsection{Method of analysis}

The data collected was analysed using SPSS. This study use one-way ANOVA to know about the differences of lifestyle aspects like health consciousness, environmental activist and religious awareness in purchasing products with labelling by using awareness and knowledge as well as attitude of consumers towards food label. Here, the data can show whether there is a relationship between lifestyle aspect with the awareness and knowledge as well as attitude of consumers towards food labelling products. And by having this data, the result obtained can show whether the objective of the study can be achieved or not. Factor analysis is used in collecting data in order to know the total variance explained and Kaiser Meyer Olkin (KMO) to measure the strength of relationship among the variables.

\section{Result}

Socio demographic information is consists of gender, marital status, education, race, occupation, religion and life style. The socio demographic information is as Table 1.

This table indicates the respondents' profile. The highest respondents for this study are female with the percentage of $52 \%$. While for the race, the highest is male which $62.5 \%$. The marital status show married is the highest respondents which contribute the percentage value of $64.5 \%$. The next is education level. There is an equal amount of education level from bachelor and postgraduate which is $28 \%$. The highest type of occupation is come from public sector that is $48.5 \%$. The lowest amount of percentage in term or religion is Hindu which is $6.4 \%$. The lifestyles of the respondents are concerning on religious awareness that can be represented by the percentage of $42 \%$ which is the highest percentage from this lifestyles aspect. This socio demographic can help this study to know about the characteristic and profile of the population sample.

The descriptive (Table 2) in one-way ANOVA shows the result that provides some very useful descriptive statistics, including the mean, standard deviation and $95 \%$ confidence intervals for the dependent variables. The descriptive table shows how many consumers concerns in terms of awareness and knowledge and attitude that can lead to the lifestyle aspect of environmental activist, health consciousness and religious awareness. Each of the questions show those consumers choose depending on their awareness and knowledge and attitude towards their lifestyles aspect.

This below result shows the awareness and knowledge section can influence consumer lifestyle aspect in deciding to purchase products with label. This descriptive table shows the number of consumer which has different awareness and knowledge that influence and lead to the different lifestyle aspect.

Table 3 shows the results obtained from different attitude of consumer which can influence and lead to the different lifestyle aspect.

This above results shows how important knowledge and awareness and attitude which can link to lifestyle aspect of consumer by using food label in deciding what to buy or purchase.

To know the different exist between awareness and knowledge and attitude towards lifestyle aspect, the F-ratio with an F-profitability values need to less than 0.05 . The less of 0.05 results shows the significant value. The ANOVA table can show the output of the ANOVA analysis and whether results have a statistically significant value or not. 
Lifestyle Demographic and Food Label Consumption

DOI: $h$ ttp://dx.doi.org/10.5772/intechopen.86022

\begin{tabular}{|c|c|c|}
\hline Characteristics & Frequency & Percentage (\%) \\
\hline \multicolumn{3}{|l|}{ Gender } \\
\hline Male & 96 & 48.0 \\
\hline Female & 104 & 52.0 \\
\hline \multicolumn{3}{|l|}{ Race } \\
\hline Malay & 125 & 62.5 \\
\hline Indian & 21 & 10.5 \\
\hline Chinese & 47 & 23.5 \\
\hline Missing & 7 & 3.5 \\
\hline \multicolumn{3}{|l|}{ Education } \\
\hline Secondary & 34 & 17 \\
\hline Diploma & 54 & 27 \\
\hline Bachelor & 56 & 28 \\
\hline Postgraduate & 56 & 28 \\
\hline \multicolumn{3}{|l|}{ Marital status } \\
\hline Married & 129 & 64.5 \\
\hline Single & 71 & 35.5 \\
\hline \multicolumn{3}{|l|}{ Occupation } \\
\hline Public sector & 97 & 48.5 \\
\hline Private sector & 87 & 43.5 \\
\hline Self-employed & 4 & 7.0 \\
\hline Retired & 2 & 1.0 \\
\hline \multicolumn{3}{|l|}{ Religion } \\
\hline Islam & 133 & 66.5 \\
\hline Christian & 14 & 7.0 \\
\hline Buddhist & 40 & 20.0 \\
\hline Hindu & 13 & 6.5 \\
\hline \multicolumn{3}{|l|}{ Lifestyles } \\
\hline Physical activity & 49 & 24.5 \\
\hline Environmental activist & 15 & 7.5 \\
\hline Health consciousness & 52 & 26.0 \\
\hline Religious awareness & 84 & 42.0 \\
\hline
\end{tabular}

Table 1.

Socio-demographic profile of the respondents $(n=200)$.

All the results in Tables $\mathbf{3}$ and $\mathbf{4}$ show that there are differences between lifestyles aspect which influenced by the different awareness and knowledge and attitude as the results above state that the awareness and knowledge and attitude have significantly influence the different lifestyle aspect. This is because all the values are less than 0.05 which is $(\mathrm{p}<0.05)$.

For the factor analysis, the awareness and knowledge results show minimum adequacy as it is 0.524 which means the amount of it is barely accepted. According to Fen and Sabaruddin [14] and Hair et al. [15], to have a statistical significant of factor analysis, factor loadings must greater than 0.50 . There is a relationship between 


\begin{tabular}{|c|c|c|c|c|c|c|c|c|c|}
\hline & & \multirow[t]{2}{*}{$\mathbf{N}$} & \multirow[t]{2}{*}{ Mean } & \multirow[t]{2}{*}{$\begin{array}{c}\text { Std. } \\
\text { deviation }\end{array}$} & \multirow[t]{2}{*}{$\begin{array}{l}\text { Std. } \\
\text { error }\end{array}$} & \multicolumn{2}{|c|}{$\begin{array}{c}95 \% \text { Confidence } \\
\text { interval for } \\
\text { mean }\end{array}$} & \multirow[t]{2}{*}{ Minimum } & \multirow[t]{2}{*}{ Maximum } \\
\hline & & & & & & $\begin{array}{l}\text { Lower } \\
\text { bound }\end{array}$ & $\begin{array}{l}\text { Upper } \\
\text { bound }\end{array}$ & & \\
\hline \multirow[t]{4}{*}{ PB1 } & $\begin{array}{l}\text { Environmental } \\
\text { activist }\end{array}$ & 15 & 6.20 & 1.373 & 0.355 & 5.44 & 6.96 & 4 & 7 \\
\hline & $\begin{array}{c}\text { Health } \\
\text { consciousness }\end{array}$ & 52 & 5.00 & 1.804 & 0.250 & 4.50 & 5.50 & 1 & 7 \\
\hline & $\begin{array}{l}\text { Religious } \\
\text { awareness }\end{array}$ & 84 & 6.48 & 1.275 & 0.139 & 6.20 & 6.75 & 1 & 7 \\
\hline & Total & 200 & 5.88 & 1.621 & 0.115 & 5.65 & 6.11 & 1 & 7 \\
\hline \multirow[t]{4}{*}{ CA9 } & $\begin{array}{c}\text { Environmental } \\
\text { activist }\end{array}$ & 15 & 6.27 & 0.884 & 0.228 & 5.78 & 6.76 & 5 & 7 \\
\hline & $\begin{array}{c}\text { Health } \\
\text { consciousness }\end{array}$ & 52 & 5.90 & 1.107 & 0.154 & 5.60 & 6.21 & 3 & 7 \\
\hline & $\begin{array}{c}\text { Religious } \\
\text { awareness }\end{array}$ & 84 & 6.50 & 0.736 & 0.080 & 6.34 & 6.66 & 4 & 7 \\
\hline & Total & 200 & 6.25 & 0.965 & 0.068 & 6.12 & 6.38 & 3 & 7 \\
\hline \multirow[t]{4}{*}{ Ingredient } & $\begin{array}{c}\text { Environmental } \\
\text { activist }\end{array}$ & 15 & 3.80 & 3.098 & 0.800 & 2.08 & 5.52 & 1 & 7 \\
\hline & $\begin{array}{c}\text { Health } \\
\text { consciousness }\end{array}$ & 52 & 6.42 & 1.786 & 0.248 & 5.93 & 6.92 & 1 & 7 \\
\hline & $\begin{array}{c}\text { Religious } \\
\text { awareness }\end{array}$ & 84 & 5.64 & 2.525 & 0.276 & 5.09 & 6.19 & 1 & 7 \\
\hline & Total & 200 & 5.83 & 2.383 & 0.169 & 5.50 & 6.16 & 1 & 7 \\
\hline \multirow[t]{4}{*}{ Nutritional } & $\begin{array}{l}\text { Environmental } \\
\text { activist }\end{array}$ & 15 & 5.73 & 2.052 & 0.530 & 4.60 & 6.87 & 1 & 7 \\
\hline & $\begin{array}{c}\text { Health } \\
\text { consciousness }\end{array}$ & 52 & 6.00 & 1.597 & 0.221 & 5.56 & 6.44 & 1 & 7 \\
\hline & $\begin{array}{c}\text { Religious } \\
\text { awareness }\end{array}$ & 84 & 4.98 & 2.313 & 0.252 & 4.47 & 5.48 & 1 & 7 \\
\hline & Total & 200 & 5.35 & 2.135 & 0.151 & 5.05 & 5.64 & 1 & 7 \\
\hline \multirow[t]{4}{*}{ Halal } & $\begin{array}{c}\text { Environmental } \\
\text { activist }\end{array}$ & 15 & 6.20 & 2.111 & 0.545 & 5.03 & 7.37 & 1 & 7 \\
\hline & $\begin{array}{c}\text { Health } \\
\text { consciousness }\end{array}$ & 52 & 4.02 & 2.697 & 0.374 & 3.27 & 4.77 & 1 & 7 \\
\hline & $\begin{array}{l}\text { Religious } \\
\text { awareness }\end{array}$ & 84 & 5.29 & 2.623 & 0.286 & 4.72 & 5.85 & 1 & 7 \\
\hline & Total & 200 & 4.91 & 2.644 & 0.187 & 4.54 & 5.27 & 1 & 7 \\
\hline \multirow[t]{4}{*}{ Health } & $\begin{array}{c}\text { Environmental } \\
\text { activist }\end{array}$ & 15 & 4.27 & 2.840 & 0.733 & 2.69 & 5.84 & 1 & 7 \\
\hline & $\begin{array}{c}\text { Health } \\
\text { consciousness }\end{array}$ & 52 & 6.27 & 1.300 & 0.180 & 5.91 & 6.63 & 1 & 7 \\
\hline & $\begin{array}{c}\text { Religious } \\
\text { awareness }\end{array}$ & 84 & 5.24 & 2.171 & 0.237 & 4.77 & 5.71 & 1 & 7 \\
\hline & Total & 200 & 5.50 & 2.059 & 0.146 & 5.21 & 5.79 & 1 & 7 \\
\hline
\end{tabular}




\begin{tabular}{|c|c|c|c|c|c|c|c|c|c|}
\hline & & \multirow[t]{2}{*}{$\mathbf{N}$} & \multirow[t]{2}{*}{ Mean } & \multirow[t]{2}{*}{$\begin{array}{c}\text { Std. } \\
\text { deviation }\end{array}$} & \multirow[t]{2}{*}{$\begin{array}{l}\text { Std. } \\
\text { error }\end{array}$} & \multicolumn{2}{|c|}{$\begin{array}{l}\text { 95\% Confidence } \\
\text { interval for } \\
\text { mean }\end{array}$} & \multirow[t]{2}{*}{ Minimum } & \multirow[t]{2}{*}{ Maximum } \\
\hline & & & & & & $\begin{array}{l}\text { Lower } \\
\text { bound }\end{array}$ & $\begin{array}{l}\text { Upper } \\
\text { bound }\end{array}$ & & \\
\hline \multirow[t]{4}{*}{ Television } & $\begin{array}{l}\text { Environmental } \\
\text { activist }\end{array}$ & 15 & 4.73 & 1.486 & 0.384 & 3.91 & 5.56 & 1 & 6 \\
\hline & $\begin{array}{c}\text { Health } \\
\text { consciousness }\end{array}$ & 52 & 5.02 & 1.163 & 0.161 & 4.70 & 5.34 & 1 & 7 \\
\hline & $\begin{array}{l}\text { Religious } \\
\text { awareness }\end{array}$ & 84 & 4.46 & 1.571 & 0.171 & 4.12 & 4.81 & 1 & 7 \\
\hline & Total & 200 & 4.79 & 1.427 & 0.101 & 4.59 & 4.99 & 1 & 7 \\
\hline \multirow[t]{4}{*}{$\begin{array}{l}\text { Family } \\
\text { members }\end{array}$} & $\begin{array}{c}\text { Environmental } \\
\text { activist }\end{array}$ & 15 & 4.73 & 1.223 & 0.316 & 4.06 & 5.41 & 2 & 7 \\
\hline & $\begin{array}{c}\text { Health } \\
\text { consciousness }\end{array}$ & 52 & 5.21 & 1.319 & 0.183 & 4.84 & 5.58 & 2 & 7 \\
\hline & $\begin{array}{l}\text { Religious } \\
\text { awareness }\end{array}$ & 84 & 4.52 & 1.668 & 0.182 & 4.16 & 4.89 & 2 & 7 \\
\hline & Total & 200 & 4.89 & 1.514 & 0.107 & 4.67 & 5.10 & 2 & 7 \\
\hline \multirow[t]{4}{*}{ Bill board } & $\begin{array}{c}\text { Environmental } \\
\text { activist }\end{array}$ & 15 & 4.60 & 1.404 & 0.363 & 3.82 & 5.38 & 2 & 7 \\
\hline & $\begin{array}{c}\text { Health } \\
\text { consciousness }\end{array}$ & 52 & 3.69 & 1.766 & 0.245 & 3.20 & 4.18 & 1 & 7 \\
\hline & $\begin{array}{l}\text { Religious } \\
\text { awareness }\end{array}$ & 84 & 3.57 & 1.638 & 0.179 & 3.22 & 3.93 & 1 & 7 \\
\hline & Total & 200 & 3.91 & 1.705 & 0.121 & 3.67 & 4.15 & 1 & 7 \\
\hline \multirow{4}{*}{$\begin{array}{l}\text { Do you } \\
\text { always } \\
\text { check halal } \\
\text { logo before } \\
\text { purchasing } \\
\text { food } \\
\text { products? }\end{array}$} & $\begin{array}{l}\text { Environmental } \\
\text { activist }\end{array}$ & 15 & 1.27 & 0.458 & 0.118 & 1.01 & 1.52 & 1 & 2 \\
\hline & $\begin{array}{c}\text { Health } \\
\text { consciousness }\end{array}$ & 52 & 1.56 & 0.502 & 0.070 & 1.42 & 1.70 & 1 & 2 \\
\hline & $\begin{array}{l}\text { Religious } \\
\text { awareness }\end{array}$ & 84 & 1.11 & 0.311 & 0.034 & 1.04 & 1.17 & 1 & 2 \\
\hline & Total & 200 & 1.29 & 0.455 & 0.032 & 1.23 & 1.35 & 1 & 2 \\
\hline
\end{tabular}

Table 2.

Descriptives.

lifestyles aspect with them as SPSS shows that the Bartlett test of sphericity is significant when the value is 0 . This factor analysis can determine the relationship between lifestyle aspect with the awareness and knowledge. This can be proved in Table 5 .

But the total variance explained shows the result in vice versa. Total variance explained stated that the higher the percentage of variance a proposed model manages to explain, the more valid the model seems to be. Table 6 shows the result of total variance explained. The result below come up with the percentage of 29.223 from total variance explained. According to Salman and Siddiqui [16], the factors with the variance explained less than $50 \%$ were figured as not significant. Hence, the model is not valid for this study.

However the result from attitude segment shows there is a link and relationship between lifestyles aspect as the Bartlett test of sphericity is significant when 
ANOVA

\begin{tabular}{|c|c|c|c|c|c|c|}
\hline & & $\begin{array}{l}\text { Sum of } \\
\text { squares }\end{array}$ & df & $\begin{array}{c}\text { Mean } \\
\text { square }\end{array}$ & F & Sig. \\
\hline \multirow[t]{3}{*}{ PB1 } & $\begin{array}{c}\text { Between } \\
\text { groups }\end{array}$ & 73.359 & 3 & 24.453 & 10.656 & 0.000 \\
\hline & $\begin{array}{l}\text { Within } \\
\text { groups }\end{array}$ & 449.761 & 196 & 2.295 & & \\
\hline & Total & 523.120 & 199 & & & \\
\hline \multirow[t]{3}{*}{ CA9 } & $\begin{array}{c}\text { Between } \\
\text { groups }\end{array}$ & 11.700 & 3 & 3.900 & 4.398 & 0.005 \\
\hline & $\begin{array}{l}\text { Within } \\
\text { groups }\end{array}$ & 173.800 & 196 & 0.887 & & \\
\hline & Total & 185.500 & 199 & & & \\
\hline \multirow[t]{3}{*}{ Ingredient } & $\begin{array}{c}\text { Between } \\
\text { groups }\end{array}$ & 87.842 & 3 & 29.281 & 5.506 & 0.001 \\
\hline & $\begin{array}{l}\text { Within } \\
\text { groups }\end{array}$ & 1042.378 & 196 & 5.318 & & \\
\hline & Total & 1130.220 & 199 & & & \\
\hline \multirow[t]{3}{*}{ Nutritional } & $\begin{array}{l}\text { Between } \\
\text { groups }\end{array}$ & 37.615 & 3 & 12.538 & 2.826 & 0.040 \\
\hline & $\begin{array}{l}\text { Within } \\
\text { groups }\end{array}$ & 869.580 & 196 & 4.437 & & \\
\hline & Total & 907.195 & 199 & & & \\
\hline \multirow[t]{3}{*}{ Halal } & $\begin{array}{l}\text { Between } \\
\text { groups }\end{array}$ & 78.712 & 3 & 26.237 & 3.918 & 0.010 \\
\hline & $\begin{array}{l}\text { Within } \\
\text { groups }\end{array}$ & 1312.483 & 196 & 6.696 & & \\
\hline & Total & 1391.195 & 199 & & & \\
\hline \multirow[t]{3}{*}{ Health } & $\begin{array}{l}\text { Between } \\
\text { groups }\end{array}$ & 59.353 & 3 & 19.784 & 4.942 & 0.002 \\
\hline & $\begin{array}{l}\text { Within } \\
\text { groups }\end{array}$ & 784.647 & 196 & 4.003 & & \\
\hline & Total & 844.000 & 199 & & & \\
\hline \multirow[t]{3}{*}{ Television } & $\begin{array}{l}\text { Between } \\
\text { groups }\end{array}$ & 17.108 & 3 & 5.703 & 2.880 & 0.037 \\
\hline & $\begin{array}{l}\text { Within } \\
\text { groups }\end{array}$ & 388.072 & 196 & 1.980 & & \\
\hline & Total & 405.180 & 199 & & & \\
\hline \multirow[t]{3}{*}{ Family members } & $\begin{array}{c}\text { Between } \\
\text { groups }\end{array}$ & 21.837 & 3 & 7.279 & 3.283 & 0.022 \\
\hline & $\begin{array}{l}\text { Within } \\
\text { groups }\end{array}$ & 434.518 & 196 & 2.217 & & \\
\hline & Total & 456.355 & 199 & & & \\
\hline \multirow[t]{3}{*}{ Bill board } & $\begin{array}{l}\text { Between } \\
\text { groups }\end{array}$ & 36.887 & 3 & 12.296 & 4.451 & 0.005 \\
\hline & $\begin{array}{l}\text { Within } \\
\text { groups }\end{array}$ & 541.493 & 196 & 2.763 & & \\
\hline & Total & 578.380 & 199 & & & \\
\hline
\end{tabular}




\begin{tabular}{lcccccc}
\hline \multicolumn{7}{c}{ ANOVA } \\
\hline & \multicolumn{7}{c}{$\begin{array}{c}\text { Sum of } \\
\text { squares }\end{array}$} & df & $\begin{array}{c}\text { Mean } \\
\text { square }\end{array}$ & F & Sig. \\
\hline $\begin{array}{l}\text { Do you always check halal logo } \\
\text { before purchasing food products? }\end{array}$ & $\begin{array}{l}\text { Between } \\
\text { groups }\end{array}$ & 6.609 & 3 & 2.203 & 12.489 & 0.000 \\
\cline { 2 - 7 } & $\begin{array}{l}\text { Within } \\
\text { groups }\end{array}$ & 34.571 & 196 & 0.176 & \\
\cline { 2 - 7 } & Total & 41.180 & 199 & & \\
\hline
\end{tabular}

Table 3.

Awareness and knowledge.

\begin{tabular}{|c|c|c|c|c|c|c|}
\hline \multicolumn{7}{|c|}{ ANOVA } \\
\hline & & $\begin{array}{l}\text { Sum of } \\
\text { squares }\end{array}$ & df & $\begin{array}{l}\text { Mean } \\
\text { square }\end{array}$ & F & Sig. \\
\hline \multirow[t]{3}{*}{ Ing2 } & $\begin{array}{l}\text { Between } \\
\text { groups }\end{array}$ & 23.304 & 3 & 7.768 & 7.549 & 0.000 \\
\hline & $\begin{array}{l}\text { Within } \\
\text { groups }\end{array}$ & 201.691 & 196 & 1.029 & & \\
\hline & Total & 224.995 & 199 & & & \\
\hline \multirow[t]{3}{*}{ Ing3 } & $\begin{array}{l}\text { Between } \\
\text { groups }\end{array}$ & 20.127 & 3 & 6.709 & 10.354 & 0.000 \\
\hline & $\begin{array}{l}\text { Within } \\
\text { groups }\end{array}$ & 126.993 & 196 & 0.648 & & \\
\hline & Total & 147.120 & 199 & & & \\
\hline \multirow[t]{3}{*}{ Ing4 } & $\begin{array}{l}\text { Between } \\
\text { groups }\end{array}$ & 8.070 & 3 & 2.690 & 3.920 & 0.010 \\
\hline & $\begin{array}{l}\text { Within } \\
\text { groups }\end{array}$ & 134.485 & 196 & 0.686 & & \\
\hline & Total & 142.555 & 199 & & & \\
\hline \multirow[t]{3}{*}{ Ing7 } & $\begin{array}{l}\text { Between } \\
\text { groups }\end{array}$ & 23.561 & 3 & 7.854 & 10.276 & 0.000 \\
\hline & $\begin{array}{l}\text { Within } \\
\text { groups }\end{array}$ & 149.794 & 196 & 0.764 & & \\
\hline & Total & 173.355 & 199 & & & \\
\hline \multirow[t]{3}{*}{ PB2 } & $\begin{array}{l}\text { Between } \\
\text { groups }\end{array}$ & 15.400 & 3 & 5.133 & 3.523 & 0.016 \\
\hline & $\begin{array}{l}\text { Within } \\
\text { groups }\end{array}$ & 285.595 & 196 & 1.457 & & \\
\hline & Total & 300.995 & 199 & & & \\
\hline \multirow[t]{3}{*}{$\begin{array}{l}\text { The well-known brand of } \\
\text { manufactured foods are worthy }\end{array}$} & $\begin{array}{l}\text { Between } \\
\text { groups }\end{array}$ & 12.912 & 3 & 4.304 & 2.863 & 0.038 \\
\hline & $\begin{array}{l}\text { Within } \\
\text { groups }\end{array}$ & 294.683 & 196 & 1.503 & & \\
\hline & Total & 307.595 & 199 & & & \\
\hline
\end{tabular}

Table 4.

Attitude. 


\begin{tabular}{lcc}
\hline Kaiser-Meyer-Olkin measure of sampling adequacy & & 0.524 \\
\hline Bartlett's test of sphericity & $\begin{array}{c}\text { Approx. } \\
\text { Chi-Square }\end{array}$ & 54.721 \\
\cline { 2 - 3 } & $\mathrm{df}$ & 10 \\
\cline { 2 - 3 } & Sig. & 0.000 \\
\hline
\end{tabular}

Table 5.

KMO and Bartlett's test.

\begin{tabular}{lccccccccc}
\hline Factor & \multicolumn{3}{c}{ Initial eigenvalues } & \multicolumn{2}{c}{$\begin{array}{c}\text { Extraction sums of squared } \\
\text { loadings }\end{array}$} & \multicolumn{2}{c}{ Rotation sums of squared loadings } \\
\cline { 2 - 9 } & Total & $\begin{array}{c}\text { \% of } \\
\text { Variance }\end{array}$ & $\begin{array}{c}\text { Cumulative } \\
\%\end{array}$ & Total & $\begin{array}{c}\% \text { of } \\
\text { Variance }\end{array}$ & $\begin{array}{c}\text { Cumulative } \\
\%\end{array}$ & Total & $\begin{array}{c}\text { \% of } \\
\text { Variance }\end{array}$ & Cumulative \% \\
\hline 1 & 1.436 & 28.727 & 28.727 & 0.879 & 17.576 & 17.576 & 0.879 & 17.576 & 17.576 \\
\hline 2 & 1.336 & 26.723 & 55.450 & 0.582 & 11.647 & 29.223 & 0.582 & 11.647 & 29.223 \\
\hline 3 & 0.887 & 17.743 & 73.193 & & & & & & \\
\hline 4 & 0.738 & 14.755 & 87.948 & & & & & & \\
\hline 5 & 0.603 & 12.052 & 100.000 \\
\hline
\end{tabular}

Table 6.

Total variance explained.

\begin{tabular}{lcc}
\hline Kaiser-Meyer-Olkin measure of sampling adequacy & & 0.848 \\
\hline Bartlett's test of Sphericity & $\begin{array}{c}\text { Approx. } \\
\text { chi-square }\end{array}$ & 948.520 \\
\cline { 2 - 3 } & $\mathrm{df}$ & 55 \\
\cline { 2 - 3 }
\end{tabular}

Table 7.

KMO and Bartlett's test.

\begin{tabular}{|c|c|c|c|c|c|c|c|c|c|}
\hline \multirow[t]{2}{*}{ Factor } & \multicolumn{3}{|c|}{ Initial eigenvalues } & \multicolumn{3}{|c|}{$\begin{array}{c}\text { Extraction sums of squared } \\
\text { loadings }\end{array}$} & \multicolumn{3}{|c|}{$\begin{array}{c}\text { Rotation sums of squared } \\
\text { loadings }\end{array}$} \\
\hline & Total & $\begin{array}{c}\% \text { of } \\
\text { Variance }\end{array}$ & $\begin{array}{c}\text { Cumulative } \\
\%\end{array}$ & Total & $\begin{array}{c}\% \text { of } \\
\text { Variance }\end{array}$ & $\begin{array}{c}\text { Cumulative } \\
\%\end{array}$ & Total & $\begin{array}{c}\% \text { of } \\
\text { Variance }\end{array}$ & $\begin{array}{c}\text { Cumulative } \\
\%\end{array}$ \\
\hline 1 & 4.606 & 41.872 & 41.872 & 4.215 & 38.316 & 38.316 & 4.131 & 37.555 & 37.555 \\
\hline 2 & 1.540 & 14.000 & 55.872 & 1.081 & 9.824 & 48.140 & 1.007 & 9.153 & 46.708 \\
\hline 3 & 1.222 & 11.107 & 66.979 & 0.688 & 6.255 & 54.394 & 0.845 & 7.686 & 54.394 \\
\hline 4 & 0.838 & 7.620 & 74.599 & & & & & & \\
\hline 5 & 0.606 & 5.505 & 80.104 & & & & & & \\
\hline 6 & 0.579 & 5.259 & 85.363 & & & & & & \\
\hline 7 & 0.444 & 4.032 & 89.395 & & & & & & \\
\hline 8 & 0.376 & 3.417 & 92.812 & & & & & & \\
\hline 9 & 0.305 & 2.770 & 95.583 & & & & & & \\
\hline 10 & 0.252 & 2.287 & 97.870 & & & & & & \\
\hline 11 & 0.234 & 2.130 & 100.000 & & & & & & \\
\hline
\end{tabular}

Table 8 .

Total variance explained. 
the value is 0 . This indicates that there is relationship occur between attitude and lifestyles aspect. This can be proved in Table 7.

The KMO from attitude results shows an adequacy as it is greater than 0.6. The amount of it is 0.848 and it is acceptable. According to Cerny and Kaiser [17], interpretive adjectives for the KMO measure of sampling adequacy are: marvellous (0.90-1.00), meritorious (0.80-0.90), middling (0.70-0.80), mediocre (0.80$0.70)$, miserable (0.50-0.59) and unacceptable (0.00-0.49).

Table 8 explains on the total variance. The total variance explained give the greater value which is more than $50 \%$. This variance of the results is $54.304 \%$. The greater the amount of variance explained the best result will be obtained. The result shows the validity of the model as the percentage of variance a proposed model manages to explain.

\title{
5. Conclusion
}

From overall of study, there are three objectives in this study that need to be achieved at the end of study. First objective is to determine intention level of consumers' lifestyles demographics and food label consumption. The factor of awareness, knowledge and attitude shows an impact toward consumers' lifestyles demographics and food label consumption.

Secondly was the relationship between lifestyles with awareness, knowledge and attitude. The finding shows that there is significant relationship between lifestyles with the factors of awareness, knowledge and attitude. This is because the values obtain are less than 0.05 which is $(\mathrm{p}<0.05)$.

Finally pertaining to the influential factors that influence the respondents, shows that attitude with the highest variance with $54.304 \%$ compare to knowledge and awareness. Hence the attitude behaviour influences toward the lifestyles demographic toward food label consumption. Nevertheless food label can guide consumers on deciding the products to purchase.

\section{Author details}

\author{
Zul Ariff Abdul Latiff \\ Faculty of Agro Based Industry, Universiti Malaysia Kelantan, Jeli, Kelantan, \\ Malaysia
}

*Address all correspondence to: zulariff@umk.edu.my

\section{IntechOpen}

(C) 2020 The Author(s). Licensee IntechOpen. This chapter is distributed under the terms of the Creative Commons Attribution License (http://creativecommons.org/licenses/ by/3.0), which permits unrestricted use, distribution, and reproduction in any medium, provided the original work is properly cited. (cc) BY 


\section{References}

[1] Berkman HW, Christopher C. Consumer Behavior: Concepts and Strategies. Encino, CA: Dickenson Publishing Co; 1978

[2] Ostrow R, Smith SR. The Dictionary of Marketing. Reed Business

Information, Inc.; 1988

[3] Sathish R. Consumer behavior and lifestyles marketing. 2012;1(10). ISSN 22773622

[4] Engel JF, Blackwell RD, Miniard PW. Customer Behaviour. 7th ed. Hinsdale, IL: The Dryden Press; 1996

[5] Drichoutis AC, Lazaridis P, Nayga RM. Consumers' use of nutritional labels: A review of research studies and issues. Academy of Marketing Science Review. 2006, 2006;9:1-22

[6] CBS News. A closer look at 'green' products manufacturers are making more environmentally friendly products, but not all stand up to the test. May 18, 2008. Available from: www.cbsnews.com/stories/2008/05/18/ eveningnews/main4105507.shtml

[7] Veisten K. Willingness to pay for ecolabeled wood furniture: Choice-based conjoint analysis versus open-ended contingent valuation. Journal of Forest Economics. 2007;13(1):29-48

[8] Nikolić A, Uzunović M, Spaho N. Lifestyle pattern underlying organic and traditional food consumption. British Food Journal. 2014;116(11):1748-1766

[9] Burgmann T. Growing Muslim population pushing companies to produce products they can eat. The Star, Online version, 22 July, 2007. Available from: www.thestar.com/Business/ article/238551

[10] Sumali A. Halal: New market opportunities. In: Proceedings of the 9th
Efficient Consumer Response (ECR) Conference. 2006. pp. 1-19

[11] Mohamed Z, Shamsudin MN, Rezai G. The effect of possessing information about halal logo on consumer confidence in Malaysia. Journal of International Food \& Agribusiness Marketing. 2013;25:73-86

[12] Anir NA, Nizam MNM, Masliyana. RFID Tag for Halal Food Tracking in Malaysia: Users Perceptions and Opportunities. In: 7th WSEAS Int. Conf. on Telecommunications and Informatics (TELE-INFO ‘08); Istanbul, Turkey. 2008

[13] Latiff ZA, Rezai G, Mohamed Z, Ayob MA. Food labels' impact assessment on consumer purchasing behavior in Malaysia. Journal of Food Products Marketing. 2015:137-146

[14] Fen YS, Sabarudin NA. An extended model of theory of planned behaviour in predicting exercise intention. International Business Research. 2008;1(4)

[15] Hair JF, Black WC, Babin BJ, Anderson RE. Multivariate Data Analysis: A Global Perspective. New Jersey: Pearson Prentice Hall; 2006

[16] Salman F, Siddiqui K. An exploratory study for measuring consumers awareness and perceptions towards halal food in Pakistan. Interdisciplinary Journal of Contemporary Research in Business. 2011;3(2):639-651

[17] Cerny BA, Kaiser HF. A study of a measure of sampling adequacy for factor-analytic correlation matrices. Multivariate Behavioral Research. 1977;12(1):43-47 


\title{
Chapter 8
}

\section{Profiling Green Consumers with Data Mining}

\author{
Alireza Ziaei-Bideh and Mahsa Namakshenas-Jahromi
}

\begin{abstract}
Concern about the environment has led to a new segment of consumers called green consumers. Because not all the consumers are equally green, using target marketing for persuading them to buy green product is essential. The first step in target marketing strategy is to segment the market and then develop profiles of the resulting market segments. This study aims to identify distinct green market segments based on demographic, psychographic, and behavioral variables and also investigate the relationship between each variable and green consumer behavior. This study uses self-organizing maps (SOM) to segment and then develop profiles of Iranian green consumers. Based on the results, four market segments have been identified and were named intense greens, potential greens, egoist browns, and intense browns based on profiles of consumers in each segment. The results of this study also indicate that the level of education and income together with egoistic value and environmental unfriendly habits correlate negatively with the greenness (intent and intense of green behaviors) of Iranian consumers and the age of consumers together with environmental attitude and knowledge, biospheric and altruistic values, and religiosity correlate positively.
\end{abstract}

Keywords: green consumers, market segmentation, profiling, data mining, self-organizing maps

\section{Introduction}

Increase of environmental pollution and damage, together with the increase in public concern about the surrounding natural environment, has so far influenced the purchase and consumption behaviors, and thus, has led to emergence of a new group of consumers called green consumers $[1,2]$. Even though there is no universally accepted definition of the green consumer [3], the most adopted is that green consumers or environmental friendly consumers are those who consider the impact of manufacturing process and consumption of environmental resources while making purchase or participating in other market related activities and make their decisions accordingly [4].

Due to the increase in the number of green consumers, green marketers have started to target green segments of market to exploit the opportunities existing in these segments. Green marketing and promoting environmental friendly consumption behavior are necessary in two ways: first, acceleration in the trend of exploitation and destruction of natural resources essential for human life such as water, oil, and forests is a serious threat for human being. The main causes of this 
destructive trend include population growth and detrimental consumption habits. This trend highlights the importance of encouraging people to promote environmental friendly or the so-called green behaviors [5, 2].

Second, public concern about environmental issues is arising; thus, everyday more consumers are willing to purchase and consume products introduced as environmental friendly. In order to respond to this growing need, it is essential to develop and implement green marketing strategies [6].

Consumers are not equally green and the levels of their willingness to purchase green products are not equal [7]. Therefore, to market green products effectively, it is essential to implement targeted marketing strategies rather than mass marketing. The initial step in implementation of targeted marketing strategy is market segmentation and determination of the unique characteristics of each segment. Profitability and performance of market segmentation depend on the accuracy of consumer profiling in each segment because imprecise prediction of market segment members reduces efficiency of marketing strategies [8].

Similarly, in Iran, according to evidence, the public concern about environmental issues has increased among consumers, and green segments have emerged in markets. Researchers have come to the conclusion that attitudes toward environmental issues and environmental friendly behaviors and factors that encourage consumers to purchase green products are not the same in all cultures [9]. Hence, due to the unique cultural norms and values of Iranian citizens, it is necessary to conduct appropriate studies to determine profile and characteristics of Iranian green consumers. However, despite the increasing number of green consumers in Iran and thus the importance of segmenting them and determining their profiles, no significant study has so far been conducted in this area. Focusing on the need for research in this field, the aim of this study is segmenting and profiling green consumers using data mining approach. Other objectives of this study are to determine the role of each demographic, behavioral, and psychographic variable in the behavior of Iranian green consumers.

\section{Customer segmentation variables}

The first step in market segmentation is to determine variables by which the segmentation should be performed. Researchers have used various demographic, psychographic, and behavioral variables for market segmentation and profiling of green consumers. Utilization of variables that have the greatest impact on consumers' green behavior and thus can best determine the segments of green markets will lead to favorable results in segmentation [6]. The variables that have been used in previous studies to determine green segments of market and have been proven to affect environmental friendly behavior of consumers will be discussed next.

\subsection{Demographic variables}

Diamantopoulos et al. reviewed the results of previous researches about the impact of various demographic variables on knowledge, attitude, and behavior of green consumers. In previous researches, as their study results show, age, gender, education, and income are emphasized among demographic variables, and their effectiveness is confirmed [7].

Do Paco et al. segmented green consumers based on their environmental attitude and knowledge and then studied demographic characteristics of each segment. These researchers segmented green market into three segments named: the uncommitted, the greens activists, and the undefined. Their results show that 
the green activists are highly educated consumers with high income within the age groups 25-34 and 45-54, who have positive attitudes toward environmental friendly activities and practice green behaviors more than other consumers [6].

Abeliotis et al. in their research among Greek people came to the conclusion that women tend to have an environmental friendly behaviors more than men, also that income is negatively associated with the tendency of people toward green behaviors. The results of their study indicated no significant relationship between education level and green behavior of consumers [10].

A summary of the results of other studies conducted on the effects of demographic variables on behavior and attitude of green consumers is given in Table 1.

\subsection{Psychographic variables}

Psychographic variables are one of the most beneficial and widely used variables in segmentation of consumers, especially green consumers [6]. Based on previous studies, the psychological variables associated with the values and beliefs of consumers, which have the greatest impact on consumers' attitudes and behaviors, have been identified. These variables will be discussed below:

Personal values: one of the most common theories in predicting green behavior of consumers is the value-belief-norm theory [5,20-24]. Based on this theory, as Stern [4] describes, personal values including altruistic, biospheric, and egoistic are the most important variables influencing people's environmental friendly behaviors. People with higher levels of altruism base their behavior on the perceived costs and benefits for other people in society. Biospheric people consider the effects of their actions on environment and living organisms and decide accordingly. Those, whose egoistic value is stronger, review the costs and benefits of environmental friendly behaviors only for themselves. Hence, if the earned benefits of such activities are more that their cost, they will act environmental friendly; otherwise, they will have negative attitude toward these activities. Researchers have found that the levels of consumers' altruistic and biospheric values positively correlate with green behavior, but selfishness correlates negatively [5, 21].

Religiosity: another psychographic variable which, despite its less emphasis in previous researches, is expected to have a positive impact on the behavior of Iranian

\begin{tabular}{lll}
\hline Variables & Research result & Reference \\
\hline \multirow{2}{*}{ Gender } & Women are greener & {$[10-13]$} \\
\cline { 2 - 3 } & Men are greener & {$[14]$} \\
\cline { 2 - 3 } & Without effect & {$[1,15,16]$} \\
\hline \multirow{2}{*}{ Age } & Positive effect & {$[6,7,10,16]$} \\
\cline { 2 - 3 } & Negative effect & {$[12,17]$} \\
\cline { 2 - 3 } Education & Without effect & {$[15,18]$} \\
\cline { 2 - 3 } & Positive effect & {$[5,10,12,17-19]$} \\
\cline { 2 - 3 } & Negative effect & {$[1,6,15]$} \\
\hline Income & Without effect & {$[7]$} \\
& Positive effect & {$[1,5,11,13,15,16]$} \\
\cline { 2 - 3 } & Negative effect & {$[10,17]$} \\
\cline { 2 - 3 } & Without effect & {$[7]$} \\
\hline
\end{tabular}

Table 1.

Role of demographic variables in green behaviors of consumers. 
consumers is religiosity or religious values. Rice in a research on Egyptian Muslim consumers proved that the level of religiosity of consumers directly and significantly correlates with their intention to pro-environmental behavior [25]. Also, Biel and Nilsson concluded that people who believe nature is holy are more willing to behave pro-environmentally and green [26].

\subsection{Behavioral variables}

Segmenting green consumers by behavioral variables is based on their environmental knowledge and attitude as well as their tendency to demonstrate environmental friendly behaviors [6]. The most effective behavioral variables, which their effect on consumers' environmental friendly behavior has been confirmed in previous studies, will be discussed below:

Environmental attitudes: social psychology researchers have addressed attitude as the most important variable in predicting behavior and behavioral intentions [27]. In respect with marketing and green consumers, numerous studies have been conducted on the impact of environmental attitudes on environmental friendly behaviors [28, 29]. For example, Mostafa concluded that consumers' attitudes toward purchasing green products and also advertisements by manufacturers of green products have a positive effect on consumers' purchase intention [8].

Environmental knowledge: environmental knowledge can be defined as a general knowledge of facts, concepts, and issues related to the environment [30]. Researchers have identified two different types of environmental knowledge: abstract knowledge about environmental problems, causes and solutions to these problems and concrete knowledge about the behaviors that can be done in those situations. Comparing people who actively participate in pro-environmental activities with those who show less intention in this regard, researchers concluded that the difference in level of their environmental knowledge is the main reason of the different behaviors among these two groups of people $[1,14,18,31]$.

Personal habits: another behavioral variable that is proven to play a role in consumers' green behavior is personal habits [5, 21, 24, 29, 32, 33]. Typically, behavior change includes giving up an old habit and replacing it with a new one. Habits affect person's willingness and intention to change their behavior and to convert attitudinal factors into actual behavior [5]. Previous researchers have concluded that personal habits affect people's tendency to perform green behaviors such as recycling, reducing energy consumption and using green energy sources. In order to give up a habit and act oppositely, Thogersen and Moller believe it is necessary that the desired behavior is repeated and rewarded frequently [34]. Hence, it is expected that consumers' habits related to environmental unfriendly behaviors will affect negatively on their willingness to perform green activities.

\section{Methodology}

This study is an applied research in terms of objectives and a survey-analytic research in terms of methodology. Also, since this study examines the data associated with a specific period of time, it is a cross-sectional study.

\subsection{Sample and sampling method}

The target population of this research is consumers in Yazd province. A convenience sampling method was used to select the respondents. So that, the interviewers randomly selected passers-by, asked them to take part in the study 
and to complete the standardized, self-administered questionnaire. A total of 300 initial responses have been received. After eliminating the confounding questionnaires, the number of final sample analyzed was 252 , resulting in a response rate of $84 \%$. Among the 252 respondents, $60 \%$ were male and $40 \%$ female. About $92 \%$ of the respondents have a bachelor's degree or less and $76 \%$ aged from 18 to 35 years. Also, most respondents (43\%) had a medium income of between 5,000,000 and 8,000,000 Rials.

\subsection{Survey instrument}

A questionnaire was used to collect the required data. All measures have been adopted from previous studies, and also, they were assessed by three marketing professors so that respondents would understand the questions correctly. Cronbach's alpha was used to determine the reliability of the questionnaire. Table 2 shows the Cronbach's alpha values and researches that the measures have taken from.

\subsection{A review on self-organizing maps}

Self-organizing map (SOM) is a method based on neural networks, which provides a powerful and fascinating tool to display multidimensional data in spaces with lower dimensions (usually one or two). Research experiments show that utilizing new methods such as neural networks and self-organizing maps for segmenting consumers and predicting their behavior lead to better and more accurate results compared with conventional statistical methods $[8,37,38]$.

Self-organizing maps are a kind of neural networks with unsupervised learning capability that are suitable for analyzing complex spaces. This model of neural networks was first introduced by Kohonen in 1981. SOM is effective at clustering and visualizing essential features of complex data and has a unique structure that allows multivariate data to be projected nonlinearly onto a rectangular grid layout with a rectangular or hexagonal lattice.

The structure of self-organizing maps is composed of two distinct layers: an input layer and an output layer which is called map layer as shown in Figure 1. The map layer is usually designed as a two-dimensional arrangement of neurons that maps n-dimensional input to two dimensions, preserving topological order. Each neuron in the map layer corresponds to an information node with dimensions equal

\begin{tabular}{lcc}
\hline Variable & Reference & Cronbach's alpha \\
\hline Biospheric value & {$[29]$} & 0.71 \\
\hline Altruistic value & {$[29]$} & 0.68 \\
\hline Egoistic value & {$[29]$} & 0.76 \\
\hline Religiosity & Authors & 0.73 \\
\hline Green behavior & {$[35]$} & 0.80 \\
\hline Environmental knowledge & {$[8]$} & 0.78 \\
\hline Environmental attitude & {$[36]$} & 0.69 \\
\hline Green behavior intent & Authors & 0.73 \\
\hline Nongreen habits & {$[5]$} & 0.76 \\
\hline
\end{tabular}

Table 2.

Reliability and sources of questionnaire measures. 
to the dimensions of the analyzed space [39]. The two-dimensional map network consists of one layer of strongly interconnected neurons. Each neuron is connected to the $\mathrm{n}$-dimensional input via a set of $\mathrm{n}$ weights.

After training the self-organizing network, a number of weight nodes are obtained, each of which represents a portion of the analyzed space. Also, the number of obtained weight nodes is the same as the number of neurons. Hence, if appropriate number of neurons is selected and the network is trained properly, the weighted display corresponding to neurons of each network can well represent the analyzed space. In the output of self-organizing maps, corresponding to the value of each attribute in the weight node, an RGB vector and thus a color will be considered in a way that all values can be visualized using color spectrum ranging from dark blue (the lowest value) to dark red (the highest value).

The SOM algorithm repeatedly repositions records in the map until a classification error function is minimized. Records that have similar characteristics are adjacent in the map, and dissimilar records are situated at a distance determined by degree of dissimilarity. In particular, SOM consists of a layer of input vectors and a two-dimensional grid of output nodes. Each output node is connected to all the input vectors through the link of weights. When an input vector is presented, the closest match (most similar) of the output node is identified as the winning node. The input vector is thus mapped to the location of the winning node. The weights of the winning node and its neighborhoods are then updated closer to the original input vector. This process repeats until weights are stabilized, and all input vectors are mapped onto the output array. In this way, input vectors with similar data patterns are located into adjacent region, while dissimilar vectors are situated at a distance in the output map. Therefore, it will be possible to identify clusters on the map visually. Various software packages are available to analyze data using self-organizing maps. In this study, Viscovery SOMine version 5.0 was used.

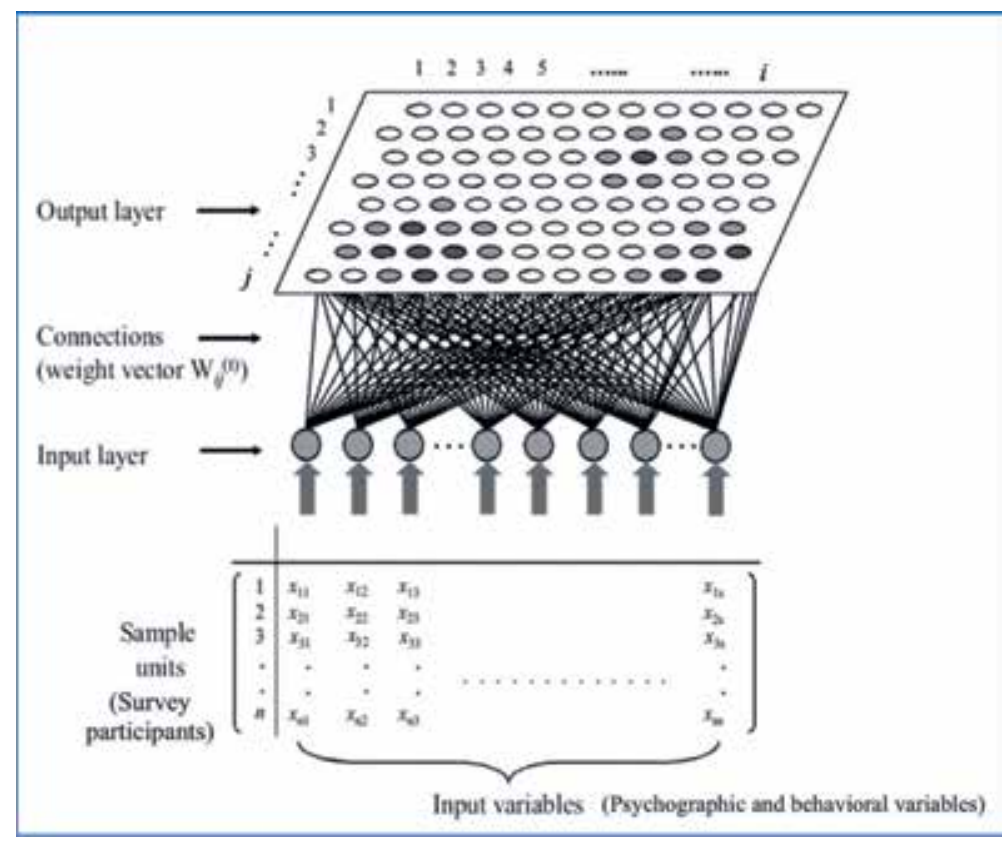

Figure 1.

Basic structure of self-organizing map (SOM) (adapted from [40]). 


\section{Data analysis and results}

\subsection{Network training and evaluation}

Several experiments have been carried out with different combinations of parameters and selected the better neural architecture based on the following criteria: average quantization error, the meaningfulness of clusters, the visual interpretability, and the SOM-Ward cluster indicator. The resulting best segmentation is obtained through 551 neurons in the output layer $(19 \times 29$ matrix $)$. SOMine software, automatically selects the best dimensions for the map network based on the selected number of neurons in the output layer. After testing various dimensions and training the network, the software chose network dimensions equal to $19 \times 29$. Training schedule is set in a way that the software can autonomously provide maximum accuracy for the training of the network. Also, the tension level of the network training is set to 0.5 . Training data of network constitute 252 (sample size) nine-dimensional vectors (psychographic and behavioral variables). Data associated with demographic factors was not used in training. After training the network and final segmentation, demographic characteristics of green consumers in each segment will be investigated.

Quantization error is used as a measure to evaluate the accuracy and validity the self-organizing maps. Quantization error, which is a value between 0 and 1, shows the level at which output maps are able to visualize input data on a two-dimensional space, where quantization error value close to (0) shows more accuracy of the network [41]. The final value of quantization error for the network used in this research was equal to 0.1898 .

\subsection{Analyzing output maps and final segmentation}

Most researchers use U-Matrix which is one of the outputs of self-organizing maps for final clustering and determining the boundaries of each segment or cluster. Since, this method does not define exact and clear boundaries for each segment $[8,36]$, therefore in this study, a hierarchical cluster analysis method called SOM-Ward clusters is used to determine the boundaries of each segment and also to determine the optimal number of clusters. Final segmentation of green consumers in four clusters or segments is shown in Figure 2. This two-dimensional hexagonal grid shows clear division of the input pattern into four clusters. The clusters divide the input data into disjoint areas containing similar vectors. Since the order on the grid reflects the neighborhood within the data, features of the data distribution can be read off from the emerging landscape on the grid. The application of the SOM algorithm brought together samples by resemblance. The more similar the samples are, the closer they are positioned in the output space.

After defining boundaries of segments, the characteristics of consumers in each segment should be investigated. Table 3 shows the average of psychographic and behavioral variables in each of the segment.

Another output of self-organizing maps is feature maps which show vector distribution of each of the segmentation variables in the whole analysis space. At the bottom of each of these maps, a color spectrum, ranging from blue to red, is shown that indicates various values of the variables. Via these maps, the situation of variable in each of the market segments can be studied, and also, the correlation between the different variables can be examined by visually comparing the pattern of shaded pixels for each map [36]. The feature maps reported for each segmentation variable are shown in Figure 3. On these maps, the nodes which share similar information are organized in close color proximity to each other. Figure 3 shows the feature maps for every cluster and for all input attributes. 


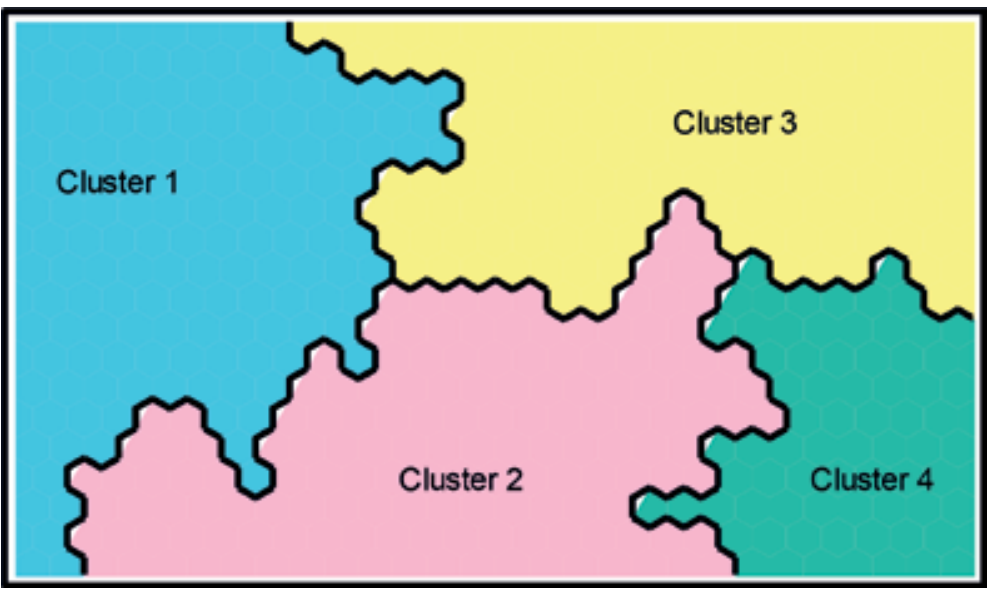

Figure 2.

Final segmentation map.

\begin{tabular}{cccccccccc}
\hline & $\begin{array}{c}\text { Green } \\
\text { behavior }\end{array}$ & $\begin{array}{c}\text { Env. } \\
\text { know. }\end{array}$ & Attitude & Intent & Habit & Egoistic & Altruistic & $\begin{array}{c}\text { Bio } \\
\text { spheric }\end{array}$ & $\begin{array}{c}\text { Religio } \\
\text { sity }\end{array}$ \\
\hline Seg. 1 & 4.25 & 3.92 & 4.49 & 4.26 & 1.66 & 3.01 & 4.39 & 4.77 & 4.21 \\
\hline Seg. 2 & 3.54 & 3.44 & 4.02 & 3.35 & 1.96 & 3.52 & 3.84 & 4.52 & 3.50 \\
\hline Seg. 3 & 3.29 & 3.25 & 4.25 & 3.48 & 3.10 & 2.98 & 4.37 & 4.88 & 3.73 \\
\hline Seg. 4 & 2.66 & 2.60 & 3.54 & 2.74 & 3.75 & 3.34 & 3.56 & 4.20 & 3.21 \\
\hline
\end{tabular}

Table 3.

Average of psychographic and behavioral variables in each segment.

As shown in Figure 3, the analysis space has nine dimensions. By comparing these maps, the following results can be obtained:

- Variables of attitudes, knowledge, intent to pro-environmental behavior, and green behavior are positively correlated with each other, because wherever one variable is red (high value), the other variables have almost the same value. Level of correlation between the variables can be observed from the intensity of the color similarity.

- Among psychographic variables, biospheric, altruistic, and religion values are positively correlated to each other and also to behavior variables including attitude, intent, knowledge, and green behavior, while egoistic is negatively correlated to other variables.

- The variable habit is negatively correlated to other behavioral variables, especially green behaviors, and also to variables such as biospheric and altruistic.

Besides the feature maps reported for psychographic and behavioral variables, the status of demographic variables in each segment can also be studied through feature maps provided by the software. Figure 4 shows these feature maps.

Figure 4 shows that consumers with different gender, age, education, and income are scattered in all sectors. At first glance, it appears as no specific relationship exists between demographic variables and behavior of green consumers. 


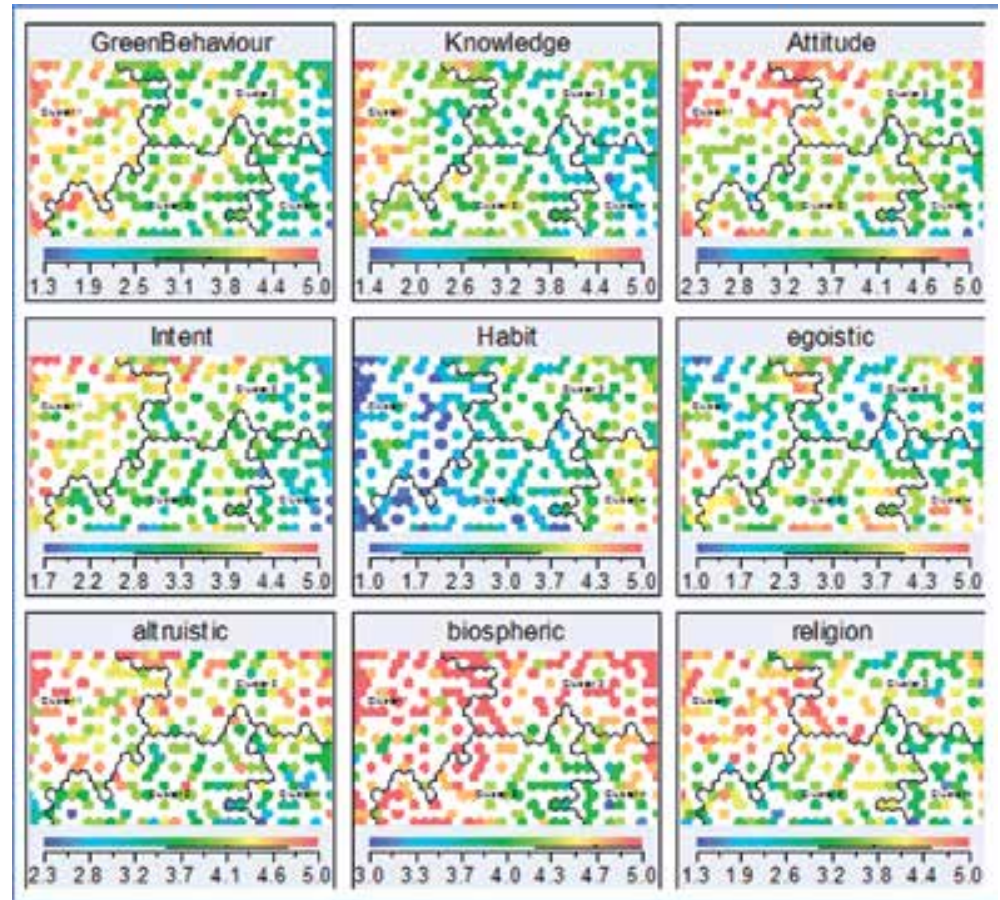

Figure 3.

Feature maps for psychographic and behavioral variables.
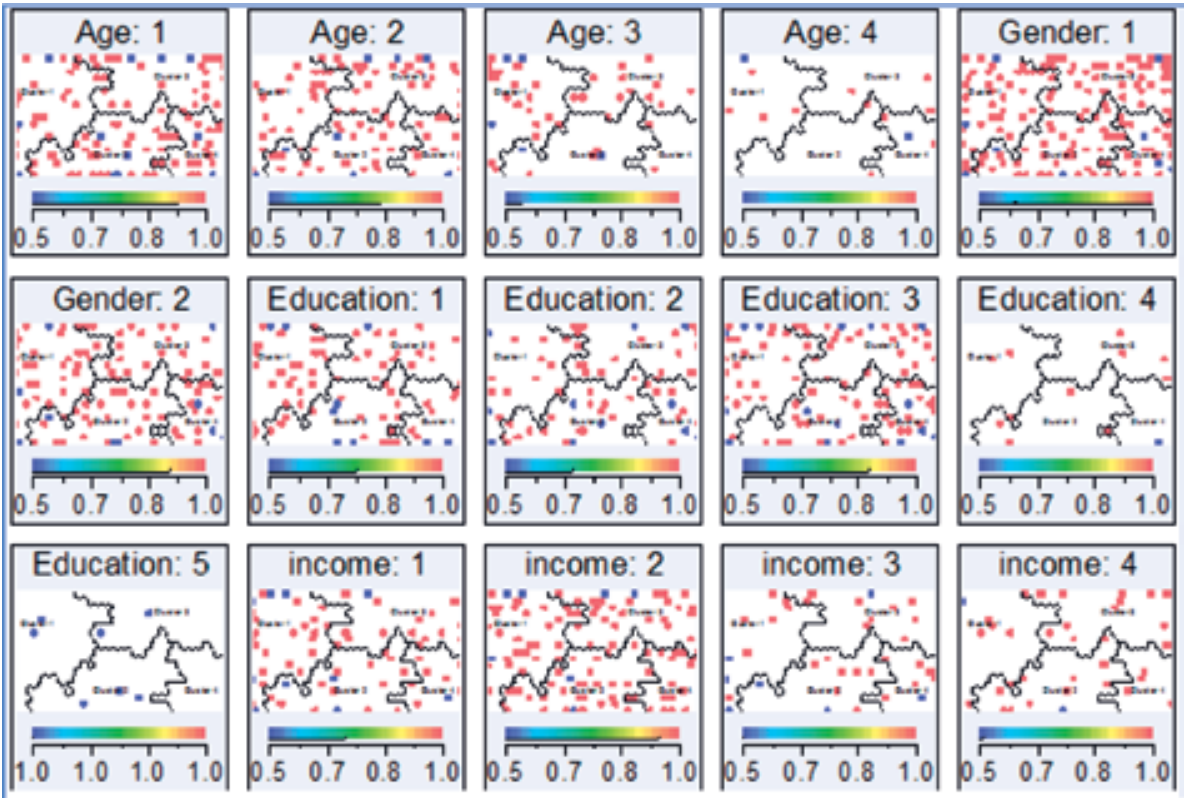

Figure 4.

Feature maps for demographic variables.

However, according to Figure 5, which shows the importance of each demographic variable corresponding to other variables in that segment and also relative to importance of that variable in other segments, different results can be deduced. 
The following results can be obtained from Figure 5:

- Consumers within the age group 18-24 are mostly scattered in segments 2 and 3 of the market, and most of the consumers in the segment 1 are within the age group 35-49. Consumers at other ages are scattered in different market segments.

- In the segment 1 of the market, aggregation of women is more than men, while in segments 2 and 3, aggregation of men is more than women.

- Most of the consumers with no graduate education are in the segment 1 , and most of the consumers in segment 4 have postgraduate education.

- Most of the consumers in segment 1 of the market have incomes less than 5,000,000 Rials, and high-income consumers are mostly in segments 4 and 5.

\subsection{Naming and describing market segments}

Once market segments are identified, they should be named and described based on their consumer profiles. Marketers and producers of environmental friendly products can use this information to identify their target market and then to utilize suitable marketing strategies and marketing mix based on characteristics of that segment. To provide a better description for each segment, SOMine draws a diagram for psychographic and behavioral variables in each segment like that drawn for demographics. The diagram is shown in Figure 6.

According to Figures 5 and 6 and Table 3, which show the importance of psychographic, behavioral, and demographic variables in each market segment, market segments can be named as follows:

Intense greens (segment 1): this segment that includes $29.37 \%$ of total consumers can be assumed as the greenest segment of the market. In terms of demographic characteristics, most consumers in this segment are within the age group 35-49, and aggregation of women is more than men in this segment. In terms of education, most of the extreme greens are nongraduates. In terms of psychographic characteristics, extreme greens are biospheric, altruistic, and religiosity consumers

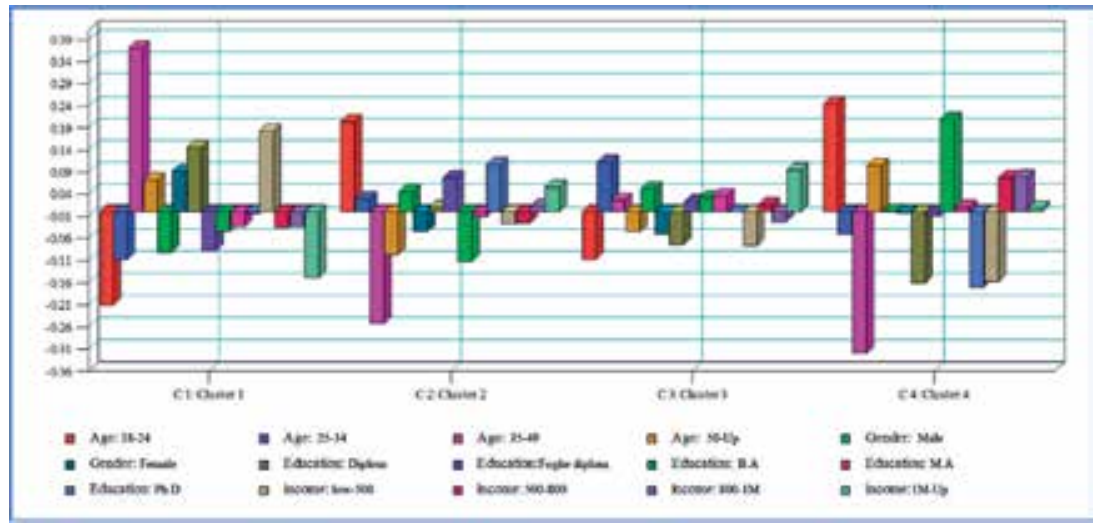

Figure 5.

Importance of demographic variables in each market segment. 


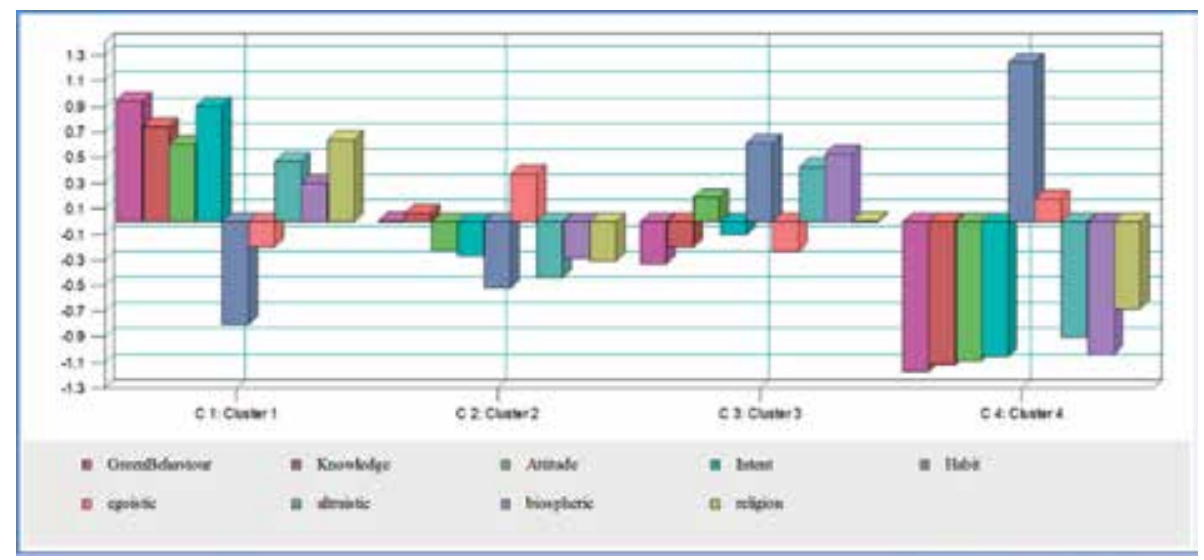

Figure 6.

Importance of psychographic and behavioral variables in each market segment.

with low level of egoistic value. In terms of behavioral characteristics, these consumers have high level of knowledge about environmental issues and positive attitude toward green behaviors. Also, their willingness to purchase green products and behave in an environmental friendly manner is higher than the rest of the consumers. Nongreen habits are very rare in this segment.

Egoistic browns (segment 2): this segment of the market includes $26.19 \%$ of total consumer. In terms of demographic characteristics, people of this segment are within the age group 18-24, and most of them are with an income level of above 10 million Rials. Consumers in this segment of the market mostly have undergraduate education. In terms of the psychographic characteristics, the level of altruistic, biospheric, and religiosity values is very low among this group of consumers, which is one of the main reasons for their negative attitudes toward green behaviors. In terms of behavioral characteristics, although these consumers claim that they have some knowledge about environmental issues and environmental friendly products, but their egoistic is the main reason for their low tendency toward green behavior.

Potential greens (segment 3): this segment includes $28.57 \%$ of total consumers. In terms of demographic characteristics, most of the consumers in this segment are within the age group 25-34, with an income above 10 million Rials. Most of the potential greens are men. No specific educational pattern can be found in this segment. In terms of behavioral characteristics, although these consumers have positive attitudes toward environmental friendly behaviors, frequency of green behaviors in their daily life is very low, and they show environmental unfriendly habits. In terms of the psychographic characteristics, due to the high level of altruistic and biospheric values, these consumers have the potential to become true greens.

Intense browns (segment 4): this segment of the market that is the smallest and the nongreen part of the market, includes $15.87 \%$ of total consumers. Most of the intense browns are within the age group 18-24 with graduate-level education, and their income is between 5 and 10 million Rials. In terms of behavioral characteristics, these consumers' environmental knowledge and attitude and thus their tendency to green behavior and purchase of green products are very low. In contrast, they show nongreen behaviors. In terms of psychographic characteristics, altruistic, biospheric, and religious values in this group are very low, and they are egoistic consumers. 


\section{Conclusions and practical implications}

In this research, Iranian green consumers where segmented based on their psychographic and behavioral characteristics with the use of a self-organizing map algorithms. Then the demographic characteristics of consumers in each segment were investigated. In the following sections, first the effects of each segmentation and demographic variables on behavior of green consumer are discussed. Then based on the results, practical suggestions on targeting each market segment are presented.

\subsection{Role of demographic variables in pro-environmental behaviors}

Gender: the results show that in the segment 1 which is occupied by extreme greens, most of the consumers are women, and in other segments of the market where tendency to green behaviors and frequency of environmental friendly activities are low, population of men is greater than women. Previous researchers including Memery et al. [12] and Abeliotis et al. [10] also concluded that women are generally greener than men.

Age: since most egoistic browns and intense browns are within the age group 18-24 years and also most intense greens are at older ages, 25-49, it can be concluded that age correlates positively with the greenness (environmental friendliness) of the consumers. Dsouza et al. [16] and Abeliotis et al. [10] also obtained a similar result.

Education: although no definite conclusion about the education can be deduced, it seems that level of education is negatively correlated with the greenness of consumers, because the abundance of uneducated people is the highest in the greenest segment of the market. Also, most of the intense browns have high education levels. Do Paco et al. $[1,6]$ also found similar results in their studies.

Income: based on the results of this study, it can be concluded that the income level has negative effect on greenness of consumers. The number of consumers with high income level in the brown segments of the market is higher than the other segments, which shows that consumers with higher income have lower intent to environmental friendly activities. Previous researchers, Banyte et al. [17] and Abeliotis et al. [10] also found the same result.

\subsection{Effects of behavioral and psychographic variables on pro-environmental behaviors}

Personal values: the importance of personal values in each of the market segments shows that biospheric and altruistic have positive effect and egoistic has negative effect on the level of greenness of consumers. The majority of consumers in the green segments of the market, such as intense greens and potential greens, are altruistic and biospheric consumers with low level of egoistic value. Previous researchers including Johnson et al. [9] and Cordano et al. [21] also obtained similar results.

Religiosity: as expected, due to the Islam's advice about holiness of nature and importance of green behaviors such as avoiding damage to environment, dissipation, and protection of organisms, religiosity has positive effect on greenness of Iranian consumers. Rice [25] also achieved similar results in a study on the Egyptians.

Green knowledge and attitude: according to the results of this study, consumers' knowledge about environmental issues and green products and also their attitude toward green purchase and behavior have positive effects on consumers' greenness. Most of the previous researches achieved similar findings. 


\subsection{Practical recommendations on targeting each market segment}

Intense green targeting: this segment includes the best group of consumers for the target market. Since most of the extreme greens are within the age group 35-49 and have low education levels, marketers can use marketing strategies appropriate to these consumers. It is noteworthy that extreme greens are not individuals with high income; thus, determining appropriate and reasonable prices to encourage these consumers to purchase green products is necessary. Also, because biospheric, altruistic, and religiosity are very high in this market segment, therefore marketers can emphasize on these values in their advertisements in order to encourage these consumers to purchase green products.

Egoistic brown targeting: at the first glance, egoistic browns do not seem to be suitable market segment for green products. However, if marketers can make these consumers aware of the dangers of environmental problems for themselves and also of the long-term benefits of environmental friendly products, they may be able to encourage this group of consumers to purchase green products and practice environmental friendly behaviors.

Potential green targeting: due to the strong values of altruistic and biospheric, potential greens can be a suitable target market for green products. The main cause for their low tendency to green behaviors is their low environmental knowledge. Consequently, marketers that target this group of consumers can encourage them to purchase green products by increasing their knowledge about the functions and benefits of green products and about threats of environmental issues.

Intense browns: this segment of the market that consist of consumers with higher level of income and from lower age groups relative to other segments is not a suitable target for marketing environmental friendly products.

\section{Author details}

Alireza Ziaei-Bideh* and Mahsa Namakshenas-Jahromi

Department of Business Management, Yazd University, Yazd, Iran

*Address all correspondence to: ess.ziaei@gmail.com

IntechOpen

(C) 2019 The Author(s). Licensee IntechOpen. This chapter is distributed under the terms of the Creative Commons Attribution License (http://creativecommons.org/licenses/ by/3.0), which permits unrestricted use, distribution, and reproduction in any medium, provided the original work is properly cited. (cc) BY 


\section{References}

[1] Do Paco AMF, Raposo MLB. Green consumer market segmentation: Empirical findings from Portugal. International Journal of Consumer Studies. 2010;34:429-436

[2] Noonan KE, Coleman LJ. Marketing to green communities: How to successfully reach the green consumer. Journal of Marketing Analytics. 2013;1:18-31

[3] Connolly J, Shaw D. Identifying fair trade in consumption choice. Journal of Strategic Marketing. 2006;14:353-368

[4] Stern PC. Toward a coherent theory of environmentally significant behavior. Journal of Social Issues. 2000;56:407-424

[5] Jansson J, Marell A, Nordlund A. Green consumer behavior: Determinants of curtailment and eco-innovation adoption. Journal of Consumer Marketing. 2010;27:358-370

[6] Do Paco AMF, Raposo MLB, Filho WL. Identifying the green consumer: A segmentation study. Journal of Targeting, Measurement and Analysis for Marketing. 2009;17:17-25

[7] Diamantopoulos A, Schlegelmilch BB, Sinkovics RR, Bohlen GM. Can socio-demographics still play a role in profiling green consumers? A review of the evidence and an empirical investigation. Journal of Business Research. 2003;56:465-480

[8] Mostafa MM. Shades of green: A psychographic segmentation of the green consumer in Kuwait using selforganizing maps. Expert Systems with Applications. 2009;36:11030-11038

[9] Johnson CY, Bowker JM, Cordell HK. Ethnic variation in environmental belief and behavior: An examination of the new ecological paradigm in a social psychological context. Environment and Behavior. 2004;36:157-186

[10] Abeliotis K, Koniari C, Sardianou E. The profile of the green consumer in Greece. International Journal of Consumer Studies. 2010;34:153-160

[11] Rowlands IH, Scott D, Parker P. Consumers and Green electricity: Profiling potential purchasers. Business Strategy and the Environment. 2003;12:36-48

[12] Memery J, Megicks P, Wiliams J. Ethical and social responsibility issues in grocery shopping: A preliminary typology. Qualitative Market Research: An International Journal. 2005;8:339-412

[13] Ngo AT, West GE, Calkins PH. Determinants of environmentally responsible behaviours for greenhouse gas reduction. International Journal of Consumer Studies. 2009;33:151-161

[14] Mostafa MM. Gender differences in Egyptian consumers? Green purchase behaviour: The effects of environmental knowledge, concern and attitude. International Journal of Consumer Studies. 2007;31:220-229

[15] Jain SK, Kaur G. Role of sociodemographics in segmenting and profiling green consumers. Journal of International Consumer Marketing. 2006;18:107-146

[16] Dsouza C, Taghian M, Lamb P, Peretiatko R. Green decisions: Demographics and consumer understanding of environmental labels. International Journal of Consumer Studies. 2007;31:371-376

[17] Banyte J, Brazioniene L, Gadeikiene A. Ivestigation of green consumer 
profile: A case of Lithuanian market of eco-friendly food products. Economics and Management. 2010:374-384

[18] Tilikidou I. The effects of knowledge and attitudes upon Greeks' pro-environmental purchasing behaviour. Corporate Social Responsibility and Environmental Management. 2007;14:121-134

[19] Ishaswini N, Datta SK. Proenvironmental concern influencing green buying: A study on Indian consumers. International Journal of Business and Management. 2011;6:124-133

[20] Cleveland M, Kalamas M, Laroche M. Shade of green: Linking environmental locus of control and proenvironmental behaviors. The Journal of Consumer Marketing. 2005;22:198-212

[21] Cordano M, Welcomer S, Scherer RF, Pradenas L, Parada V. A crosscultural assessment of three theories of pro-environmental behavior: A comparison between business students of Chile and the United States. Environment and Behavior. 2010;43:634-657

[22] De Groot JIM, Steg L. Value orientations to explain beliefs related to environmental significant behavior: How to measure egoistic, altruistic, and biospheric value orientations. Environment and Behavior. 2008;4:330-354

[23] Hansla A, Gamble A, Juliusson A, Gärling T. The relationships between awareness of consequences, environmental concern, and value orientations. Journal of Environmental Psychology. 2008;28:1-9

[24] Nordlund AM, Garvill J. Effects of values, problem awareness, and personal norm on willingness to reduce personal car use. Journal of Environmental Psychology. 2003;23:339-347

[25] Rice G. Pro-environmental behavior in Egypt: Is there a role for Islamic environmental ethics? Journal of Business Ethics. 2006;65:373-390

[26] Biel A, Nilsson A. Religious values and environmental concern: Harmony and detachment. Social Science Quarterly. 2005;86:178-191

[27] Kotchen MJ, Reiling SD. Environmental attitudes, motivations, and contingent valuation of nonuse values: A case study involving endangered species. Ecological Economics. 2000;32:93-107

[28] Halpenny EA. Pro-environmental behaviours and park visitors: The effect of place attachment. Journal of Environmental Psychology. 2010;30:409-421

[29] Steg L, Dreijerink L, Abrahamse W. Factors influencing the acceptability of energy policies: A test of VBN theory. Journal of Environmental Psychology. 2005;25:415-425

[30] Fuller DA. Sustainable marketing: Managerial-ecological issues. Thousand Oaks, CA: SAGE Publications, Inc; 1999

[31] Fraj Andres E, Salinas EM. Impact of environmental knowledge on ecological consumer behaviour: An empirical analysis. Journal of International Consumer Marketing. 2007;19:73-102

[32] Eriksson L, Garvill J, Nordlund AM. Interrupting habitual car use: The importance of car habit strength and moral motivation for personal car use reduction. Transportation Research Part F: Traffic Psychology and Behaviour. 2008;11:10-23

[33] Jansson J, Marell A, Nordlund A. Elucidating green consumers: A cluster 
analytic approach on proenvironmental purchase and curtailment behaviors. Journal of Euromarketing. 2009;18:245-267

[34] Thogersen J, Moller B. Breaking car use habits: The effectiveness of a free one-month travelcard. Transportation. 2008;35:329-345

[35] Milfont TL, Duckitt J. The structure of environmental attitudes: A first- and second-order confirmatory factor analysis. Journal of Environmental Psychology. 2004;24:289-303

[36] Mostafa MM. A psycho-cognitive segmentation of organ donors in Egypt using Kohonen's self-organizing maps. Expert Systems with Applications. 2011;38:6906-6915

[37] Gronholdt L, Martensen A.

Analysing customer satisfaction data: A comparison of regression and artificial neural networks. International Journal of Market Research. 2005;14:121-130

[38] Haverila M, Rod M, Ashill N. Cell phone product-market segments using product features as a cluster variate: A multi-country study. Journal of Strategic Marketing. 2013;21:101-124

[39] Kohonen T. Self Organizing Maps. Berlin: Springer Series in Information Sciencess; 2001

[40] Choi J, Kim S, Jeng K. Detecting response patterns of zooplankton to environmental parameters in shallow freshwater wetlands: Discovery of the role of macrophytes as microhabitat for epiphytic zooplankton. Journal of Ecology and Environment. 2015;8:133-143

[41] Wendel J, Buttenfield B.

Formalizing Guidelines for Building Meaningful Self-Organizing Maps. Sixth International Conference on Geographic Information Science; Zurich; 2010 


\title{
STARZ-DRP: Improving Efficiency of Patient Care in Community Pharmacies
}

\author{
Nazri Nordin and Mohamed Azmi Hassali
}

\begin{abstract}
Customers are always becoming the center of interest among the physicians, dentists, and pharmacists in the healthcare system. However, they are always having favorable feeling with the community pharmacists (CPs) as the first spot to seek advice. For that reason, it is essential to determine the character, behavior, and habit of customers toward the CPs and their extended pharmacy services. In addition, it is critical to determine the possible factors, which might have an effect on their characters, behaviors, and habits. The outcome of the analysis might help the CPs to understand the scenario in a particular way. Afterward, a structured and systematic approach known as "STARZ-DRP" is instigated as a basic skill to ensure whether each pharmacist has the self-confidence and self-competence to interact with the customers. The entire course of action shall empower the strength of personality among the CPs in the healthcare system.
\end{abstract}

Keywords: community pharmacist, medication protector, STARZ-DRP, drug-related problems, customer

\section{Introduction}

Customers are always becoming the center of interest among the health providers in the healthcare system [1]. The healthcare modus operandi might be unsuccessful in achieving its goal if the customers are not willing to amalgamate themselves with the health professional. Therefore, it is critical that the healthcare practitioners such as physicians, dentists, and pharmacists be aware of the character or nature of their customers toward the services. In other words, the practitioners must possess quality characteristics or features, which enable them to have an effect on the character, development, or behavior of the customers toward them. Otherwise, the customers shall fail to show their concern for the provision of a wide range of local services.

Among the health professionals, the community pharmacists (CPs) turn into the most accessible practitioner in the healthcare system [2]. They, at all times, fulfill the function as the first spot which the people shall seek for initial medical and medication advice [2]. It shall reflect a clear image for CPs as a "gatekeeper" in the healthcare system [3] when the CPs are having considerable skill, proficiency, and intelligence to make a triage action plan [4]. Triage action plan is precisely marked as a strategy to assist the people to determine whether their medical problems 
require a specific medication, further medical examination, or restricted guidance [4]. Such course of action shall be helpful to ensure that the people are accessible to the excellence level of healthcare service, which shall have the chance to keep them away from unwanted side effect or adverse reaction due to inappropriate medicine use [5]. Nonetheless, it is critical to determine the phenomenon which the customer acts or conducts himself or herself toward the CPs particularly related to the provision of extended pharmacy services. The performance shall help the CPs to discern the way of behaving among the people when they visit the pharmacies for a specific purpose. For that reason, it is necessary to conduct a study to find out the features, characters, or habits behind the behaviors among the people of extended pharmacy services.

In Section 2, we shall outline a general description showing the awareness among the people of extended pharmacy services through their feeling, sensation, consciousness, perception, or recognition. The way such illustration turns out is derived from the outcome notified in the previous studies which was performed in many countries.

In Section 3, a structured and systematic approach known as "STARZ-DRP" is brought into use or operation for the first time as an essential foundation or starting point to provide a wide range of extended pharmacy services. "STARZ-DRP" is a simple mnemonic, which emerges from the pharmaceutical care concept. It maneuvers the CPs to assess the customer-related information, formulate a therapy plan, and establish a follow-up schedule to review the outcome of the plan. This modus operandi aims to help the CPs to determine if the customers' health problems are being caused by a specific medication or if they require a specific medication, extended services, referral to other health professionals, or advice to resolve their problems. Such course of action is essential to ensure whether the customers are accessible to medications, which are safe, effective, indicative, and costeffective. Foremost, it is essential to make sure the CPs are demonstrating a quality, characteristic, or feature as a competence health professional. If everything turns out all right, the people shall act or conduct oneself in a specified behavior toward the extended pharmacy services. Otherwise, the customers might refuse to agree to the extended roles of CPs in the healthcare system.

In Section 4, we shall discuss in detail taking into account different issues or ideas notified in Sections 2 and 3. Afterward, we shall weigh up the possible action to bring the "STARZ-DRP" to the attention as a potential marketing tool that the CPs use to market particular courses of action based on the consumer's behavior, or in other words, based on the consumer's situation.

\section{Methods}

Scholars in the Universiti Sains Malaysia, Malaysia, have carried out, accomplished, and made a list of awareness among the people of extended pharmacy services [6]. They commerce the first part of the action, typically to achieve the aim by executing a systematic search of international literature reviews and studies, using Google Scholar as an electronic database, searching for open access articles, which point out the extended pharmacy services, perception of the extended services, and barriers toward the services, starting from January 2005 till January 2017. For that reason, it is reasonable to illustrate the findings in this column as the way to notify the possible behaviors among the people toward the CPs and their extended services. 


\section{Results}

In the writing paper, the scholars point out that there are a wide range of features, characters, and attributes among the people toward the CPs and the extended pharmacy services [6]. For example, they are not a regular shopper of the pharmacies [7] and they express complete disapproval of the CPs to criticize their lifestyles [7]. Also, they possess insufficiency of adequate confidence and trust of CPs [8-13], lack of interrelationship between pharmacist and customer [7, 11, 14-17], and are not ready to reform the long-established act in such a way to involve directly with the CPs [7]. Sometimes, they move with urgent haste and have no time to spend with the CPs [7]. Foremost, most of them manifest lack of facts and information about the extended pharmacy services [7], which make them bewildered about them $[8,11,15,18,19]$, and they are not ready to reimburse the CPs for the services [20].

Other features which have the capacity to have an effect on the character, development, or behavior of the people toward the CPs and the extended services are the characteristics of the CPs themselves. For example, the people be aware of through observation or information that the CPs bring forward the businessoriented services as the center of interest in the pharmacies [12, 14-16, 21-23], particularly when their pharmacy program places great emphasis on product rather than patient-oriented elements [18], CPs are not always available in the premise when they need to consult them about their medical problem [7], CPs possess lack of self-confidence $[8,18,20]$ and self-competence $[8,19]$ due to lack of knowledge, skills, $[7,9,10,13,15,17,18,20,22,24,25]$, and trainings $[8,15,16,20,25]$ about the extended services, CPs have been too busy with their daily business activity [7] and they have no time to counsel the people [7-10, 20, 21, 23, 26], CPs are not well trained in particular skills or type of behavior through sustained practice and instruction during their pharmacy program [22, 25], CPs inform that the extended services are typically not a formal practice in pharmacy $[18,20]$, and CPs are having no help or participation from other healthcare providers such as physicians to work, function, or do something well in the pharmacies [7-9, 11, 15, 20, 21, 25, 27].

Also, the writing paper put in the picture the operation in the pharmacies has a prominent attribute or aspect, which has an effect on the character, development, and behavior of the people toward the CPs and their extended services. For example, the people shall refuse to agree to the extended services if the pharmacies possess a shortage of CPs $[7,18,20]$ and staffs [23], absence of a private counseling space [7-9, 19], a documentation scheme [14] and a high standard counseling approach $[7,13,22]$, lack of financial support $[7,8]$, and insufficient support from the business possessor [7, 22] or administration [8].

\section{4. "STARZ-DRP” as an instrument to magnify the image of CPs}

"STARZ-DRP" consists of letters, which constitute a systematic sequence of assessing individual features (see Table 1). It is essential that the CPs must follow the sequences so that they might not fail to include some critical features, which are potential to be the origins of the ongoing medical disorder. The first in the sequence (STAR) is helping the CPs to rule out if the abnormal vital signs and physical features (see Table 2) need for a particular medication, medical examination, or advice. Figure 1 illustrates the flowchart of the modus operandi. The following sequence $(Z)$ is about helping out the CPs to identify the actual or potential drugrelated problems (see Table 3 ). 


\begin{tabular}{|c|c|}
\hline Letter & Description \\
\hline $\mathrm{S}$ & $\begin{array}{l}\text { Symptom presentation refers to subjective evidence of health problem perceived by the } \\
\text { patient. }\end{array}$ \\
\hline $\mathrm{T}$ & Time of onset and duration of the present symptoms. \\
\hline A & $\begin{array}{l}\text { Associated symptoms refer to patient symptoms explored and determined by the pharmacist } \\
\text { during the interview. It does not refer to the symptoms presented earlier by the patient. This is } \\
\text { done by using the pictorial documentation form. To aid and ease the pharmacist during the } \\
\text { interview, the human body is arbitrarily divided into four regions: (i) front: the part of the } \\
\text { body facing the pharmacist (asking for symptoms like bloating, heartburn, nausea, vomiting, } \\
\text { breathlessness, etc.), (ii) back (asking for symptoms like lower and upper back pain, shoulder } \\
\text { pain, and neck pain), (iii) upper (head) (asking for symptoms like headache, dizziness, } \\
\text { problems with sleep, etc.), and (iv) lower (asking for symptoms like numbness in both legs } \\
\text { and hands, constipation, and swollen feet). Perhaps, the method is likened to a filtering or } \\
\text { screening process to rule out the presence of severe symptoms. }\end{array}$ \\
\hline $\mathrm{R}$ & $\begin{array}{l}\text { Recurrence problem refers to the symptoms that have been treated before, specifically when } \\
\text { the symptoms recur and persist despite the treatment prescribed. }\end{array}$ \\
\hline $\mathrm{Z}$ & $\begin{array}{l}\text { Zoom into the patient's medication experience that refers to information collected by the } \\
\text { pharmacist related to any medical problems (for example, hypertension, diabetes, } \\
\text { hyperthyroid, etc.), medication utilization (for example, use of prescription and } \\
\text { nonprescription drugs, and herbal supplements), immunization history, allergies, drug } \\
\text { sensitivities, drug side effects, adverse reactions, and the consumption of alcohol, caffeine and } \\
\text { tobacco. }\end{array}$ \\
\hline $\begin{array}{l}\text { referring } \\
\text { The pati } \\
\text { temperat }\end{array}$ & $\begin{array}{l}\text { diagnostic tool, rather it is a format with the purpose of organizing a community pharmacist's knowl } \\
\text { hat allows he/she to begin identifying the actual and potential drug-related problems and subsequer } \\
\text { e patients to the appropriate healthcare professionals. } \\
\text { vital signs will be measured when necessary. At times, the patient's blood pressure, pulse rate, and } \\
\text { ire measured to aid the pharmacist in assessing the appropriateness of symptoms for self-medication. }\end{array}$ \\
\hline
\end{tabular}

Table 1.

Definition of letters in STARZ ${ }^{\#, *}$.

- Any chest pain in a patient looking gray, sweating, or ill

- Severe pain in the chest, abdomen, head, or ears

- Blood loss from any orifice

- Increasing breathlessness

- Difficulty in swallowing

- Tenderness over blood vessels

- A history of severe injury, particularly a penetrating injury, or loss of consciousness

- Persistent raised temperature, blood pressure, or heart rate

- Loss of weight

- Anorexia

- Yellow skin color

- Ankle swelling

- Yellow skin color

- Yellow or green sputum

- Yellow or green discharge from penis or vagina

- Urinary symptoms

- Any menstrual abnormality

- Any swelling or lump of any size, including joints

- Weakness in arms or legs

- Any visual changes

Source: [43].

Table 2.

List of signs and symptoms acquire immediate medical attention. 


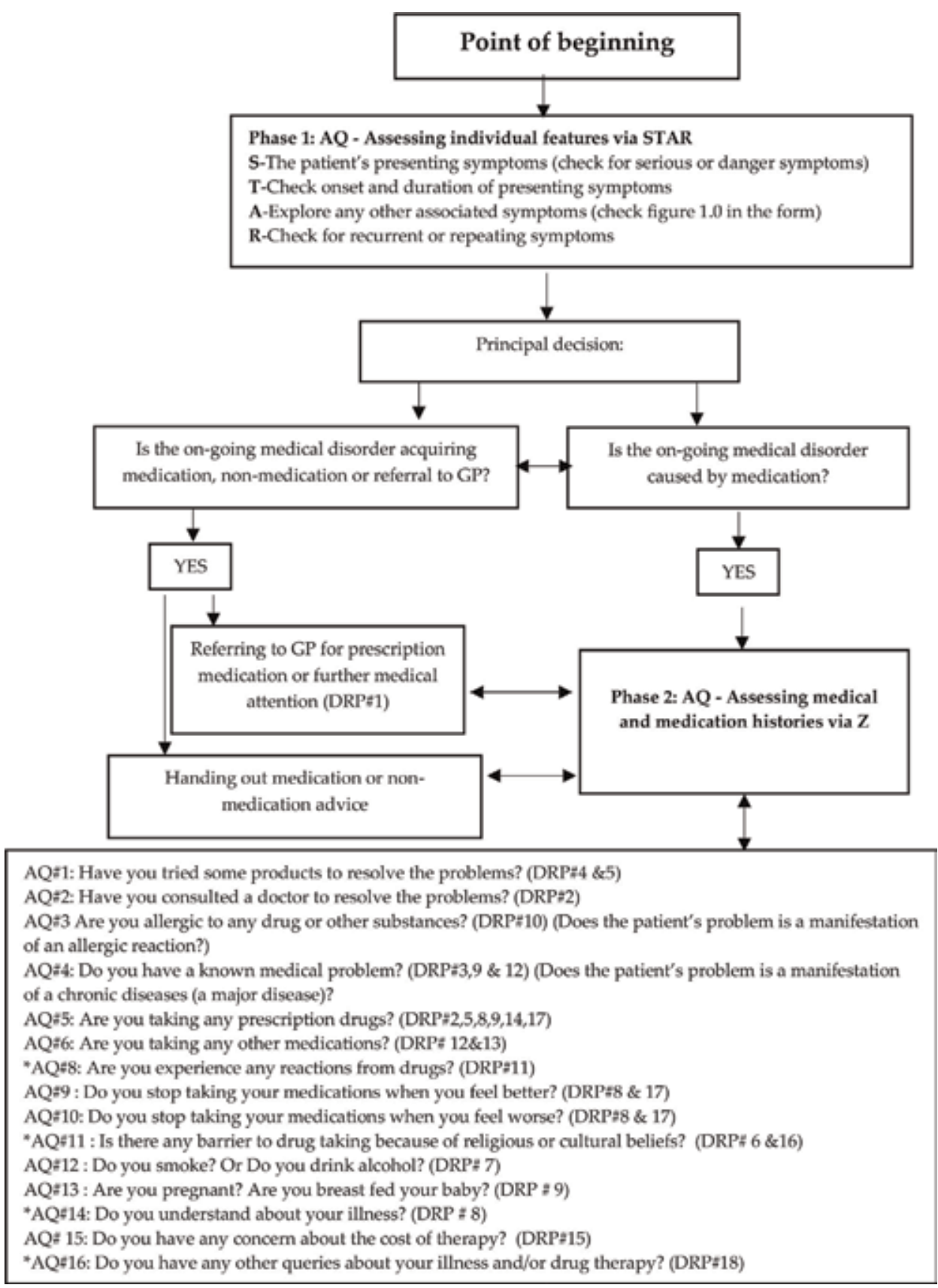

Figure 1.

Flowchart of STARZ-DRP modus operandi. GP = general practitioner, DRP = drug-related problem, $A Q=$ assessment question, and ${ }^{*}$ auxiliary assessment question. Refer to Table 3 for a list of the drug-related problems.

"STARZ-DRP" is converted into a printed paper to ensure the CPs have the chance to record their action of assessing someone (see Figure 2). The printed paper shall help the CPs to reminisce about the drug therapy plan as the way to evaluate and impart it to the customers' health status. A referral form is established and illustrated in Figure 3. It aims to ease the nonverbal communication between physician and pharmacist regarding the CPs' findings in the first place. 


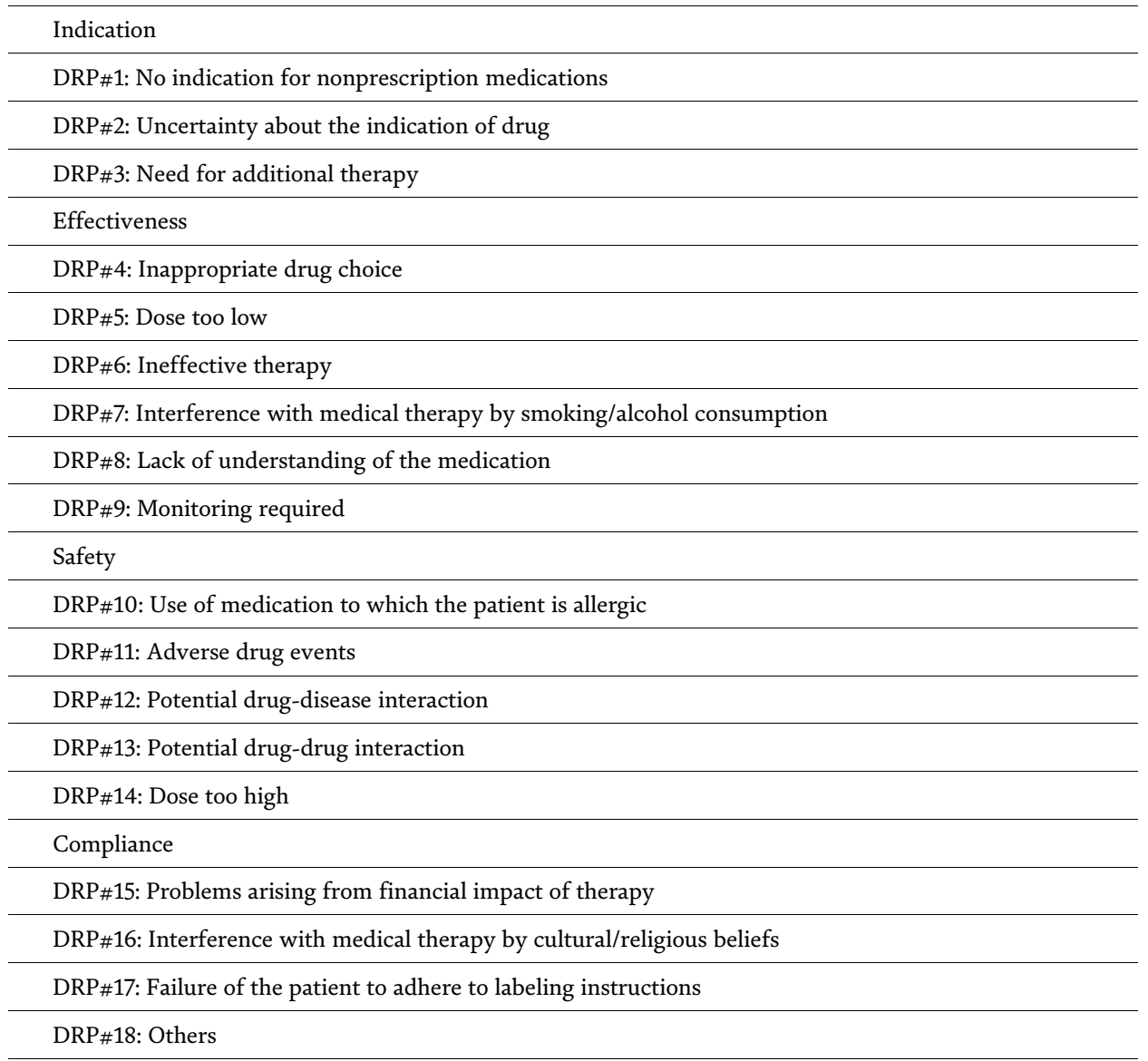

Table 3.

Categories of drug-related problems.

"STARZ-DRP" is a well-defined tool, which have the chance to influence the behavior among the customers toward the extended services of CPs. It reflects that the CPs are in a suitable state to act as a medication protector in the healthcare system. The materials that provide official information or evidence or that serve as a record are a critical process of establishing the truth, accuracy, or validity of the CPs' actions. The entire action or process of using the tool shall have the chance to improve the acceptance among the customers toward the CPs' extended services particularly when the CPs are showing their seriousness to safeguard the medication use.

\section{Discussion}

Customers are the humans who possess the feeling of wanting to know or learn about something or someone as the way to give an affirmative answer to the action of introducing a plan, an intention, or an idea. Most of the time, the answers are possibly influenced by their character, development, or behavior. Irene Carrasco, in her writing, pinpoints that there are eight factors that shall influence customers to act in a specific behavior, which are age, culture, socioeconomic level, perception, attitude, trend, personality, and experience [28]. 
Age: character, behavior, and attitude toward a thought or suggestion as a possible course of action might not be the same as each other if someone performs a study involving different ages [29]. Older and younger customers might assign a standard or value to a purpose or intention according to their particular scale [29]. Earlier studies clearly show the existence or truth of the outcome by giving proof or evidence for attention [30,31]. It discloses that the older customers possess greater emotional control and less negative effect toward a plan or intention [30, 31]. They integrate their practical contact with and observation of facts or events to reflect their character, behavior, and attitude [32]. Also, they are always possessing themselves toward positive than negative reaction [33], reflecting favorable amygdala

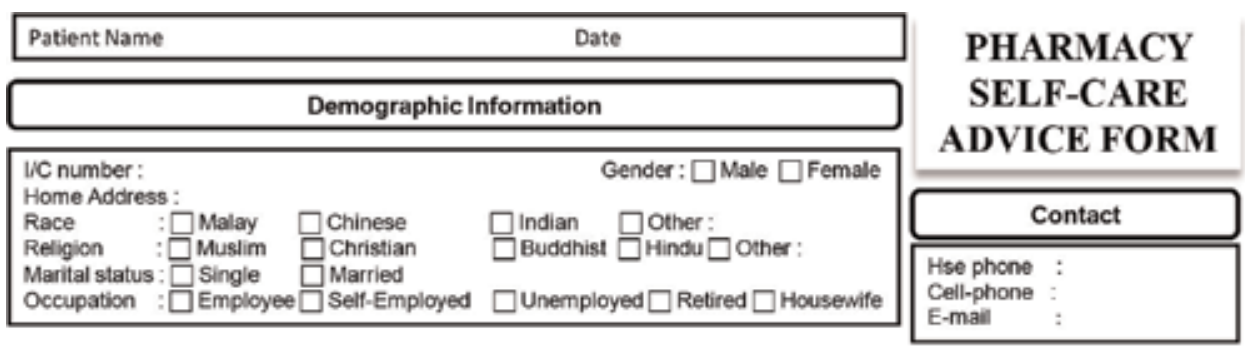

\begin{tabular}{|l|l|l|}
\hline \multicolumn{3}{|c|}{ A. Request Related To : (check all that apply) } \\
\hline$\square$ Treatment for condition: & $\square$ A specific product : & $\square$ Other, specify: \\
\hline
\end{tabular}

(1). Check patients' signs and symptoms

1. State sign and symptom (refer figure 1.0):

2. Duration:

3. Other associated symptom

$\square$ Yes (specify) :

$\square$ No

4. Rocurrence sign and symptom $\square$ Yes

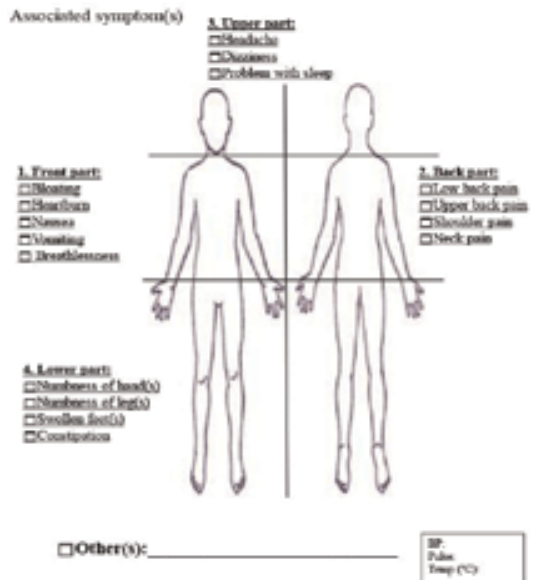

Figure 1.0

๑ Copyright by UNIVERSITI SAINS MALAYSIA
(2). Zoom to identify drug-related problem

1. Have you tried some products to resolve the problem ? $\square$ Yes $\square$ No Specify the product::

2. Have you consulted a doctor to resolve the problem? $\square$ Yes

3. Do you have a known medical problem ? $\square$ Yes $\square$ No Type of medical problem and how long :

4. Are you allergic to any drug or other substance? $\square$ Yes $\square$ No Type of drug/substance

5. Are you taking any prescription drug ? $\square$ Yes $\square$ No

Specify the product:

6. Are you taking any other medications/herbals/supplements ? $\square$ Yes $\square$ No Specify the product :

7. Do you use of alcohol/caffeine/tobacco ? $\square$ Yes $\square$ No Specify the use:

8. Do you stop taking medication when you feel better ? $\square$ Yes $\square$ No

9. Do you stop taking medication when you feel worse ? $\square$ Yes $\square$ No

10. Do you have any concern about the cost of therapy? $\square$ Yes $\square$ No

11. Are you pregnant? (Optional question) $\square$ Yes $\square$ No 
(3). SIgn and Symptom Assessment

\begin{tabular}{|c|c|c|}
\hline 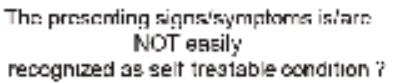 & 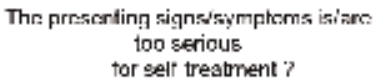 & $\begin{array}{l}\text { The partiment resuires further maxtical } \\
\text { exsmination? }\end{array}$ \\
\hline$\square$ Yes $\sqsupset$ No & $\square$ Yes $\square$ No & $\square$ Yes $\square$ No \\
\hline
\end{tabular}

(4). Pharmacy Care Plan

\begin{tabular}{|c|c|c|}
\hline 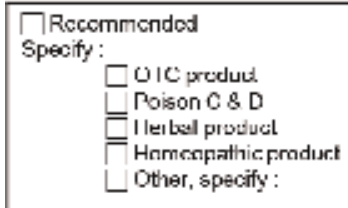 & 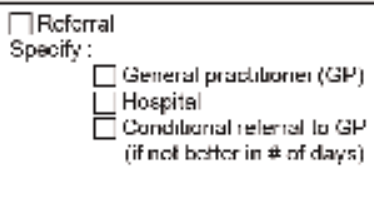 & 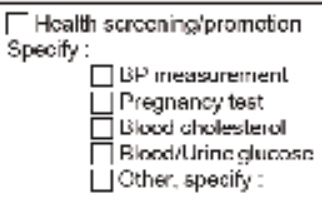 \\
\hline List of product: & Reason for refersal : & Describe advice: \\
\hline
\end{tabular}

(5). Follow-up

Providc reasons and how to :

B. States Drug-Related Problem

\begin{tabular}{|c|c|c|c|}
\hline Indication & Effectiveness & Safpty & Compliance \\
\hline 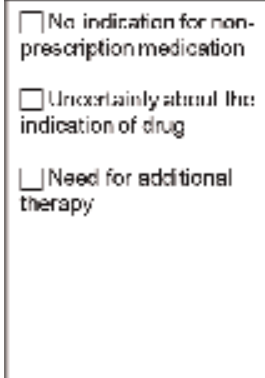 & 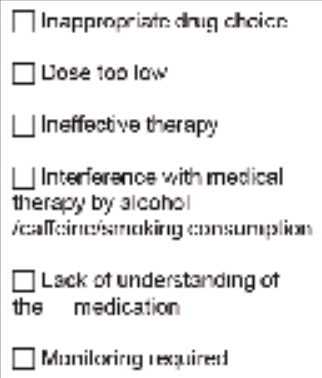 & 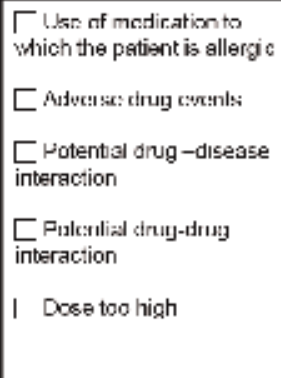 & 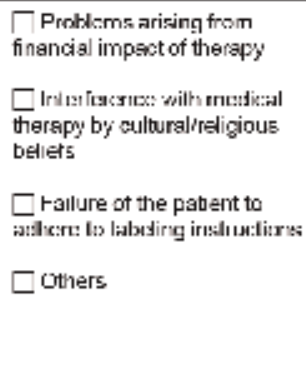 \\
\hline
\end{tabular}

Figure 2.

9 Copyright by UNIVERSITI SAINS MALAYSIA

Pharmacy self-care advice form.

activation [34]. For that reason, it is critical to continuously give them information on a particular subject as the way to ensure the action of consenting to receive or undertake something offered; whereas the CPs must take possession of the role to educate the younger customers to perceive the significance, explanation, or cause of providing the extended services.

Culture: It is the attitude and behavioral characteristic of a particular social group. It shall reflect the way the particular group possess their feelings or thoughts in response to a situation or event. At the present time, the healthcare system encounters a digital culture, in which the customers might have the access to become an online shopper [35], in which they can make the purchase of a wide 


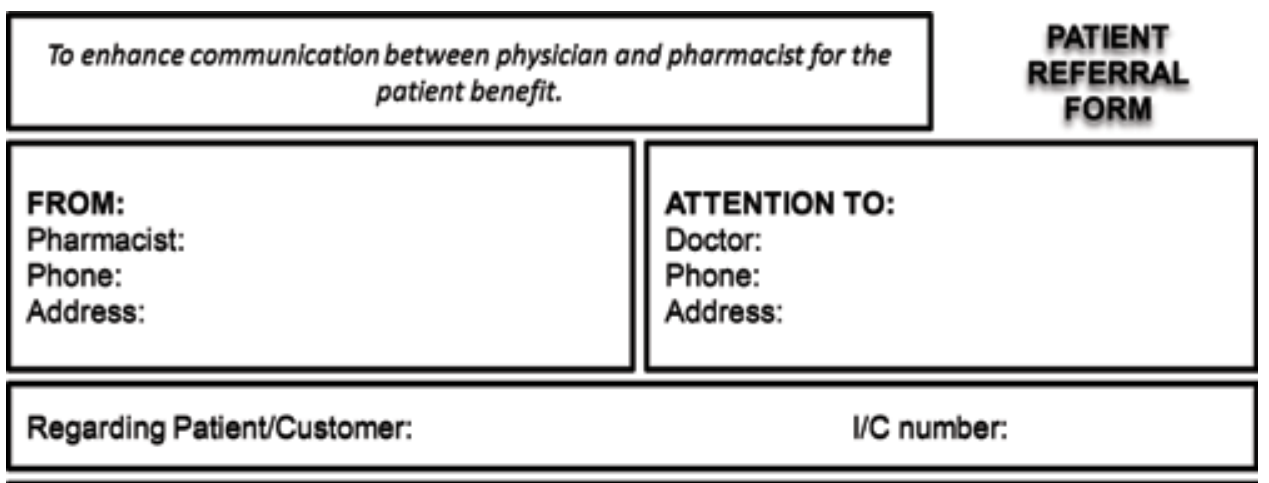

Ilm concerned about the following problems and wish to call it to your attention:

(i) Related to the patient's presenting signs/symptoms

(ii) Related to the patient's medication use

(iii) Related to the patient's factors:

I Recommend:

Further assessment \& examination

Need additional therapy:

$\square$ Resolve the drug related problem

Please contact me as soon as possible, so we can provide the best care possible to the patient.

Thank You

o copyright by UNIVERSITI SAINS MALAYSIA

Figure 3.

Referral form.

range of vitamins, supplements, and healthy foods in the state of being away from the CPs. Consequently, the event shall make the CPs' role becoming smaller in the healthcare system. The CPs shall not have the chance to ensure whether the people are accessible to the products, which are safe, effective, indicative, and cost-

effective. For that reason, it is essential to impart knowledge to the people as how to operate the digital culture in a skillful manner. In the scenario, they should integrate the CPs as their healthcare partner to improve their behaviors and be back to the 
right choice of treatment. However, at first, the people must possess favorable confidence and trust with the CPs' ability to do something well.

Socioeconomic level: It relates to or concerns with the interaction of social and economic factors toward the action of consenting to something offered. An earlier study gives a practical exhibition and explanation of significant relationship between buying behavior and income level [36]. Nonetheless, the people might think carefully about buying medications, typically during the global financial crisis when they are more cautious to spend money [36]. At this moment, the people shall try to find cheaper medications by looking or otherwise seeking carefully and thoroughly using the search engine in the internet. Such course action is danger because they shall have the access to a product that is not officially indexed in the local health directory. The product might possibly harm their health status and even worsen it, which can cause unwanted side effects. Therefore, it is advisable that they enhance their direct involvement with the CPs as a prospective approach to make sure a problem does not occur.

Attitude: The people shall have their own settled way of thinking or feelings about something to accept or reject as desired. Sometimes, their thinking or feelings are made known through the position of their body, which indicates a particular mental state. For example, if the customers have a particular belief or idea about the benefits of a specific service, they might possess a strong desire to make use of it. Otherwise, they shall irresponsibly withdraw themselves from the situation to search for another act of assistance, which is able to carry out the role as expected. Therefore, it is critical to ensure that the CPs indulge themselves with the facts, information, and skills acquired through experience or education as the way to cause the people to believe firmly in the truth of the CPs' competence to counsel them [37]. The CPs should also make alterations to their way in which one acts or conducts oneself, especially toward the interaction with their customers. They must always be in the position to give professional help and advice to someone to resolve his or her medical and medication problem regardless of unfavorable reasons. Some of the unfavorable reasons are the CPs do not have time to interact with the customers or they are busy with the management operation. This standpoint of action shall have an effect on the character, development, or behavior of the customers toward the CPs and their extended services.

Trend: It is a general direction in which something is developing or changing as the process of becoming better suited to its surrounding or condition. In the modern era, a digital marketing has grown to be a considerable medium, in which the people can purchase products or services, compare the prices, and justify their values if they satisfy their desire [38]. Today, there are some favorable mediums, which ease the people to pay close attention to the digital era such as Facebook, YouTube, Instagram, and WhatsApp. The mediums are having a strong effect on the people's feelings or thoughts because they make sure the people can have the access to the information within a second. Also, the people can avoid the need to use the money on unnecessary transportation cost since they can have the products in front of their doors. Foremost, the digital marketing can save time particularly among the people who live in the urban area. They do not have to drive a car to purchase a product and have themselves in a very slow-moving traffic, caused by roadworks, an accident, or heavy congestion. Therefore, a digital marketing shall become a favorable way of business strategy to ensure the products or services are available near to the customers. For that reason, the CPs must take the challenge to change their way of practice and pay particular attention to the digital marketing as a prospective approach to interact with the customers. Otherwise, the people shall deliberately cease to think of the CPs as a healthcare provider in the healthcare system. 
Personality: It is the combination of characteristics or qualities that form an individual's distinctive character, behavior, and habit. Personality is critical in the marketing strategy because it has the potential to influence other people to possess favorable or unfavorable thinking or feeling of the services offered [39]. For example, the people might have confidence and trust with the CPs who allow their charisma, character, and competence to be visible as the way to instigate the power of attraction. Their strength of charm personality shall have an effect on the character, development, or behavior of the people to possess favorable feelings of the products and services offered. For that reason, the CPs must ensure that they have the quality, characteristic, or feature that have the potential to enhance a pleasing personality in the eyes of the customers. The CPs can begin to possess such personality by improving their education and experience. Most of the time, the people are having confidence to interact with the CPs who are competence to help them to achieve their goals. That is the main reason behind the favorable feelings among the people toward the physicians because the physicians are able to possess a strong personality in their practice.

Experience: It is the knowledge or skill acquired by a period of practical experience of something, especially which is gained in a particular profession, situation, education, or events. It has the possibility to influence the character or behavior among the people to accept or reject the products or services offered [40]. For example, the people who possess better health quality of life after presenting at a specific counseling shall have themselves to visit the premise again or more than once. Also, they shall take the necessary action to support or actively encourage other people to have the same experience. Such course of action is a free notice or announcement in a public medium. However, the CPs must make themselves ready or able to perform a high standard of practice. For that reason, the CPs should gain or acquire knowledge or skill in related services by study, experience, or being taught. Hopefully, it can open the eyes among the people to the CPs' role as a medication protector in the healthcare system.

Perception: This factor is potential having an influence on the behaviors among the people to possess favorable or unfavorable feelings of something offered to them. The people shall weigh-up the values of the product or service and transform their findings into either satisfactory or unsatisfactory perception. Therefore, many companies are willing to spend millions of dollars to ensure their products shall reflect acquiescence perception to the customers' senses. In the healthcare context, the CPs must always make better of their services to catch the attention among the people to notice them or their services as interesting or important [37]. The CPs must intensify, increase, or further improve the quality, value, or extent of their knowledge and skills so that they shall have the chance to demonstrate the truth or existence of something by evidence or argument. Optimistically, with hope, it can possibly enhance the image of CPs as a prospective healthcare provider in the healthcare system.

Self-care treatment has become a general direction in managing health among the people in many countries [41]. It is defined as the art of practice, in which the people take their initiative to perform self-diagnosis and start to self-medicate as the way to improve their health status [41]. The entire process is danger to put in the picture because the people are not competence to act as a physician or a pharmacist. As a consequence, they might have the access to a medication, which is not safe, effective, indicative, and cost-effective. Therefore, it is critical to encourage the CPs to perform or undergo the first part of being a medication protector by possessing a particular ability to make an accurate triage action plan for the self-care customers [42]. Nonetheless, the course of action is having the chance to put in the picture if the CPs have a strong feeling to employ a structured and systematic approach 
known as "STARZ-DRP" as a possible modus operandi [41]. This tool used in the earlier studies determines its feasibility to help the CPs to triage the customers with minor ailments [5]. The study reveals that majority of the customers who visit the selected pharmacies are not appropriate candidates for self-care treatment [5]. At most, the CPs convince them to seek the physicians for further medical examination [5]. The study makes known that the CPs are having the chance to give a practical exhibition and explanation of using the "STARZ-DRP" model as the way to help the people to self-medicate in a proper manner [5]. Such course of action can improve the character, behavior, or habit among the people toward the CPs and their extended services.

"STARZ-DRP" is brought to attention of the general practitioners (GPs) in an earlier study, and they have pointed out their favorable perceptions as notified below. In general, the GPs mark "STARZ-DRP" as a potential tool to magnify the image of CPs as a medication protector in the healthcare system.

"I fully agree with the use of STARZ-DRP as a structured and systematic approach to assist the community pharmacist to make triaging decision. There need to be guideline for the pharmacist and they should only dispense medication prescribed by a GP/Physician" (GP2).

"The above answers are the usual questions and asked to every patient during consultation. It is important and essential that these questions are put forward clearly to every patient and stress to them the danger and consequences" (GP4).

"Pharmacist should use this structured and systematic approach during consultation" (GP5).

"Easy to remember. Good" (GP6).

"A good mnemonic in approaching systematically" (GP7).

"Excellency" (GP8).

"It is a good approach for pharmacists to deliver consultation" (GP10).

"It is a good guide for the prescriber to assess patients' need. Easy to remember" (GP11).

"Helpful in remembering the 2 components of the tool" (GP12).

"It would be very helpful in view of education of patient and problem solving for beneficial of patient" (GP13).

"All are essentials in relative patients" (GP14).

"It's a good idea, pharmacist and doctor can work together" (GP15).

"Very useful tool for community pharmacists"(GP16).

"Excellent" (GP17).

"Useful easy to remember" (GP18).

"Useful guide for community pharmacist. If a person requests for a prescription drug, the pharmacist should ask for a doctor's prescription, without, which the person should be asked to see a doctor" (GP20).

The study also determines the CPs' point of views of "STARZ-DRP" and their responses are disclosed below.

"STARZ-DRP approach would greatly assist the community pharmacy in arriving at a certain decision based on an informed assessment. This would lead to the correct and specific prescription to the patients" (CP1).

"A very systematic and useful tool for CP to identify the health problem" (CP2).

"Community pharmacy is a gate door for public before seeking for a doctor. Some people may wish to avoid from physician counseling fee and seek for medication from community pharmacy. Thus, the STARZ-DRP can be standardized in all community pharmacy practice to reduce the medication-related problem and improve the quality of life" (CP3).

"It is a very systematic way and essential steps in getting information from customer. The questions are important for a pharmacist to make a decision/conclusion on the problem/issue. Data analyzing is crucial in determining the right medication for our 
patients. It ensures we do not provide the same therapy, same medicines, etc. The STAR model ensures a pharmacist does not leave/forget vital questions in prognosing/deciding on medication" (CP6).

"STARZ-DRP is very important and essential for a pharmacist" (CP7).

"This is a complete tool for the patient assessment. The questions stated in this tool is essential and useful to figure out patient complaints and drug-related issues. Hope you will be inspiring us with your innovative thinking for years to come. Well done" (CP8).

"Very useful" (CP10).

"Easily understood and highly clear-cut" (CP11).

"This pharmacy self-care advice form is very useful for a pharmacist to sort out what questions should we ask before dispense medication to patients" (CP13).

"Very useful in CP's practice. Simple and easy to use. Essential in helping CP to identify underlying causes of some chronic complicated cases. Useful in helping CP to decide proper and correct treatment for patients. Essential for CP to identify possible drug-drug or drug-disease interaction. Easy to use for CP to identify all DRPs" (CP16).

"Structured and systematic format to help pharmacist in consultation with customers/ patients at community setting" (CP17).

"These questionnaires are very tool to determine the patient can be treated by pharmacist or need to refer to doctor. Also, can detect other factors that could contribute to the illness" (CP18).

"Can be implemented as a standardized tool" (CP19).

"STARZ-DRP is essential in order to give best service to community" (CP24).

"Good approach" (CP26).

"The mnemonic STARZ-DRP is very essential to get a better treatment target" (CP27).

"Prior to this, I never get attention to this, now you fellows highlight its importance in a pharmacists' duty, the mnemonic is concise and deep in its objective, this will render a further understanding and put more interest in practice as a pharmacist" (CP28).

"Easy step to step to access patient. Structural. No point left" (CP29).

"Comprehensive good approach when need to refer to the doctor" (CP31).

"It seems focused type of questions in collecting patient information" (CP32).

\section{Conclusion}

As a conclusion, it is critical to understand the character, behavior, or habit of the customers toward the CPs and their extended services. The CPs must take the chance to analyze the possible factors which might have an effect on the customers' features and establish a strategy to enhance their favorable behavior to the services offered. They shall begin to possess the strategy by having a basic skill to help the people who have a desire to self-medicate. "STARZ-DRP" shall be acknowledged as the basic skill, which each pharmacist should learn thoroughly. Hopefully, the tool shall enhance the CPs' confidence and competence to interact with the customers in the community pharmacy settings. In addition, it shall empower the strength of personality among the CPs in the healthcare system. As a result, the customers shall possibly pay particular attention to the services offered.

\section{Acknowledgements}

Authors would like to thank the Human Research Ethics Committee USM (USM/JEPeM/15040145) for giving the approval to conduct a study related to the tool known as "STARZ-DRP." 


\section{Conflict of interest}

All authors declare no conflict of interest in the study.

\section{Author details}

Nazri Nordin* and Mohamed Azmi Hassali

Social and Administrative Pharmacy Department, School of Pharmaceutical

Sciences, Universiti Sains Malaysia, Penang, Malaysia

*Address all correspondence to: drnazrinordin74@gmail.com

\section{IntechOpen}

(C) 2020 The Author(s). Licensee IntechOpen. This chapter is distributed under the terms of the Creative Commons Attribution License (http://creativecommons.org/licenses/ by/3.0), which permits unrestricted use, distribution, and reproduction in any medium, provided the original work is properly cited. (cc) BY 


\section{References}

[1] Dawn AG, Lee PP. Patient satisfaction instruments used at academic medical centers: Results of a survey. American Journal of Medical Quality. 2003;18(6):265-269

[2] Tsuyuki RT, Beahm NP, Okada H, Al Hamarneh YN. Pharmacists as accessible primary health care providers: Review of the evidence. Canadian Pharmacists Journal. 2018; 151(1):4-5

[3] van Hoof JJ, Cents MH, Megens NM, van der Tang SJ. Druggists and pharmacists as gatekeepers: Sales routines and compliance with sales protocols for over-the-counter naproxen $275 \mathrm{mg}$ medicines in the Netherlands. Health Policy. 2014;117(3): 353-360

[4] Curley LE, Moody J, Gobarani R, et al. Is there potential for the future provision of triage services in community pharmacy?. Journal of Pharmacy Policy and Practice. 2016;9:29

[5] Nordin N, Sarriff A, Hassali MA. STARZ-DRP: A tool for pharmacy triage services. Asian Journal of Pharmaceutical and Clinical Research. 2017;10(10):151-157

[6] Nordin N, Hassali MA, Sarriff A. A global picture of extended pharmacy services, perceptions, and barriers towards its performance: A systematic review. Asian Journal of Pharmaceutical and Clinical Research. 2017;10(11): 417-427

[7] Laliberte MC, Perreault S, Damestoy $\mathrm{N}$, et al. Ideal and actual involvement of community pharmacists in health promotion and prevention: A crosssectional study in Quebec, Canada. BMC Public Health. 2012;12:192

[8] Warchal S, Brown D, Tomlin N, et al. Attitudes of successful candidates of supplementary prescribing courses to their training and their extended roles. The Pharmaceutical Journal. 2006;276: 348-352

[9] Scheerder G, De Coster I, Van Audenhove C. Pharmacists' role in depression care: A survey of attitudes, current practices, and barriers.

Psychiatric Services. 2008;59:1155-1161

[10] Poudel A, Khanal S, Kadir A, et al. Perception of Nepalese community pharmacists towards patient counseling and continuing pharmacy education program: A multicentric study. Journal of Clinical and Diagnostic Research. 2009;3:1408-1413

[11] You JH, Wong FY, Chan FW, et al. Public perception on the role of community pharmacists in selfmedication and self-care in Hong Kong. BMC Clinical Pharmacology. 2011;11:19

[12] Rayes IK, Hassali MA, Abduelkarem AR. Perception of community pharmacists towards the barriers to enhanced pharmacy services in the healthcare system of Dubai: A quantitative approach. Pharmacy in Practice. 2015;13(2):506

[13] Sadek MM, Elnour AA, Al Kalbani NMS, et al. Community pharmacy and the extended community pharmacist practice roles: The UAE experiences. Saudi Pharmaceutical Journal. 2016; 24(5):563-570

[14] Al-Wazaify M, Albsoul-Younes A. Pharmacy in Jordan. American Journal of Health-System Pharmacy. 2005;62: 2548-2551

[15] Wong FYY, Chan FWK, You JHS, et al. Patient self-management and pharmacist-led patient selfmanagement in Hong Kong: A focus group study from different healthcare 
professionals' perspectives. BMC Health Services Research. 2011;11:121

[16] Yamamura S, Yamamoto N, Oide S, et al. Current state of community pharmacy in Japan: Practice, research, and future opportunities or challenges. The Annals of Pharmacotherapy. 2006; 40(11):2008-2014

[17] Saira A, Mohamed Azmi H, Mohamed Izham MI, et al. The role of pharmacists in developing countries: The current scenario in Pakistan. Human Resources for Health. 2009;7:54

[18] Fang Y, Yang S, Zhou S, et al. Community pharmacy practice in China: Past, present and future. International Journal of Clinical Pharmacy. 2013;35(4):520-528

[19] Malangu N. The future of community pharmacy practice in South Africa in the light of the proposed new qualification for pharmacists: Implications and challenges. Global Journal of Health Science. 2014;6(6): 226-233

[20] Berbatis CG, Sunderland VB, Joyce $A$, et al. Enhanced pharmacy services, barriers and facilitators in Australia's community pharmacies: Australia's National Pharmacy Database Project. The International Journal of Pharmacy Practice. 2007;15(3):185-191

[21] George PP, Molina JAD, Cheah J, Chan SC, Lim BP. The evolving role of the community pharmacist in chronic disease management-A literature review. Annals of the Academy of Medicine, Singapore. 2010;39:861-867

\section{[22] Egorova SN, Akhmetova T.}

Pharmaceutical counseling: Between evidence-based medicine and profits. The International Journal of Risk and Safety in Medicine. 2015;27(Suppl 1): S87-S88

[23] Rayes IK, Hassali MA, Abduelkarem AR. The role of pharmacists in developing countries: The current scenario in the United Arab Emirates. Saudi Pharmaceutical Journal. 2015;23: 470-474

[24] Hoti K, Hughes J, Sunderland B. An expanded prescribing role for pharmacists-An Australian perspective. The Australasian Medical Journal. 2011;4(4):236-242

[25] Salim AM, Elgizoli B. Exploring selfperception of community pharmacists of their professional identity, capabilities and role expansion. Journal of Pharmacy Practice and Research. 2016;5(2):116-120

[26] Ahmad A, Hugtenburg J, Welschen LMC, et al. Effect of medication review and cognitive behaviour treatment by community pharmacists of patients discharged from the hospital on drug related problems and compliance: Design of a randomized controlled trial. BMC Public Health. 2010;10:133

[27] Rayes IK, Abduelkarem AR. A qualitative study exploring physicians' perceptions on the role of community pharmacists in Dubai. Pharmacy in Practice. 2016;14(3):738

[28] Carrasco I. Which Factors Influence Consumer Behaviour? Integria IMS. 2018. Available from: https://integriaims. com/en/factors-influencing-consumerbehaviour/ [Accessed: January 17, 2019]

[29] Neiss MB, Leigland LA, Carlson NE, Janowsky JS. Age differences in perception and awareness of emotion. Neurobiology of Aging. 2007;30(8): 1305-1313

[30] Lawton MP, Kleban MH, Rajagopal D, Dean J. Dimensions of affective experience in three age groups. Psychology of Aging. 1992;7(2):171-184

[31] Mroczek DK, Kolarz CM. The effect of age on positive and negative affect: A developmental perspective on 
happiness. Journal of Personality and Social Psychology. 1998;75(5):1333-1349

[32] Labouvie-Vief G, DeVoe M, Bulka D. Speaking about feelings: Conceptions of emotion across the life span.

Psychology of Aging. 1989;4(4):425-437

[33] Isaacowitz DM, Wadlinger HA, Goren D, Wilson HR. Is there an agerelated positivity effect in visual attention? A comparison of two methodologies. Emotion. 2006;6(3): $511-516$

[34] Mather M, Canli T, English T, Whitfield S, Wais P, Ochsner K, et al. Amygdala responses to emotionally valenced stimuli in older and younger adults. Psychological Science. 2004; 15(4):259-263

[35] Wikiversity. Digital Culture. 2018. Available from: https://en.wikiversity. org/wiki/Digital_culture [Accessed: January 18, 2019]

[36] Jenefa L, Kumar RM, Kadyan JS. Socio-economic factors influencing the buying behaviour with special reference to selected garment retail outlet in Chennai. International Journal of Business and Management Invention. 2013;2(12)

[37] Hassali MA, Nordin N, Sarriff A, Saleem F. Community pharmacy marketing in the new era: A global picture of extended community pharmacy services. IntechOpen; 2018. pp. 131-149. http://dx.doi.org/10.5772/ intechopen.74326

[38] Harneet D. Growing and changing trends in consumer behaviour. Biz and Bytes. 2017;8(1):50-53

[39] UdoImeh PT, Awara NF, Essien EE. Personality and consumer behaviour: A review. European Journal of Business and Management. 2015;7(18):98-106
[40] Essays, UK. Importance of Consumer Behaviour. 2013. Available from: https://www.ukessays.com/essays/ marketing/importance-of-consumerbehaviour-to-business-managersmarketing-essay.php?vref=1 [Accessed: January 18, 2019]

[41] Bell J, Dzieka G, Pollack C, et al. Self-care in the twenty first century: A vital role for the pharmacis. Advances in Therapy. 2016;33:1691

[42] Sarriff A, Nordin N, Hassali MA. STARZ-DRP: A step-by-step approach for pharmacy triage services. Malaysia Journal of Pharmacy. 2011;1(9):311-326

[43] Holland R. When to refer. Pharmaceutical Society of Australia. 1993:15 


\section{Edited by Matthew Reyes}

This Edited Volume "Consumer Behavior and Marketing" is a collection of reviewed and relevant research chapters, offering a comprehensive overview of recent developments in the field of psychology. The book comprises single chapters authored by various researchers and edited by an expert active in the research area. All chapters are complete in itself but united under a common research study topic. This publication aims at providing a thorough overview of the latest research efforts by international authors and open new possible research paths for further novel developments. 